\title{
Characterization of Stormwater Runoff From Bridge Decks in Eastern Massachusetts, 2014-16
}

Scientific Investigations Report $2018=5033$

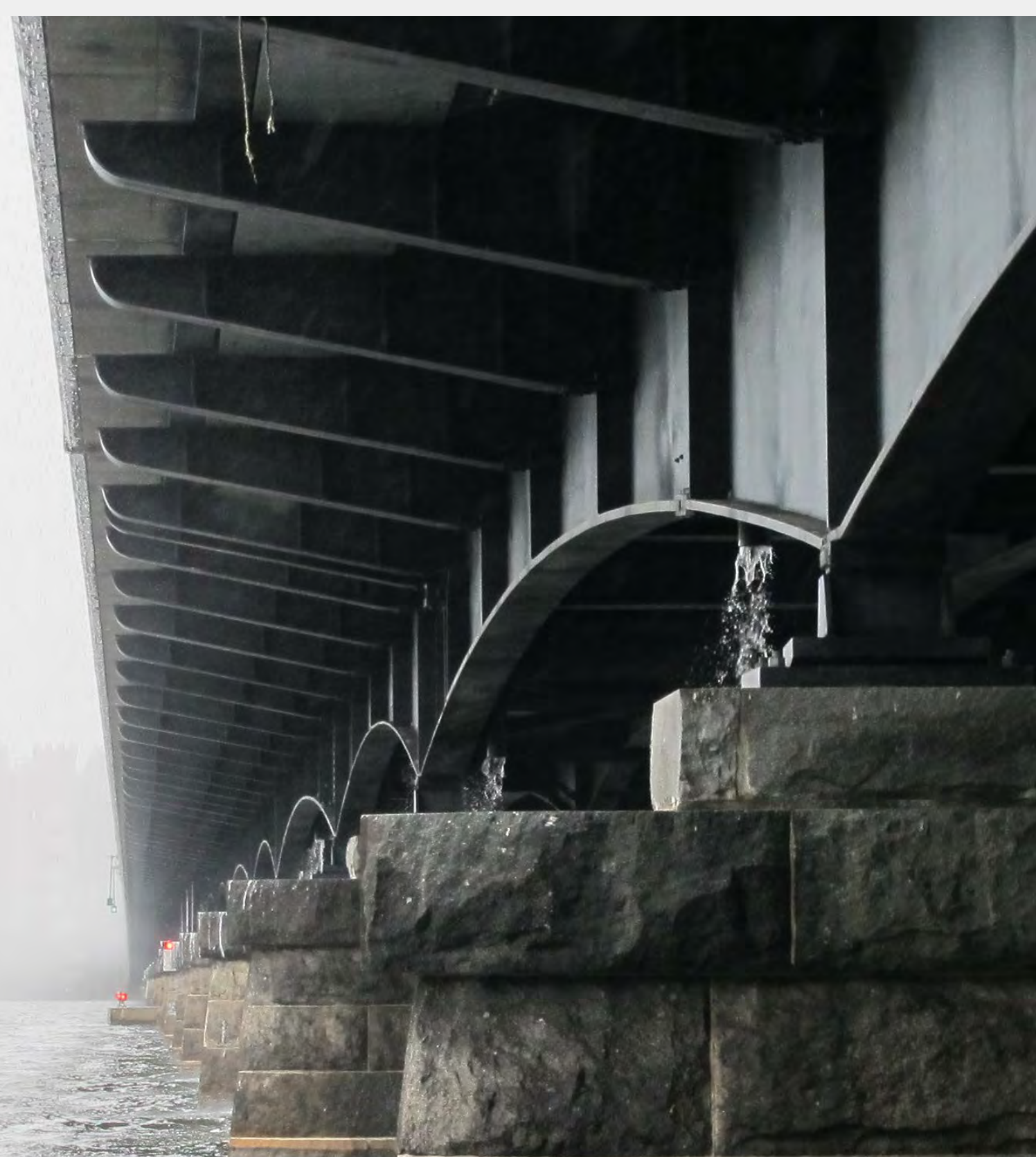

U.S. Department of the Interior U.S. Geological Survey 
Cover. Photograph of bridge-deck scuppers draining into the Charles River on State Route 2A in Boston near U.S. Geological Survey bridge-deck-monitoring station 422108071052501 during a rain storm. 


\section{Characterization of Stormwater Runoff From Bridge Decks in Eastern Massachusetts, 2014-16}

By Kirk P. Smith, Jason R. Sorenson, and Gregory E. Granato

Scientific Investigations Report 2018-5033 


\title{
U.S. Department of the Interior \\ RYAN K. ZINKE, Secretary
}

\section{U.S. Geological Survey William H. Werkheiser, Deputy Director exercising the authority of the Director}

\author{
U.S. Geological Survey, Reston, Virginia: 2018
}

For more information on the USGS - the Federal source for science about the Earth, its natural and living resources, natural hazards, and the environment-visit https://www.usgs.gov or call 1-888-ASK-USGS.

For an overview of USGS information products, including maps, imagery, and publications, visit https://store.usgs.gov.

Any use of trade, firm, or product names is for descriptive purposes only and does not imply endorsement by the U.S. Government.

Although this information product, for the most part, is in the public domain, it also may contain copyrighted materials as noted in the text. Permission to reproduce copyrighted items must be secured from the copyright owner.

Suggested citation:

Smith, K.P., Sorenson, J.R., and Granato, G.E., 2018, Characterization of stormwater runoff from bridge decks in eastern Massachusetts, 2014-16: U.S. Geological Survey Scientific Investigations Report 2018-5033, 73 p., https://doi.org/10.3133/sir20185033.

ISSN 2328-031X (print) ISSN 2328-0328 (online) ISBN 978-1-4113-4222-4 


\section{Acknowledgments}

The Jacobs Engineering Group Inc., a contractor for the Massachusetts Department of Transportation (MassD0T), provided funding for this study. The authors express their gratitude to Henry L. Barbaro, Stormwater Program Supervisor, MassD0T, and Bryan Cordeiro, stormwater analyst, MassDOT, for providing logistical support and periodic traffic control. 



\section{Contents}

Acknowledgments ……...................................................................................................................

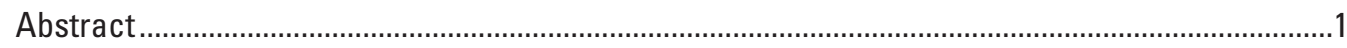

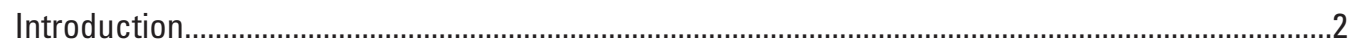

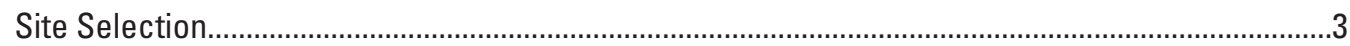

Data Collection Methods and Results of Quality-Assurance Sampling .............................................

Continuous Monitoring of Bridge-Deck Runoff .......................................................................

Design of Bridge-Deck-Monitoring Systems …………..................................................

Calculation of Runoff Coefficients ..........................................................................................

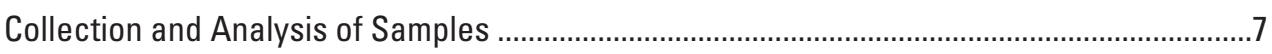

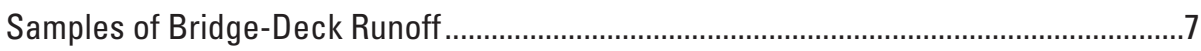

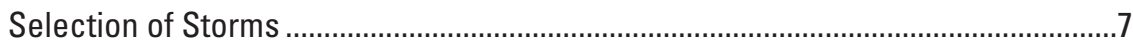

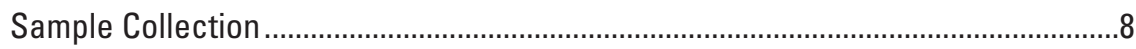

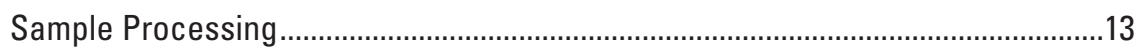

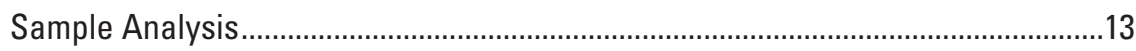

Samples of Bridge-Deck Sediment............................................................................13

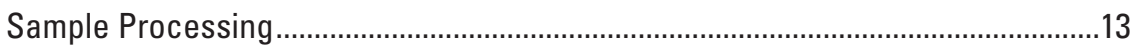

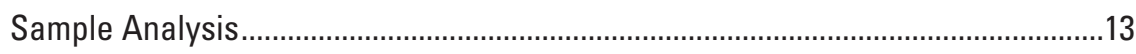

Distribution of Bridge-Deck Sediment ..............................................................................

Sample Collection and Processing ......................................................................14

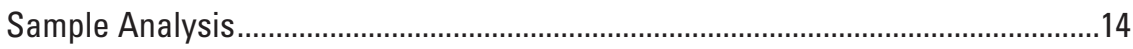

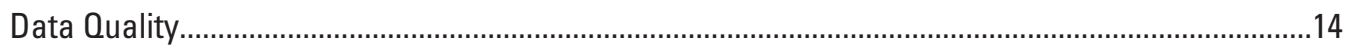

Bridge-Deck Flow ....................................................................................................... 14

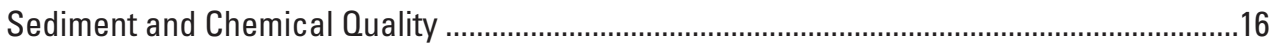

Field Blank Samples ...............................................................................................16

Concurrent Replicate-Split Runoff Samples ................................................................18

Replicate Samples of Bridge-Deck Sediment...............................................................20

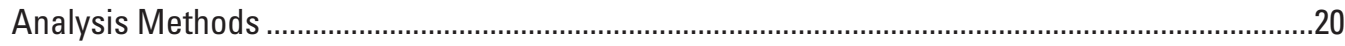

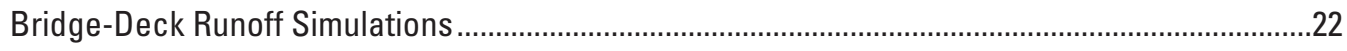

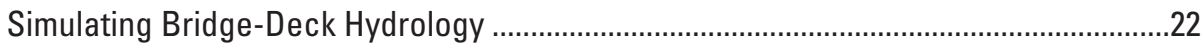

Simulating Bridge-Deck Runoff Concentrations .............................................................22

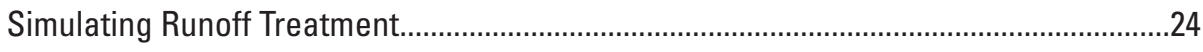

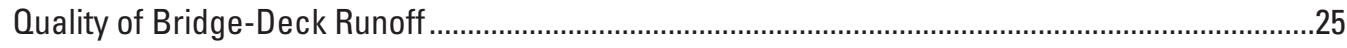

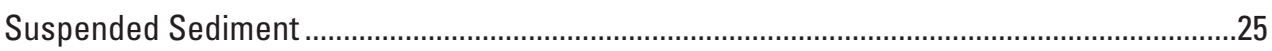

Loss on Ignition of Suspended Solids and Particulate Carbon ...............................................25

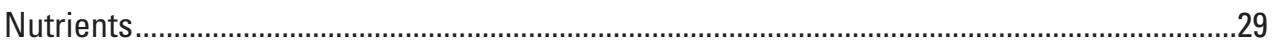

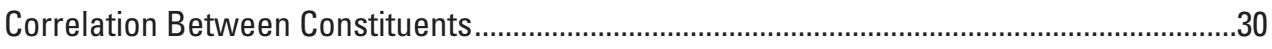

Interbridge Comparison of Constituent Concentrations .................................................................30

Spatial Distribution of Bridge-Deck Sediment.............................................................................3

Chemical Analysis of Sediment..............................................................................................

Comparisons of Highway and Bridge-Deck Constituent Concentrations ........................................39

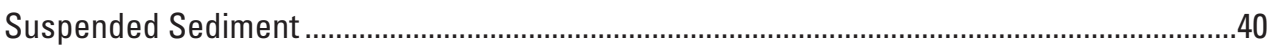

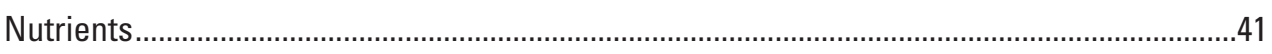

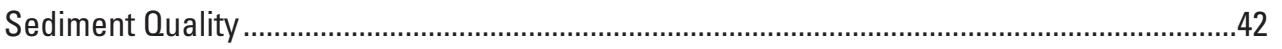




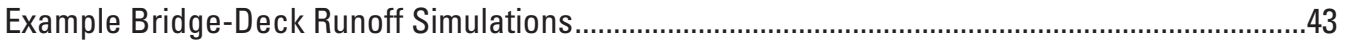

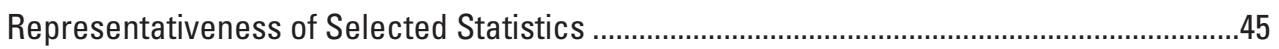

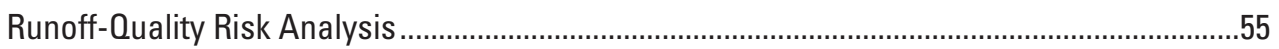

Runoff-Quality Annual Yield Analyses..................................................................................

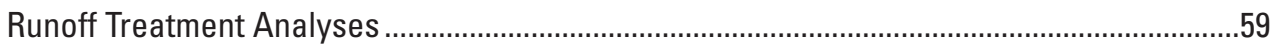

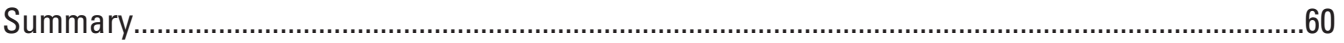

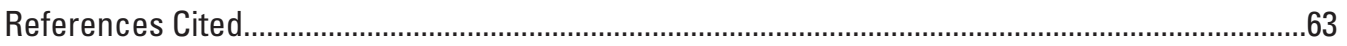

\section{Figures}

1. Maps showing locations of bridge-deck-monitoring sites in eastern Massachusetts, 2014-16.

2. Photographs of monitoring equipment at U.S. Geological Survey bridge-deck-monitoring stations on $A$, State Route 2A in Boston (422108071052501);

$B$, Interstate 90 near Weston (422025071154501); and C, State Route 20 near Quinsigamond Village (421247071470201) in eastern Massachusetts, 2014-16.

3. Photograph of an $\mathrm{H}$ flume at U.S. Geological Survey bridge-deck-monitoring station on State Route 20 near Quinsigamond Village (421247071470201) in eastern Massachusetts, 2014-16.

4. Photographs of road surface conditions that affect the runoff coefficient values...........9

5. Boxplots showing distribution of all antecedent dry periods and the antecedent dry periods for runoff events during which runoff samples were collected at U.S. Geological Survey monitoring stations on State Route 2A in Boston (422108071052501), Interstate 90 near Weston (422025071154501), and State Route 20 near Quinsigamond Village (421247071470201) in eastern Massachusetts, 2014-16

6. Boxplots showing distribution of storm totals equal to or greater than 0.05 inch recorded at U.S. Geological Survey station 01104430 during November 2001 through July 2014 and precipitation totals for storms during which samples were collected at U.S. Geological Survey bridge-deck-monitoring stations on State Route 2A in Boston (422108071052501), Interstate 90 near Weston (422025071154501), and State Route 20 near Quinsigamond Village (421247071470201) in eastern Massachusetts, August 2014 through September 2016...12

7. Graph showing example of automated flow-proportional collection of stormflow subsamples at U.S. Geological Survey bridge-deck-monitoring station at State Route 20 near Quinsigamond Village (421247071470201) in eastern Massachusetts, December 17, 2015.

8. Photograph of a static mixer assembly at U.S. Geological Survey bridge-deck-monitoring station on State Route 2A in Boston (422108071052501) in eastern Massachusetts, 2014-16.

9. Photographs of $A$, collection of bridge-deck sediment sample and $B$, vacuumed strip adjacent to 3 -foot ruler after collection of sediment sample on Interstate 90 near Weston (422025071154501)

10. Plot showing discrete measurements of pump flow in relation to the theoretical water-level/flow relation for the $\mathrm{H}$ flume compared to the distribution of peak flows recorded during sampled events at U.S. Geological Survey bridge-deck-monitoring station on State Route 20 near Quinsigamond Village (421247071470201), eastern Massachusetts, 2015-16. 
11. Boxplots showing distribution of concentrations of constituents measured in composite samples of bridge-deck runoff and in concurrent replicate-split samples collected at U.S. Geological Survey bridge-deck-monitoring stations on State Route 2A in Boston (422108071052501), Interstate 90 near Weston (422025071154501), and State Route 20 near Quinsigamond Village (421247071470201) in eastern Massachusetts, 2014-16.

12. Boxplots showing distribution of absolute relative percent difference values between replicate-split samples and composite samples of bridge-deck runoff collected at U.S. Geological Survey bridge-deck-monitoring stations on State Route 2A in Boston (422108071052501), Interstate 90 near Weston (422025071154501), and State Route 20 near Quinsigamond Village (421247071470201) in eastern Massachusetts, 2014-16.

13. Graph showing an example of the estimation of the average and standard deviation of total phosphorus concentrations in runoff composite samples collected from U.S. Geological Survey bridge-deck-monitoring station State Route 20 near Quinsigamond Village (421247071470201) by using the robust regression on order statistics method.

14. Boxplots showing distribution of three particle-size classes for suspended sediment in composite samples of bridge-deck runoff collected at U.S. Geological Survey bridge-deck-monitoring stations on State Route $2 \mathrm{~A}$ in Boston (422108071052501), Interstate 90 near Weston (422025071154501), and State Route 20 near Quinsigamond Village (421247071470201) in eastern Massachusetts, 2014-16

15. Scatterplot showing the relation between particles size less than 0.0625 millimeter

in diameter and particles size less than 0.25 millimeter in diameter to concentrations of suspended sediment in composite samples of bridge-deck runoff collected at U.S. Geological Survey bridge-deck-monitoring stations on State Route 2A in Boston (422108071052501), Interstate 90 near Weston (422025071154501), and State Route 20 near Quinsigamond Village (421247071470201) in eastern Massachusetts, 2014-16.

16. Boxplots showing distribution of concentrations of loss on ignition, particulate carbon, particulate organic carbon, and particulate inorganic carbon in composite samples of bridge-deck runoff collected at U.S. Geological Survey bridge-deck-monitoring stations on State Route 2A in Boston (422108071052501), Interstate 90 near Weston (422025071154501), and State Route 20 near Quinsigamond Village (421247071470201) in eastern Massachusetts, 2014-16.

17. Boxplots showing distribution of concentrations of total phosphorus, particulate nitrogen, and total dissolved nitrogen in composite samples of bridge-deck runoff collected at U.S. Geological Survey bridge-deck-monitoring stations on State Route 2A in Boston (422108071052501), Interstate 90 near Weston (422025071154501), and State Route 20 near Quinsigamond Village (421247071470201) in eastern Massachusetts, 2014-16.

18. Photographs of sediment sources from deterioration of the $A$, bridge-deck surface; $B$, median barrier; and $C$, shoulder area that contributed to the sediment yield on the Interstate 90 bridge near Weston, Massachusetts, 2015-16.

19. Graphs showing normalized bridge-deck sediment yields at five fixed locations on three bridges monitored by the U.S. Geological Survey on $A$, State Route $2 \mathrm{~A}$ in Boston (422108071052501); B, Interstate 90 near Weston (422025071154501); and $C$, State Route 20 near Quinsigamond Village (421247071470201) in eastern Massachusetts, 2015-16 
20. Photograph of sediment buildup propagating westward onto the State Route 20 bridge from the upgradient roadway, near Quinsigamond Village, Massachusetts,

2016.

21. Bar chart showing the percentage of the concentration estimated for selected constituents associated with the mean particle size of suspended sediment collected from three bridges monitored by the U.S. Geological Survey on State Route 2A in Boston (422108071052501), Interstate 90 near Weston (422025071154501), and State Route 20 near Quinsigamond Village (421247071470201) in eastern Massachusetts, 2014-16.

22. Boxplots showing distribution of concentrations of suspended sediment and the distribution of concentrations of three particle-size classes for suspended sediment in composite samples of highway runoff collected at USGS stations 423027071291301, 423027071291302, 423016071431501, 422821071332001, $422716071343901,422420071153302,422620071153301$, and 421647071024703 in eastern Massachusetts, 2005-7 (Smith and Granato, 2010), and from three bridge-deck-monitoring stations (422108071052501, 422025071154501, and 421247071470201) in this study, eastern Massachusetts, 2014-16

23. Boxplots showing distribution of total phosphorus and total nitrogen in composite samples of highway runoff collected at USGS stations 423027071291301, 423027071291302, 423016071431501, 422821071332001, 422716071343901, 422420071153302,422620071153301 , and 421647071024703 in eastern Massachusetts, 2005-7 (Smith and Granato, 2010), and from three bridge-deck-monitoring stations (422108071052501, 422025071154501, and 421247071470201) in this study, eastern Massachusetts, 2014-16

24. Chart showing concentrations of selected elements associated with sediment $A$, less than 0.0625 millimeter $(\mathrm{mm})$ in diameter; $B$, greater than or equal to $0.0625 \mathrm{~mm}$ to $0.25 \mathrm{~mm}$ in diameter; and $C$, greater than $0.25 \mathrm{~mm}$ in diameter in three bridge-deck composite samples collected on State Route 2A in Boston (422108071052501), Interstate 90 near Weston (422025071154501), and State Route 20 near Quinsigamond Village (421247071470201) in eastern Massachusetts, 2015-16, in relation to the range of concentrations of selected elements associated with the same grain sizes in highway-runoff sediment from USGS stations 423027071291301, 423027071291302, 422821071332001, 422716071343901, 422420071153302, and 422620071153301 in eastern Massachusetts, 2005-7 (Smith and Granato, 2010).

25. Chart showing the distribution of concentrations of selected constituents in 1 kilogram of sediment estimated on the basis of the mean concentration of each constituent associated with three particle-size ranges in highway sediment collected from USGS stations 423027071291301, 423027071291302, 422821071332001, 422716071343901, 422420071153302, and 422620071153301 in eastern Massachusetts in 2005-7 (Smith and Granato, 2010) and from bridges on State Route 2A (422108071052501) in Boston, Interstate 90 near Weston (422025071154501), and State Route 20 near Quinsigamond Village (421247071470201) in eastern Massachusetts, 2015-16, and from the mean particle-size distribution of suspended sediment in composite samples of runoff collected at each location

26. Graphs showing measured total nitrogen concentrations and concentrations simulated by using $A$, traditional statistics and $B$, statistics calculated by using robust alternative methods

27. Graphs showing measured total phosphorus concentrations and concentrations simulated by using $A$, traditional statistics and $B$, statistics calculated by using robust alternative methods 
28. Graphs showing measured suspended sediment concentrations and concentrations simulated by using $A$, traditional statistics and $B$, statistics calculated by using robust alternative methods.

29. Graphs showing concentrations simulated by using L-moments and measured $A$, total nitrogen; $B$, total phosphorus; and $C$, suspended sediment concentrations...........56

30. Graphs showing probability plots of $A$, total nitrogen and $B$, total phosphorus, including measured concentrations, concentrations simulated with the median of robust statistics (table 18), and concentrations simulated by modifying the simulated highway runoff by using the generic best-management practice statistics (table 10)

31. Graphs showing yields of $A$, total nitrogen; $B$, total phosphorus; and $C$, suspended sediment in pounds per acre per year for each simulated year by percentile......

\section{Tables}

1. Names, locations, and other bridge attributes for U.S. Geological Survey bridge-deck-monitoring stations in eastern Massachusetts, 2014-16.

2. Land-use characteristics for a one-half mile radius around the bridge-deck-monitoring stations on State Route 2A in Boston (422108071052501), Interstate 90 near Weston (422025071154501), and State Route 20 near Quinsigamond Village (421247071470201) in eastern Massachusetts, 2014-16

3. Constituents and physical properties measured in composite samples of bridge-deck runoff, reporting levels, analytical techniques, and parameter codes, 2014-16

4. Constituents measured in samples of bridge-deck sediment in milligrams per kilogram, reporting levels, analytical techniques, and parameter codes, 2014-16

5. Sample location, in percent of total bridge span, and mass of bridge-deck sediment samples in grams collected at five bridge locations on State Route 2A in Boston (422108071052501), Interstate 90 near Weston (422025071154501), and State Route 20 near Quinsigamond Village (421247071470201) in eastern Massachusetts, 2015-16

6. Bridge-deck sediment yields, in pounds per curb-mile, for three bridge locations for bridges on State Route 2A in Boston (422108071052501), Interstate 90 near Weston (422025071154501), and State Route 20 near Quinsigamond Village (421247071470201) in eastern Massachusetts, 2015-16.

7. Quality-control samples collected at U.S. Geological Survey bridge-deck-monitoring stations on State Route 2A in Boston (422108071052501), Interstate 90 near Weston (422025071154501), and State Route 20 near Quinsigamond Village (421247071470201) in eastern Massachusetts, 2014-16.

8. Summary of field-blank data and comparison to composite bridge-deck runoff samples, in milligrams per liter, collected at U.S. Geological Survey bridge-deck-monitoring stations on State Route 2A in Boston (422108071052501), Interstate 90 near Weston (422025071154501), and State Route 20 near Quinsigamond Village (421247071470201) in eastern Massachusetts, 2014-16.

9. Concentrations and absolute relative percent difference between three replicate-split and environmental composite samples of bridge-deck sediment collected from U.S. Geological Survey bridge-deck-monitoring stations on State Route 2A in Boston (422108071052501), Interstate 90 near Weston (422025071154501), and State Route 20 near Quinsigamond Village (421247071470201) in eastern Massachusetts, 2014-16. 
10. Stormwater control measure best-management practice performance statistics for flow and concentration treatment used in the Stochastic Empirical Loading and Dilution Model.

11. Summary statistics for concentrations of constituents in composite samples of bridge-deck runoff collected from State Route 2A in Boston (422108071052501), Interstate 90 near Weston (422025071154501), and State Route 20 near Quinsigamond Village (421247071470201) in eastern Massachusetts, 2014-16

12. Results and attained significance levels for Anderson-Darling tests for concentrations of selected constituents in composite samples of bridge-deck runoff collected at U.S. Geological Survey bridge-deck-monitoring stations on State Route 2A in Boston (422108071052501), Interstate 90 near Weston (422025071154501), and State Route 20 near Quinsigamond Village (421247071470201) in eastern Massachusetts, 2014-16.

13. Results and attained significance levels for Spearman rho tests for concentrations of selected constituents in composite samples of bridge-deck runoff collected at U.S. Geological Survey bridge-deck-monitoring stations on State Route 2A in Boston (422108071052501), Interstate 90 near Weston (422025071154501), and State Route 20 near Quinsigamond Village(421247071470201) in eastern Massachusetts, 2014-16

14. Attained F statistics, significance levels, predicted R-squared value, and relevant statistics from one-way analysis of variance tests and Tukey pairwise comparisons performed on the ranks of selected concentration and physical parameter values in composite samples of bridge-deck runoff collected at U.S. Geological Survey bridge-deck-monitoring stations on State Route 2A in Boston (422108071052501), Interstate 90 near Weston (422025071154501), and State Route 20 near Quinsigamond Village (421247071470201) in eastern Massachusetts, 2014-16.

15. Mean proportion of suspended sediment in three particle-size classes in composite samples of bridge-deck and highway runoff and dry weight total-recoverable concentrations by sediment-size class for selected elements in three composite samples of bridge-deck sediments collected from bridges on State Route 2A in Boston (422108071052501), Interstate 90 near Weston (422025071154501), and State Route 20 near Quinsigamond Village (421247071470201) in eastern Massachusetts, 2016, and from highways in eastern Massachusetts, 2005-7

16. Results and attained significance levels ( $p$-values) from Mann-Whitney tests for paired sample sets of constituent concentrations in bridge-deck runoff collected at U.S. Geological Survey bridge-deck-monitoring stations on State Route 2A in Boston (422108071052501), Interstate 90 near Weston (422025071154501), and State Route 20 near Quinsigamond Village (421247071470201) during 2014-16 and in highway runoff collected from U.S. Geological Survey monitoring stations on State Route 2 (USGS stations 423027071291301, 423027071291302), Interstate 190 (USGS station 423016071431501), Interstate 495 (USGS stations 422821071332001, 422716071343901), Interstate 95 (USGS stations 422420071153302, 422620071153301), and Interstate 93 (USGS station 421647071024703) in eastern Massachusetts, 2005-7.

17. Examples of maximum or typical concentrations of phosphorus, nitrogen, and sediment species in environmental samples recorded in the literature. 
18. Average, standard deviation, and skew of the common logarithms of event-mean concentrations in composite samples of bridge-deck runoff collected from State Route 2A in Boston (422108071052501), Interstate 90 near Weston (422025071154501), and State Route 20 near Quinsigamond Village (421247071470201) in eastern Massachusetts, 2014-16, as calculated by using traditional and robust methods

19. Average, standard deviation, and skew of the common logarithms of event-mean concentrations in composite samples of bridge-deck runoff collected from State Route 2A in Boston (422108071052501), Interstate 90 near Weston (422025071154501), and State Route 20 near Quinsigamond Village (421247071470201) in eastern Massachusetts, 2014-16, as calculated by using L-moment methods.

20. Simulated long-term average-annual bridge-deck runoff and stormwater control measure best-management practice discharge yields, in pounds per acre per year for total nitrogen, total phosphorus, and suspended sediment. 


\section{Conversion Factors}

U.S. customary units to International System of Units

\begin{tabular}{|c|c|c|}
\hline Multiply & By & To obtain \\
\hline \multicolumn{3}{|c|}{ Length } \\
\hline inch (in.) & 25.4 & millimeter (mm) \\
\hline foot $(\mathrm{ft})$ & 0.3048 & meter (m) \\
\hline mile (mi) & 1.609 & kilometer (km) \\
\hline \multicolumn{3}{|c|}{ Area } \\
\hline acre & 0.004047 & square kilometer $\left(\mathrm{km}^{2}\right)$ \\
\hline square foot $\left(\mathrm{ft}^{2}\right)$ & 0.09290 & square meter $\left(\mathrm{m}^{2}\right)$ \\
\hline square inch $\left(i^{2}\right)$ & 6.452 & square centimeter $\left(\mathrm{cm}^{2}\right)$ \\
\hline square mile $\left(\mathrm{mi}^{2}\right)$ & 259.0 & hectare (ha) \\
\hline square mile $\left(\mathrm{mi}^{2}\right)$ & 2.590 & square kilometer $\left(\mathrm{km}^{2}\right)$ \\
\hline \multicolumn{3}{|c|}{ Volume } \\
\hline gallon (gal) & 3.785 & liter (L) \\
\hline gallon (gal) & 0.003785 & cubic meter $\left(\mathrm{m}^{3}\right)$ \\
\hline cubic foot $\left(\mathrm{ft}^{3}\right)$ & 0.02832 & cubic meter $\left(\mathrm{m}^{3}\right)$ \\
\hline \multicolumn{3}{|c|}{ Flow rate } \\
\hline cubic foot per second (ftºs) & 0.02832 & cubic meter per second $\left(\mathrm{m}^{3} / \mathrm{s}\right)$ \\
\hline cubic foot per day $\left(\mathrm{ft}^{3} / \mathrm{d}\right)$ & 0.02832 & cubic meter per day $\left(\mathrm{m}^{3} / \mathrm{d}\right)$ \\
\hline million gallons per day (Mgal/d) & 0.04381 & cubic meter per second $\left(\mathrm{m}^{3} / \mathrm{s}\right)$ \\
\hline \multicolumn{3}{|c|}{ Mass } \\
\hline pound, avoirdupois (lb) & 0.4536 & kilogram (kg) \\
\hline ton, short (2,000 lb) & 0.9072 & metric ton $(\mathrm{t})$ \\
\hline ton, long (2,240 lb) & 1.016 & metric ton (t) \\
\hline
\end{tabular}

Temperature in degrees Celsius $\left({ }^{\circ} \mathrm{C}\right)$ may be converted to degrees Fahrenheit $\left({ }^{\circ} \mathrm{F}\right)$ as follows:

$$
{ }^{\circ} \mathrm{F}=\left(1.8 \times{ }^{\circ} \mathrm{C}\right)+32 \text {. }
$$

\section{Datum}

Horizontal coordinate information is referenced to the North American Datum of 1983 (NAD 83).

\section{Supplemental Information}

Specific conductance is given in microsiemens per centimeter at 25 degrees Celsius $(\mu \mathrm{S} / \mathrm{cm}$ at $\left.25^{\circ} \mathrm{C}\right)$.

Concentrations of chemical constituents in water are given in milligrams per liter (mg/L). 


\section{Abbreviations}

\begin{tabular}{|c|c|}
\hline AADT & annual average daily traffic \\
\hline Al & aluminum \\
\hline ANOVA & one-way analysis of variance \\
\hline As & arsenic \\
\hline $\mathrm{Ba}$ & barium \\
\hline BMP & best-management practice \\
\hline $\mathrm{Cd}$ & cadmium \\
\hline $\mathrm{Cr}$ & chromium \\
\hline $\mathrm{Cu}$ & copper \\
\hline DN & total dissolved nitrogen \\
\hline EPA & U.S. Environmental Protection Agency \\
\hline HRDB & Highway-Runoff Database \\
\hline LOI & loss on ignition of suspended solids \\
\hline MassDOT & Massachusetts Department of Transportation \\
\hline MIC & minimum irreducible concentration \\
\hline $\mathrm{Mn}$ & manganese \\
\hline $\mathrm{Ni}$ & nickel \\
\hline NWIS & National Water Information System \\
\hline$p$ & attained significance level \\
\hline $\mathrm{Pb}$ & lead \\
\hline PC & particulate carbon \\
\hline PIC & particulate inorganic carbon \\
\hline PN & particulate nitrogen \\
\hline POC & particulate organic carbon \\
\hline RPD & relative percent difference \\
\hline SD & standard deviation \\
\hline SELDM & Stochastic Empirical Loading and Dilution Model \\
\hline SS & suspended sediment \\
\hline TKN & total Kjeldahl nitrogen \\
\hline TN & total nitrogen \\
\hline TP & total phosphorus \\
\hline USGS & U.S. Geological Survey \\
\hline WWTP & wastewater treatment plant \\
\hline $\mathrm{Zn}$ & zinc \\
\hline
\end{tabular}





\title{
Characterization of Stormwater Runoff From Bridge Decks in Eastern Massachusetts, 2014-16
}

\author{
By Kirk P. Smith, Jason R. Sorenson, and Gregory E. Granato
}

\section{Abstract}

The quality of stormwater runoff from bridge decks (hereafter referred to as "bridge-deck runoff") was characterized in a field study from August 2014 through August 2016 in which concentrations of suspended sediment (SS) and total nutrients were monitored. These new data were collected to supplement existing highway-runoff data collected in Massachusetts which were deficient in bridge-deck runoff concentration data. Monitoring stations were installed at three bridges maintained by the Massachusetts Department of Transportation in eastern Massachusetts (State Route 2A in the city of Boston, Interstate 90 in the town of Weston, and State Route 20 near Quinsigamond Village in the city of Worcester). The bridges had annual average daily traffic volumes from 21,200 to 124,000 vehicles per day; the land use surrounding the monitoring stations was 25 to 67 percent impervious.

Automatic-monitoring techniques were used to collect more than 160 flow-proportional composite samples of bridgedeck runoff. Samples were analyzed for concentrations of SS, loss on ignition of suspended solids (LOI), particulate carbon (PC), total phosphorus (TP), total dissolved nitrogen (DN), and particulate nitrogen (PN). The distribution of particle size of SS also was determined for composite samples. Samples of bridge-deck runoff were collected year round during rain, mixed precipitation, and snowmelt runoff and with different dry antecedent periods throughout the 2-year sampling period.

At the three bridge-deck-monitoring stations, median concentrations of SS in composite samples of bridge-deck runoff ranged from 1,490 to 2,020 milligrams per liter (mg/L); however, the range of SS in individual composites was vast at 44 to $142,000 \mathrm{mg} / \mathrm{L}$. Median concentrations of SS were similar in composite samples collected from the State Route 2A and Interstate 90 bridge (2,010 and 2,020 mg/L, respectively), and lowest at the State Route 20 bridge $(1,490 \mathrm{mg} / \mathrm{L})$. Concentrations of coarse sediment (greater than 0.25 millimeters in diameter) dominated the SS matrix by more than an order of magnitude. Concentrations of LOI and PC in composite samples ranged from 15 to $1,740 \mathrm{mg} / \mathrm{L}$ and 6.68 to $1,360 \mathrm{mg} / \mathrm{L}$, respectively, and generally represented less than
10 and 3 percent of the median mass of SS, respectively. Concentrations of TP in composite samples ranged from 0.09 to $7.02 \mathrm{mg} / \mathrm{L}$; median concentrations of TP ranged from 0.505 to $0.69 \mathrm{mg} / \mathrm{L}$ and were highest on the bridge on State Route $2 \mathrm{~A}$ in Boston. Concentrations of total nitrogen (TN) (sum DN and $\mathrm{PN}$ ) in composite samples were variable (0.36 to $29 \mathrm{mg} / \mathrm{L}$ ). Median DN (0.64 to $0.90 \mathrm{mg} / \mathrm{L}$ ) concentrations generally represented about 40 percent of the TN concentration at each bridge and were similar to annual volume-weighted mean concentrations of nitrogen in precipitation in Massachusetts.

Nonparametric statistical methods were used to test for differences between sample constituent concentrations among the three bridges. These results indicated that there are no statistically significant differences for concentrations of SS, LOI, PC, and TP among the three bridges (one-way analysis of variance test on rank-transformed data, 95-percent confidence level). Test results for concentrations of TN in composite samples indicated that concentrations of TN collected on State Route 20 near Quinsigamond Village were significantly higher than those concentrations collected on State Route 2A in Boston and Interstate 90 near Weston. Median concentrations of TN were about 93 and 55 percent lower at State Route 2A and at Interstate 90, respectively, compared to the median concentrations of TN at State Route 20.

Samples of sediment were collected from five fixed locations on each bridge on three occasions during dry weather to calculate semiquantitative distributions of sediment yields on the bridge surface relative to the monitoring location. Mean yields of bridge-deck sediment during this study for State Route 2A in Boston, Interstate 90 near Weston, and State Route 20 near Quinsigamond Village were 1,500, 250, and 5,700 pounds per curb-mile, respectively. Sediment yields at each sampling location varied widely (26 to 25,000 pounds per curb-mile) but were similar to yields reported elsewhere in Massachusetts and the United States. Yields calculated for each sampling location indicated that the sediment was not evenly distributed across each bridge in this study for plausible reasons such as bridge slope, vehicular tracking, and bridge deterioration. 
Bridge-deck sediment quality was largely affected by the distribution of sediment particle size. Concentrations of TP in the fine sediment-size fraction (less than 0.0625 millimeter in diameter) of samples of bridge-deck sediment were about 6 times greater than in the coarse size fraction. Concentrations for many total-recoverable metals were 2 to 17 times greater in the fine size fraction compared to concentrations in the coarse size fraction (greater than or equal to 0.25 millimeter in diameter), and concentrations of total-recoverable copper and lead in the fine size fraction were 2 to 65 times higher compared to concentrations in the intermediate (greater than or equal to 0.0625 to 0.25 millimeter in diameter) or the coarse size fraction. However, the proportion of sediment particles less than 0.0625 millimeter in diameter in composite samples of bridge-deck runoff was small (median values range from 4 to 8 percent at each bridge) compared to the larger sediment particle-size mass. As a result, more than 50 percent of the sediment-associated TP, aluminum, chromium, manganese, and nickel was estimated to be associated with the coarse size fraction of the SS load. In contrast, about 95 percent of the estimated sediment-associated copper concentration was associated with the fine size fraction of the SS load.

Version 1.0.2 of the Stochastic Empirical Loading and Dilution Model was used to simulate long-term (29-30-year) concentrations and annual yields of SS, TP, and TN in bridgedeck runoff and in discharges from a hypothetical stormwater treatment best-management practice structure. Three methods (traditional statistics, robust statistics, and L-moments) were used to calculate statistics for stochastic simulations because the high variability in measured concentration values during the field study resulted in extreme simulated concentrations. Statistics of each dataset, including the average, standard deviation, and skew of the common (base 10) logarithms, for each of the three bridges, and for a lumped dataset, were calculated and used for simulations; statistics representing the median of statistics calculated for the three bridges also were used for simulations. These median statistics were selected for the interpretive simulations so that the simulations could be used to estimate concentrations and yields from other, unmonitored bridges in Massachusetts. Comparisons of the standard and robust statistics indicated that simulation results with either method would be similar, which indicated that the large variability in simulated results was not caused by a few outliers. Comparison to statistics calculated by the L-moments methods indicated that L-moments do not produce extreme concentrations; however, they also do not produce results that represent the bulk of concentration data.

The runoff-quality risk analysis indicated that bridgedeck runoff would exceed discharge standards commonly used for large, advanced wastewater treatment plants, but that commonly used stormwater best-management practices may reduce the percentage of exceedances by one-half. Results of simulations indicated that long-term average yields of TN, TP, and SS may be about 21.4, 6.44, and 40,600 pounds per acre per year, respectively. These yields are about 1.3, 3.4, and 16 times simulated ultra-urban highway yields in
Massachusetts; however, simulations indicated that use of a best-management practice structure to treat bridge-deck runoff may reduce discharge yields to about 10, 2.8, and 4,300, pounds per acre per year, respectively.

\section{Introduction}

Stormwater discharges from Massachusetts roadways can adversely affect the quality of receiving water and may result in the failure of a water body to meet Massachusetts surface-water-quality standards. Many studies have shown that highway runoff can be a source of suspended sediment (SS) and nutrients (Breault and Granato, 2000; Smith, 2002; Kayhanian and others, 2003; Smith and Granato, 2010). Data from focused bridge studies (Malina and others, 2005; Wagner and others, 2011) also indicate that concentrations of total phosphorus (TP) and SS in samples of stormwater runoff from bridge decks (hereafter referred to as "bridge-deck runoff”) are similar to concentrations in samples of runoff collected from open highways. In Massachusetts, bridge-deck runoff is collected in cast iron drainage inlets called "scuppers." Scuppers typically drain to trunk-line conveyance systems, where the runoff is discharged to a structural source control near the bridge embankment. For some bridges, bridge-deck runoff is discharged directly to the underlying land surface or water body. The Massachusetts Department of Transportation (MassDOT) owns about 4,800 bridges, and 38 percent are over water (Henry Barbaro, Massachusetts Department of Transportation, written commun., 2014). Bridge-deck scuppers do not provide water-quality treatment of stormwater runoff, and thus discharge from bridges is of concern to regulating officials.

Data on the quality of bridge-deck runoff is limited in the northeastern United States, and the transferability of existing highway-runoff data to bridge decks is not well documented. To address this data gap, the U.S. Geological Survey (USGS) piloted a field study where composite samples of bridgedeck runoff were collected between August 2014 through August 2016 to document the quality of bridge-deck runoff for concentrations of SS, total nutrients, loss on ignition of suspended solids (LOI), and particulate carbon (PC) at three bridges maintained by the MassDOT in eastern Massachusetts. The integration of these data with a technically sound highway-runoff model can be used to guide, substantiate, and support highway planning, design, and maintenance decisions. The study findings aid in the interpretation of local, regional, and national bridge-deck runoff data including concentrations, loads, potential effects on receiving waters, and the potential effectiveness of various best-management practices (BMPs). This study is also a component of the implementation of MassDOT's National Pollutant Discharge Elimination System, Small Municipal Separate Storm Sewer Systems general permit. 
This report documents concentrations of SS, SS particle size, total nutrients, LOI, and PC measured in flow-weighted composite samples of bridge-deck runoff collected from bridge scuppers for three bridges in eastern Massachusetts during a 2-year monitoring period (2014-16). It also describes the physiochemical characteristics of samples of bridge-deck sediment and documents the monitoring and sample collection methods for all data contained within the report. The report discusses the relation between concentration data for the respective constituents among the three bridge-deck stations and compares the composition and quality of sediment in samples collected from bridge decks and highways in Massachusetts. The data presented in this report are integrated in the Highway-Runoff Database (HRDB; Version 1.0.0b) (Granato and Cazenas, 2009), which serves as a preprocessor for the Stochastic Empirical Loading and Dilution Model (SELDM) (Granato, 2013). SELDM yields of SS and total nutrients and examples of BMP analysis also are presented in this report.

\section{Site Selection}

Sections of bridge deck on three highways in eastern Massachusetts were selected for this study because they represented varying traffic volumes and surrounding impervious density, factors that previously were determined to affect constituent concentrations (Smith and Granato, 2010). The USGS bridge-deck-monitoring stations were on State Route 2A (Massachusetts Avenue) in the city of Boston and over the Charles River spanning between the cities of Boston and Cambridge (station number 422108071052501; hereafter referred to as "State Route 2A monitoring station"), Interstate 90 (Massachusetts Turnpike) over the Charles River near the town of Weston (station number 422025071154501; hereafter referred to as "Interstate 90 monitoring station"), and State Route 20 near Quinsigamond Village in the city of Worcester over the Blackstone River (station number 421247071470201; hereafter referred to as "State Route 20 monitoring station") (fig. 1).

The areas that drain to the monitoring stations range from 2,300 to 10,100 square feet $\left(\mathrm{ft}^{2}\right)$ and are 100 percent impervious. These values represent the area between scupper inlets to the crown of the roadway or to the opposite roadway shoulder. Posted speed limits range from 30 to 55 miles per hour and the annual average daily traffic (AADT) volumes range from about 21,200 to about 124,000 vehicles per day (Massachusetts Department of Transportation, 2017a) (table 1). The wearing bridge surface is asphalt, except for Interstate 90, which is concrete. The land use surrounding each monitoring station is primarily developed land (43.1 to 78.8 percent) (Homer and others, 2015) with accompanying high impervious area (25 to 67 percent; Massachusetts Office of Geographic Information System, 2007) (table 2). The Charles River, the largest water body near any of the bridges, accounts for 16 percent of the surrounding area at the State Route 2A monitoring station in Boston. The amount of development near each bridge decreases from east to west (table 2).

Prior to the monitoring period, bridge scuppers at each location were cleaned by MassDOT, except for the Interstate 90 bridge where the necessary maintenance equipment was not available at the beginning of the study. The Interstate 90 bridge scuppers were cleaned in October 2015. There were no major construction activities at the three bridges during the study period. Street sweeping was done once a week, weather permitting, on the State Route 2A bridge in Boston and as necessary on the other bridges. The application of winter maintenance materials was limited to salt. A sand or sand-salt mixture was not applied to the bridges.

\section{Data Collection Methods and Results of Quality-Assurance Sampling}

The methodology described herein includes a description of the design of each bridge-deck-monitoring station (herein referred to as "monitoring station") and the collection and analysis methods for samples of bridge-deck runoff and bridge-deck sediment. At each bridge, a continuous monitoring and sampling system was installed and operated from August 2014 through August 2016. Samples of bridge-deck sediment were collected at five locations across each bridge following three dry antecedent periods during the study.

\section{Continuous Monitoring of Bridge-Deck Runoff}

Automatic-monitoring techniques were used to collect continuous measurements of water level in the runoff collection system and rainfall and to collect composite samples of bridge-deck runoff. Continuous monitoring data were collected from August 2014 through September 2016 at each bridge; composite samples of bridge-deck runoff were collected from August 2014 through August 2016 at each bridge. Runoff coefficients were calculated, in part, to determine practical flow thresholds for triggering the automatic samplers. Samples of bridge-deck runoff were collected by the automatic samplers on a flow-proportional basis.

\section{Design of Bridge-Deck-Monitoring Systems}

At each monitoring station, the outlet of a bridge-deck scupper was modified to divert runoff from the scupper outfall to a shelter containing an $\mathrm{H}$ flume rated for 2 cubic feet per second $\left(\mathrm{ft}^{3} / \mathrm{s}\right)$ where flow data were collected (fig. 2). The $\mathrm{H}$ flume combines the sensitivity and accuracy of a sharpcrested weir and the self-cleaning features of a flume (Kilpatrick and Schneider, 1983). The capacity of the flumes was sufficient to characterize all flow rates at each monitoring station. Water level in the flume was measured by a gas-purge bubbler system and a National Institute of Standards and 
Technology traceable pressure sensor. Redundant measurements of water level were made with an ultrasonic sensor at the same measurement location (fig. 3). These secondary level measurements were useful to detect debris or ice in the flume that caused the pressure sensor to measure erroneously high water levels. Continuous measurements of water level were converted to continuous flow values by programming the dataloggers with the stage-flow relation for the flume. Rainfall data were measured at the monitoring stations on Interstate 90 and State Route 20 with an unheated 8-inch (in.) diameter tippingbucket sensor mounted about 7 feet $(\mathrm{ft})$ above the ground surface. The area near the State Route 2A monitoring station was not suitable for the measurement of rainfall; instead rainfall data were available at USGS station 01104683 (Muddy River at Brookline, Massachusetts) about 1.5 miles southwest of the bridge-deck-monitoring station. Precipitation data (inclusive of mixed precipitation and snowmelt water) also were available at USGS station 422302071083801 (Fresh Pond in Gate House at Cambridge, Mass.), about 3.5 miles northwest of the bridge-deck-monitoring station but only used as a redundant data source. Rainfall was measured to estimate the total runoff for the drainage area for each station to estimate flow-proportional sampling thresholds. Each station was equipped with telemetry to transmit stored data and to enable the dataloggers to be remotely programmed.

\section{Calculation of Runoff Coefficients}

A runoff coefficient is the ratio of the volume of runoff to the volume of rainfall. Runoff coefficients for each rainfall event in this study were calculated by dividing the runoff total by the product of the measured rain total and the drainage area for each respective monitoring station. These runoff coefficients were used to select appropriate flow thresholds for triggering the automatic samplers, to identify potential errors related to measurements of rainfall or water level, and to identify changes in the contributing area. The ratio of the volume of runoff to the volume of rainfall for a given area will range from zero (no runoff) to one (100 percent of the precipitation is measured in the runoff); however, if a runoff coefficient exceeds a value of one, there likely is an error in the measurement of precipitation, flow, and (or) contributing area (Church and others, 1999). Changes in the contributing area can result when flow from an upgradient drainage area is diverted into the drainage area of interest, such as when the inlet of one or

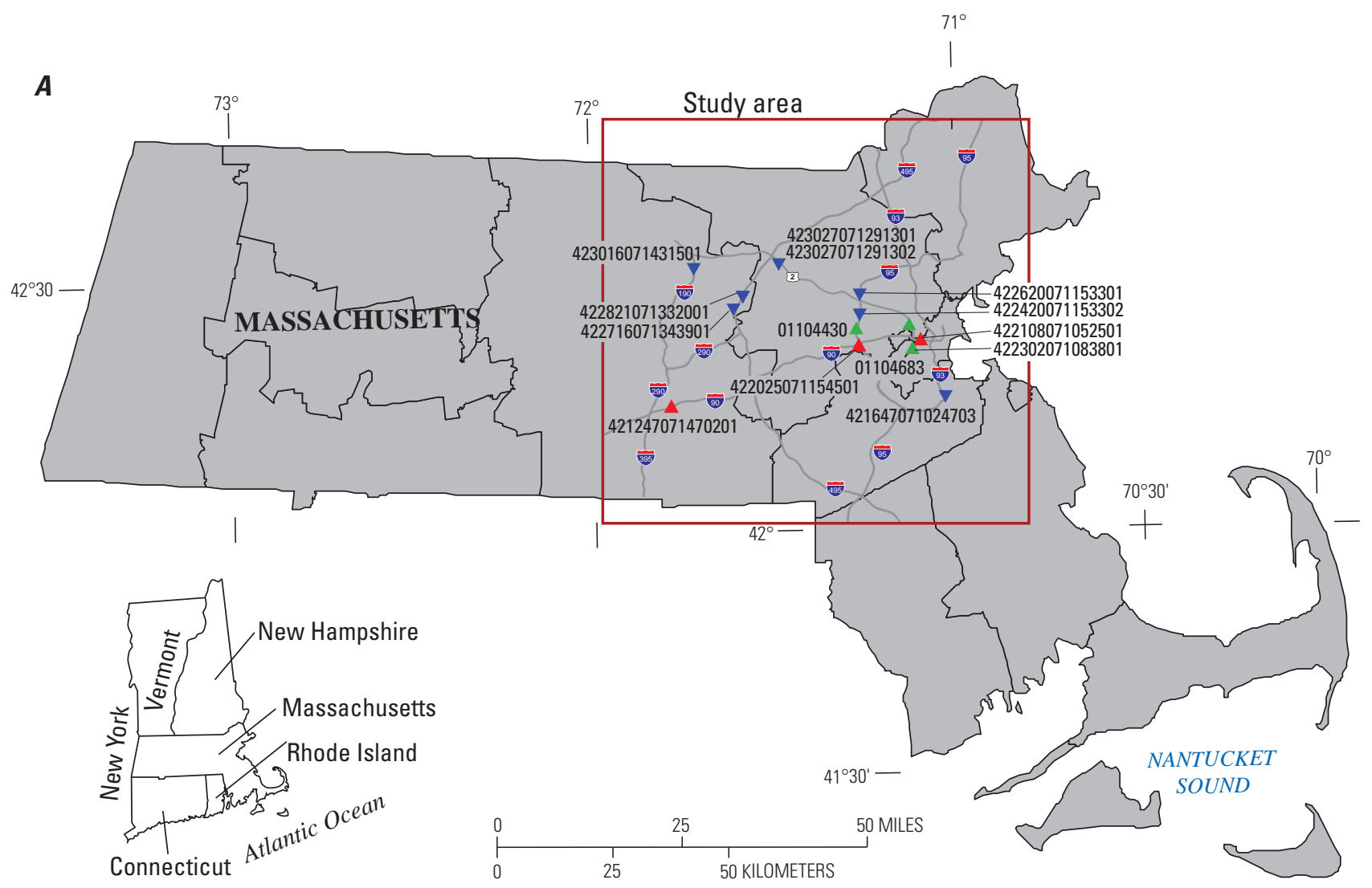

Figure 1. Locations of bridge-deck-monitoring sites in eastern Massachusetts, 2014-16. A, U.S. Geological Survey stations in this study. B, State Route 2A in Boston (422108071052501). C, Interstate 90 near Weston (422025071154501). D, State Route 20 near Quinsigamond Village (421247071470201). 

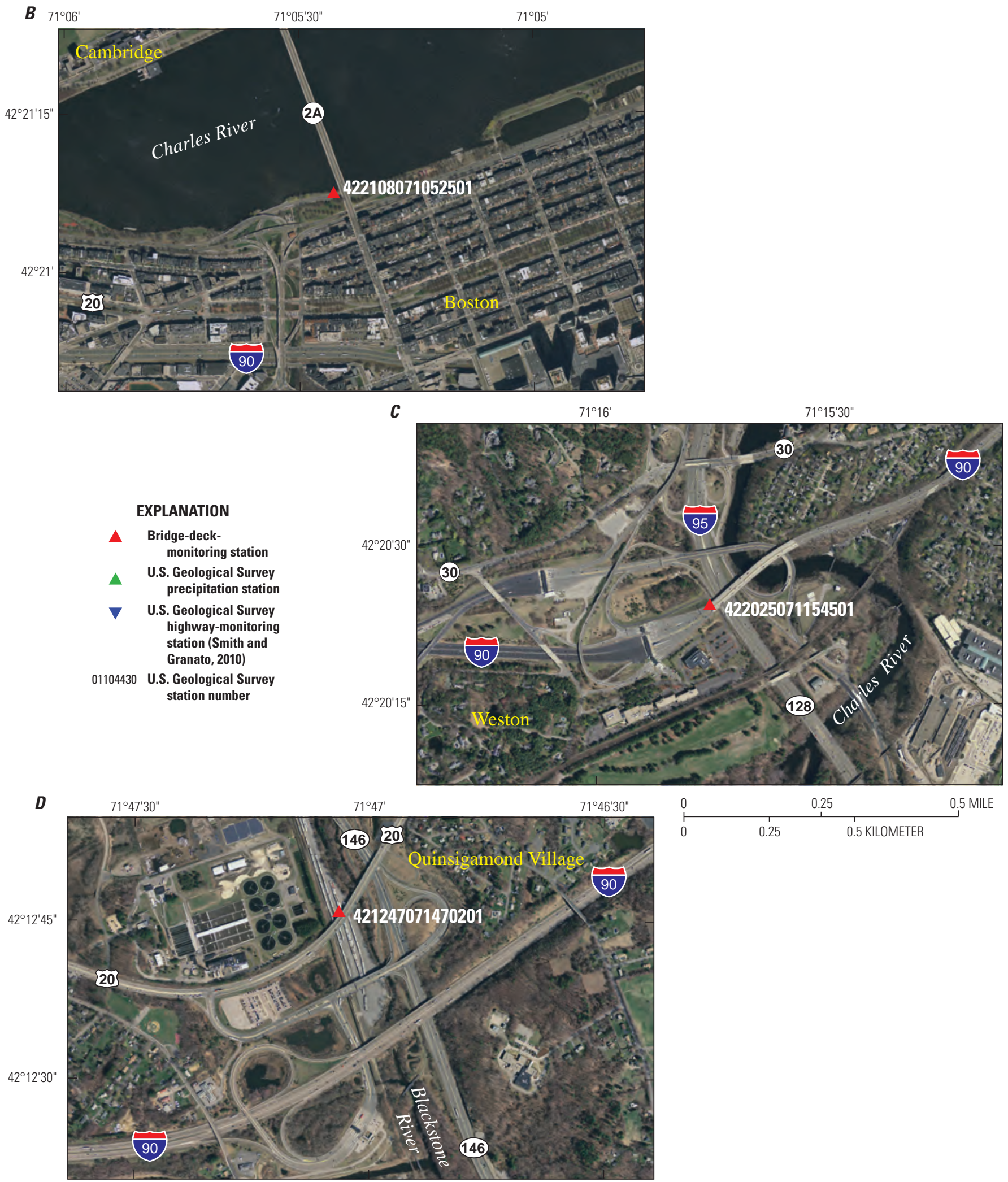

Base from Massachusetts Office of Geographic Information (MassGIS) orthophotographs, 2012-14 Lambert conformal conic projection, North American Datum of 1983

Figure 1. Locations of bridge-deck-monitoring sites in eastern Massachusetts, 2014-16. A, U.S. Geological Survey stations in this study. B, State Route 2A in Boston (422108071052501). C, Interstate 90 near Weston (422025071154501). D, State Route 20 near Quinsigamond Village (421247071470201)._- Continued 


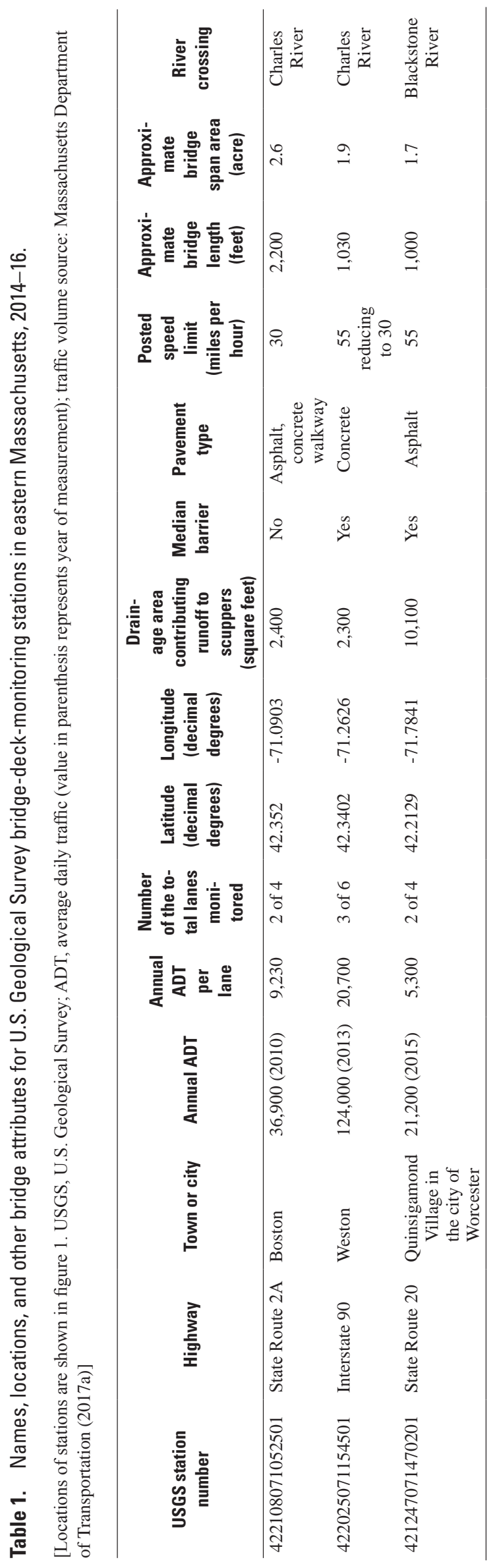


Table 2. Land-use characteristics for a one-half mile radius around the bridge-deck-monitoring stations on State Route 2A in Boston (422108071052501), Interstate 90 near Weston (422025071154501), and State Route 20 near Quinsigamond Village (421247071470201) in eastern Massachusetts, 2014-16.

[Locations of stations are shown in figure 1. Land use and total impervious area are expressed as percentages of the total area. Land-use data source: Homer and others (2015). Impervious area data source: Massachusetts Office of Geographic Information (2007)]

\begin{tabular}{lccc}
\hline \multirow{2}{*}{$\begin{array}{c}\text { Land-use } \\
\text { category }\end{array}$} & $\begin{array}{r}\text { Percentage of area in a one-half mile radius } \\
\text { around each of the U.S. Geological Survey } \\
\text { bridge-deck-monitoring stations }\end{array}$ \\
\cline { 2 - 4 } & $\begin{array}{l}\text { State Route 2A } \\
\text { Interstate 90 }\end{array}$ & State Route 20 \\
\hline $\begin{array}{l}\text { Open water } \\
\text { Developed open } \\
\text { space }\end{array}$ & 16.3 & 4.7 & 0.1 \\
$\begin{array}{l}\text { Developed land } \\
\text { Forest and shrub }\end{array}$ & 7.5 & 28.3 & 15.5 \\
$\begin{array}{l}\text { Grassland and } \\
\text { cropland }\end{array}$ & 0.4 & 43.1 & 46.3 \\
Wetland & 0.5 & 18.9 & 28.8 \\
Impervious area & 67 & 0.9 & 4.4 \\
\hline
\end{tabular}

more upgradient scuppers is partially or completely blocked by deposits of sediment, debris, or slush around the scupper grate (fig. 4A). In such cases, some or all of the water from a neighboring drainage area is diverted to a downgradient drainage system. Similarly, runoff that leaks through expansion joints in the bridge deck (fig. 4B) or obstructions to the inlet of scuppers in the monitored drainage area results in low runoff coefficients. Runoff coefficients also can vary during the winter months on the basis of available snowmelt water and scupper inlets that are frozen or blocked by snow (fig. 4C). Measurements of rainfall were not made locally at the State Route 2A monitoring station in Boston, and therefore the rainfall totals acquired from the nearby USGS stations 01104683 and 422302071083801 (fig. 1) may not always accurately reflect conditions at the bridge location.

There was a large amount of variability in the runoff coefficients during this study because the drainage areas are relativity small and blockages of scupper inlets were common; therefore, estimated constituent yields from storm runoff volume are not presented, and reported drainage area may not reflect actual contributing areas during different runoff events during the study period.

\section{Collection and Analysis of Samples}

Flow-proportional composite samples of bridge-deck runoff were collected automatically during storms. Samples for each runoff event were generally collected the following day, processed, and shipped overnight to the laboratory for analysis of concentrations of SS, TP, total dissolved nitrogen (DN), particulate nitrogen (PN), LOI, PC, particulate inorganic carbon (PIC), and particulate organic carbon (POC) (table 3). Samples of sediment in highway runoff also were sieved into specific particle-size ranges and analyzed for concentrations of TP and 10 total-recoverable metals (table 4).

\section{Samples of Bridge-Deck Runoff}

A range of 54-56 flow-proportional composite samples of bridge-deck runoff were collected automatically during rainfall, mixed precipitation, and snowmelt events between August 2014 and August 2016 at each of the monitoring stations. Composite samples of runoff were collected during runoff events that were characteristic of the range of antecedent dry periods and event rain totals (fig. 5) and a range of precipitation events (fig. 6) throughout the study period. Storm precipitation volumes during the study period were similar to storm precipitation volumes recorded during the prior 13-year period (November 2001 through July 2014) at U.S. Geological Survey station 01104430 (Hobbs Brook below Cambridge Reservoir near Kendall Green, Mass.) (fig. 6), which is approximately geographically centered among the three bridges and about 4 miles north of the Interstate 90 monitoring station (fig. 1).

\section{Selection of Storms}

Storm-event samples were selected to reflect seasonal and antecedent dry variations throughout the study period. Most of the storm precipitation volumes for sampled storms (predominately rainfall and mixed precipitation event) during this study were within the interquartile range of all storm precipitation volumes (rainfall, mixed precipitation, and snowmelt) greater than or equal to 0.05 in. recorded at each monitoring station (fig. 6). The distribution of storm precipitation volumes for sampled storms at State Route 2A monitoring station tended to be skewed higher than the distribution of storms during the study period; however, precipitation for this monitoring station was measured at USGS station 01104683 and may not always accurately reflect site conditions at the bridge.

In this study, runoff events are defined as a function of flow where sequential measurements of discharge greater than or equal to $0.005 \mathrm{ft}^{3} / \mathrm{s}$ are separated by 6 hours or more of discharge less than $0.005 \mathrm{ft}^{3} / \mathrm{s}$. Runoff events consist of any form of runoff including rainfall, mixed precipitation, and snowmelt runoff. A discharge of $0.005 \mathrm{ft}^{3} / \mathrm{s}$ was chosen as a cutoff because it was the minimum value that was discernable between the presence of flow and no flow on the basis of the resolution of level sensors and the stage-discharge relation for each monitoring station. 


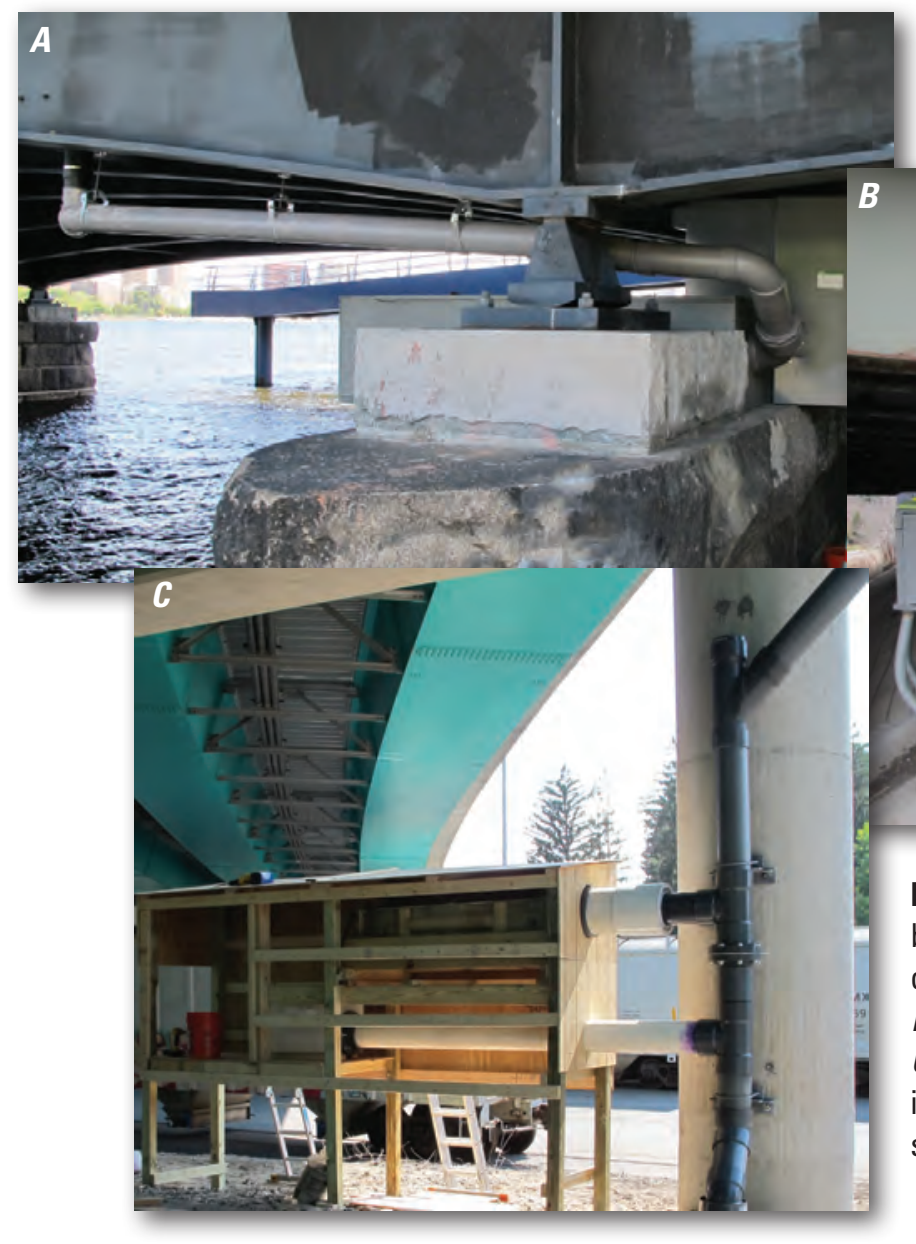

\section{Sample Collection}

Samples of bridge-deck runoff for the analysis of SS and water chemistry were collected immediately upstream from the $\mathrm{H}$ flumes in the pipe by using an unrefrigerated automatic sampler controlled by a datalogger. Each autosampler was configured to hold four 3.75-liter (L) sample bottles that were pretreated with 4 milliliters (mL) of dilute sulfuric acid. The acid was added to maintain low $\mathrm{pH}$ in the samples and prevent dissolved phosphorus from partitioning to the bottle walls prior to sample collection by field crews. The first sample was collected when flow exceeded a minimum threshold (typically

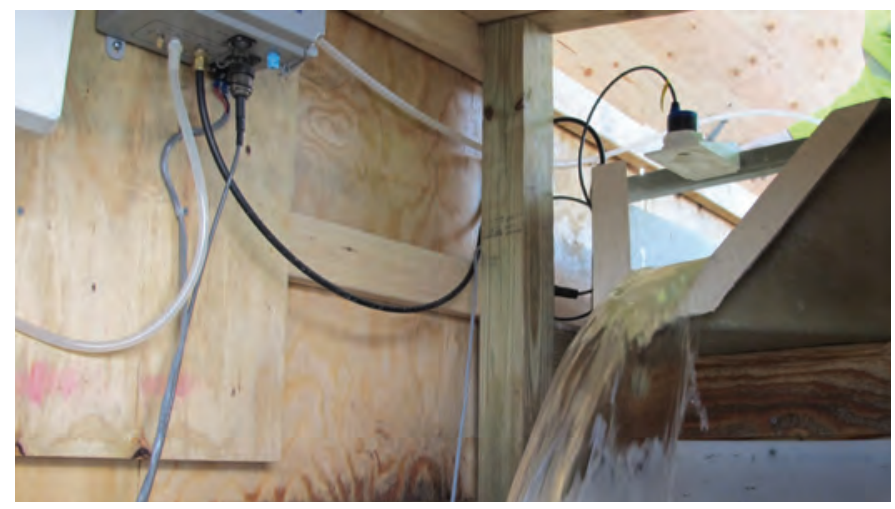

0.005 to $0.008 \mathrm{ft}^{3} / \mathrm{s}$ ), and subsequent samples were collected at flow-proportional intervals (samples collected at equal volumes of runoff) (fig. 7). After a runoff event was sampled and flow subsided below $0.005 \mathrm{ft}^{3} / \mathrm{s}$ for a minimum period of 6 hours, the datalogger was programmed to instruct the sampler to move the distributor arm to the next sample bottle. This method allowed for the collection of additional samples for subsequent runoff events without compromising the previously collected composite sample.

Approximately 50 subsamples of bridge-deck runoff were collected for an equivalent runoff of 1 in. of rain.
Figure 3. An H flume at U.S. Geological Survey bridge-deckmonitoring station on State Route 20 near Quinsigamond Village (421247071470201) in eastern Massachusetts, 2014-16. Location of station is shown on figure 1. 


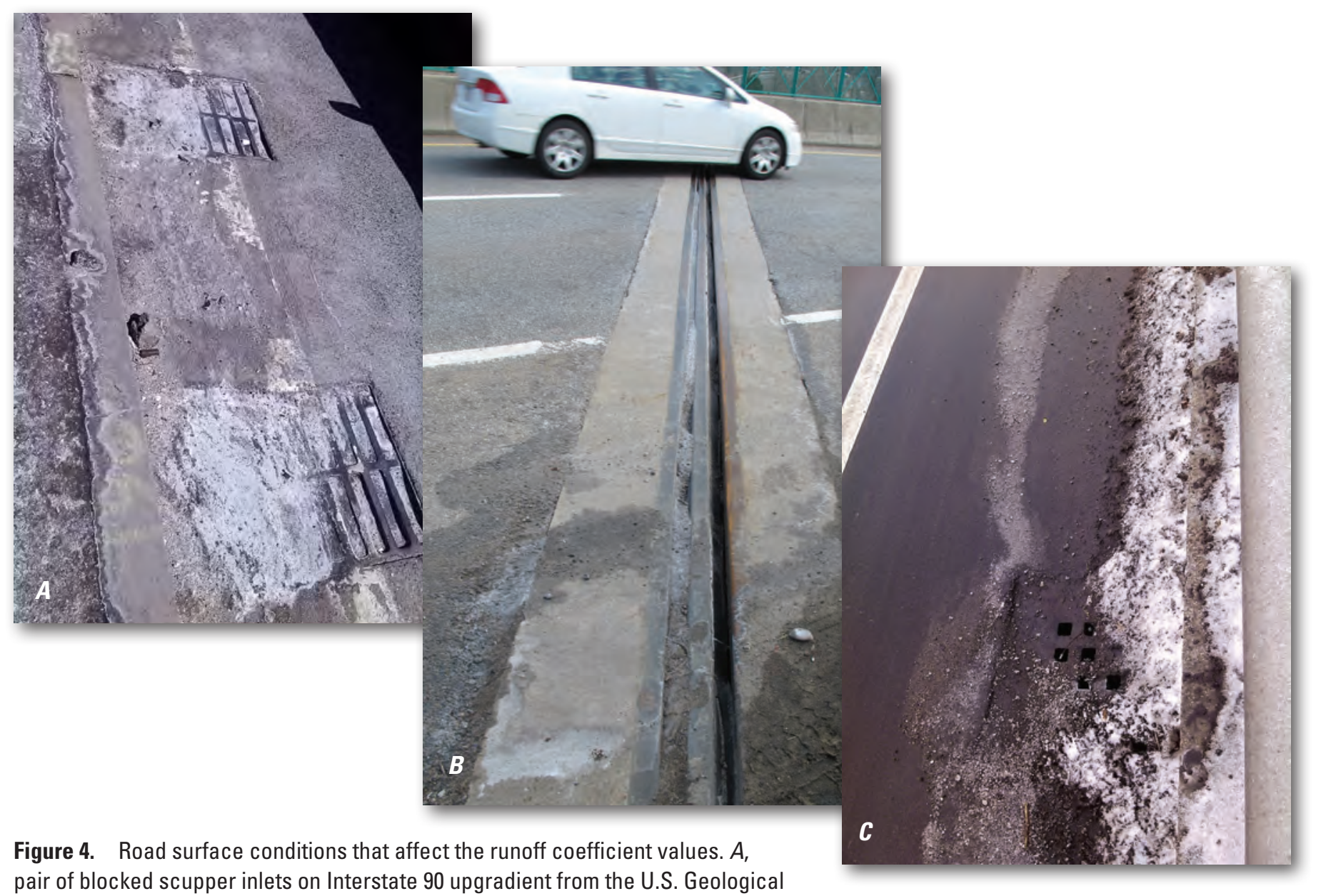

pair of blocked scupper inlets on Interstate 90 upgradient from the U.S. Geological Survey bridge-deck-monitoring station 422025071154501; B, expansion joint on State Route 20 upgradient from the U.S. Geological Survey bridge-deck-monitoring station 421247071470201; and C, partially blocked scupper inlet on State Route 2A near U.S.

Geological Survey bridge-deck-monitoring station 422108071052501, Massachusetts, 2014-16. Locations of stations are shown on figure 1.

Flow-proportional thresholds, at which point the datalogger triggered the automatic water sampler, were fixed at each site throughout the study irrespective of expected storm characteristics; only the volume for each subsample was altered. Generally, a composite of bridge-deck runoff consisted of multiple 200-mL aliquots; however, the aliquot volume for the subsamples was reduced for storms with forecasted rain amounts greater than $1.0 \mathrm{in}$. to increase the total number of potential samples, so that the 3.75-L sample bottle would be adequate in size to represent the entire storm. In some cases, the forecasted rainfall volume was underestimated and resulted in a composite of two or more bottles. For small storms with forecasted rainfall amounts less than $0.5 \mathrm{in}$., the aliquot volume for each subsample was increased to ensure that sufficient water volume was collected to satisfy analytical requirements. Because the frequency for the collection of the subsamples was a function of a flow threshold derived from an equivalent runoff of $1 \mathrm{in}$. of rain from each site, the density of subsamples forming the composite of bridge-deck runoff was comparable from storm to storm and from site to site.

Various factors were considered during the selection and construction of the sites to ensure the best possible performance of the automatic samplers. Vertical distances from fixed sampling points to the sampler-pump heads were only about $2 \mathrm{ft}$ and within optimal suction limits (Bent and others, 2001). All sampler lines were mounted in a sloping manner to allow for the complete purging and draining of sample water between samples. Sampler intakes were fixed to static mixers designed specifically for this project at each sampling point for all sampling locations (fig. 8). The purpose of the static mixer was to provide a secure and consistent mount for the sampler intake, reduce transport velocity, and provide agitation to produce a sample that represented the average concentration of SS (Smith, 2002; Smith and Granato, 2010). Sampler intakes were oriented in a horizontal and downstream direction. This configuration minimizes debris accumulation by forming a small eddy that captures sand particles at the intake and thus 


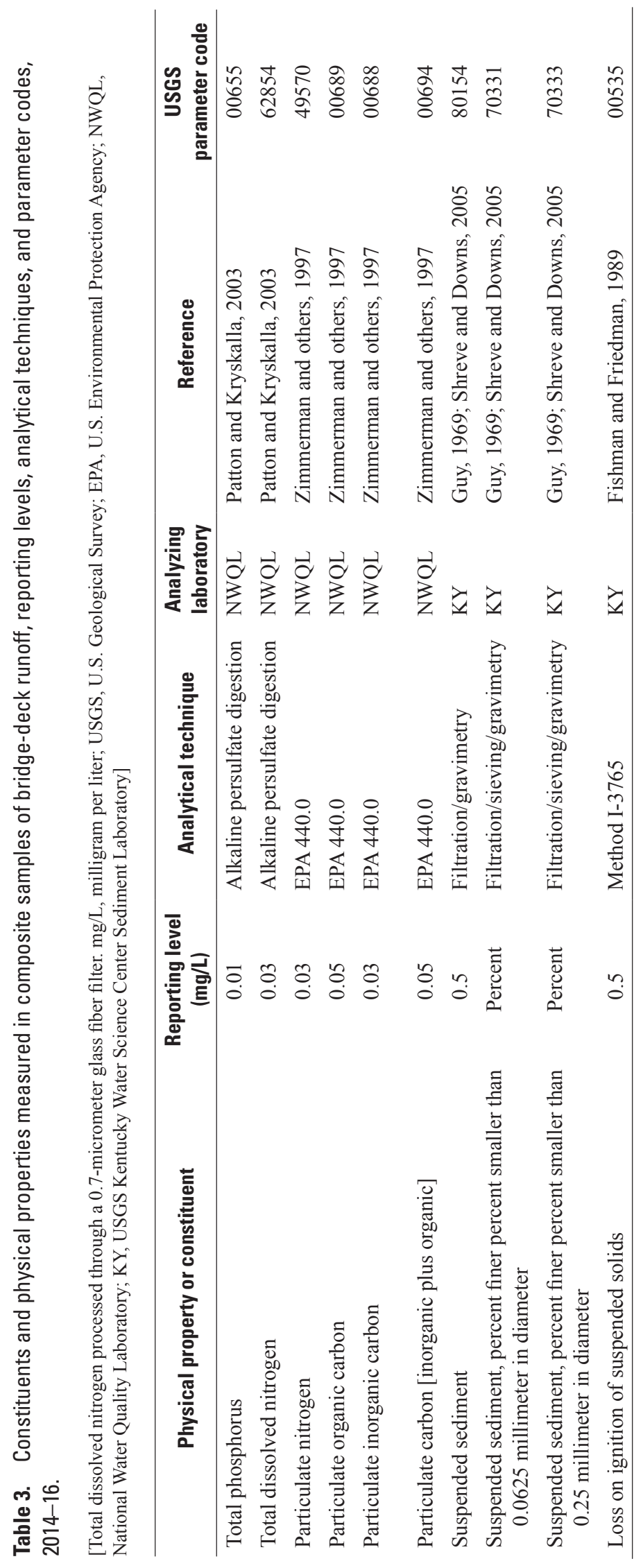


Table 4. Constituents measured in samples of bridge-deck sediment in milligrams per kilogram, reporting levels, analytical techniques, and parameter codes, 2014-16.

[Samples analyzed by RTI Laboratories, Inc., in Livonia, Michigan. USGS, U.S. Geological Survey; SM, standard method]

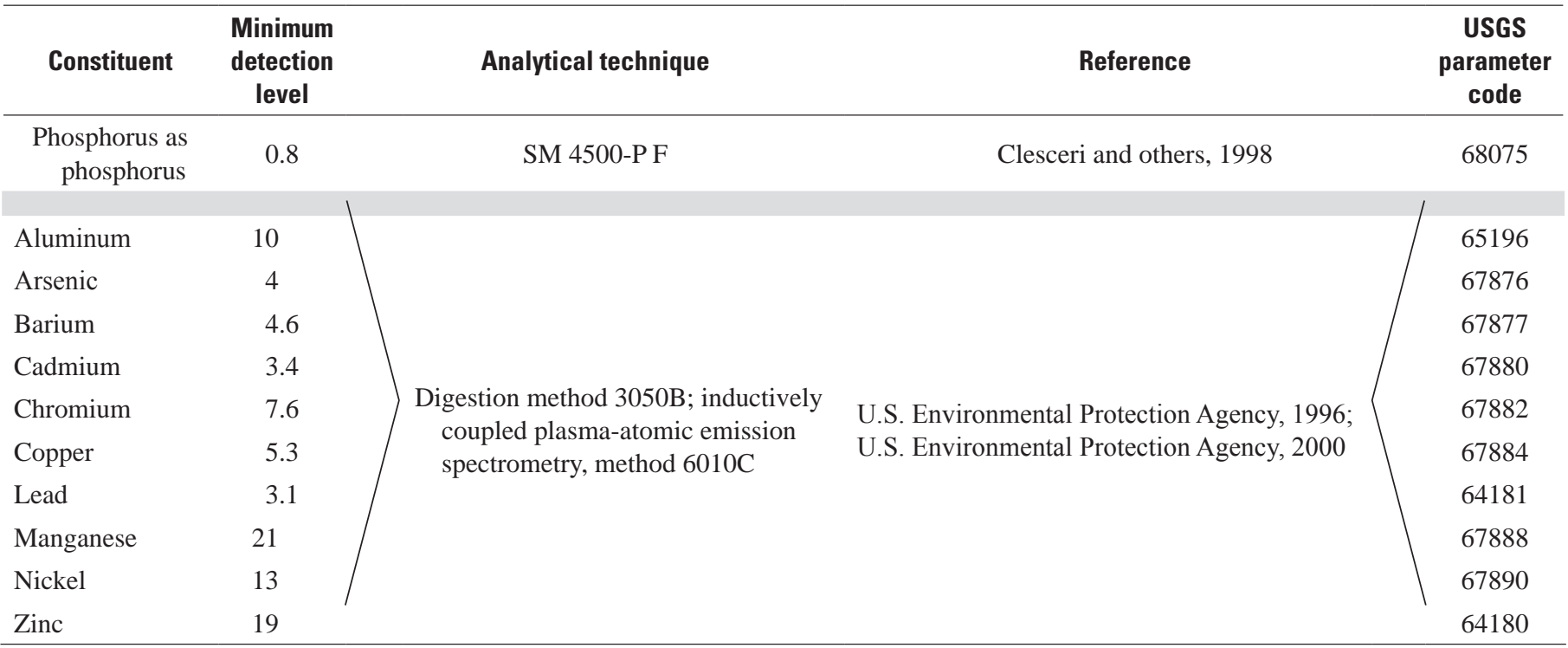

allows the sampler to collect a more representative sample of the course load (Edwards and Glysson, 1999). The static mixers were constructed from a 0.75 -in. low-density polyethylene.

Each automatic sampler was configured to hold four 3.75-L polyethylene sample bottles. Sample bottles were cleaned with phosphate-free, laboratory-grade soap and tap water; then immersed in a 5-percent solution of hydrochloric acid for a period of at least 6 hours; and finally rinsed with deionized water until the specific conductance of the waste rinse water was less than 1 microsiemens per centimeter. The sampler's intake lines consisted of 0.5-in. polyethylene tubing attached to silicon pump-head tubing and a discharge tube. Prior to the initial installation of the sampling equipment, the various tubing was cleaned as described above; however, the tubing was only cleaned with phosphate-free, laboratory-grade soap and deionized water between sample collection. As part

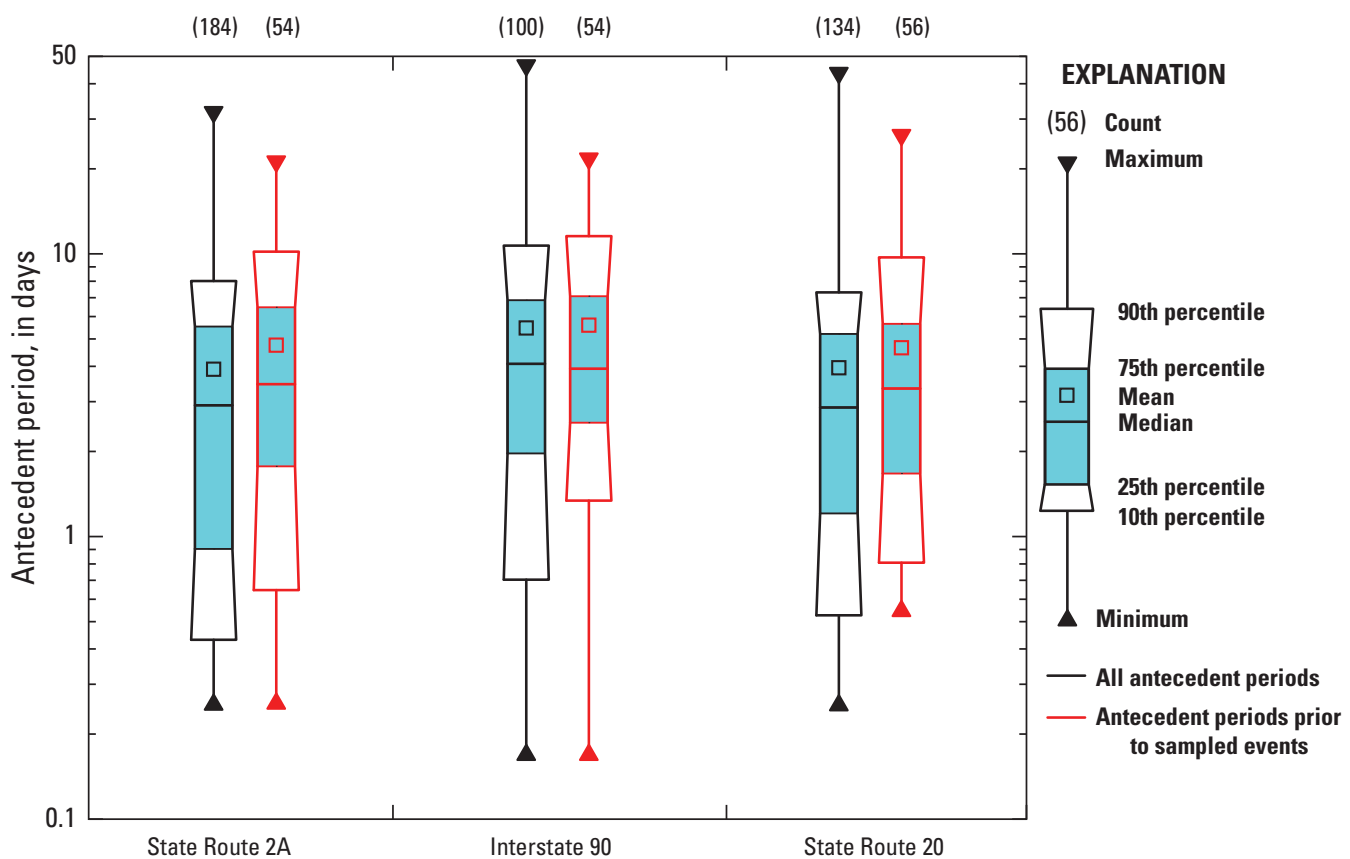

Figure 5. Distribution of all antecedent dry periods and the antecedent dry periods for runoff events during which runoff samples were collected at U.S. Geological Survey monitoring stations on State Route 2A in Boston (422108071052501), Interstate 90 near Weston (422025071154501), and State Route 20 near Quinsigamond Village (421247071470201) in eastern Massachusetts, 2014-16. Locations of stations are shown on figure 1 .

Bridge-deck-monitoring stations 


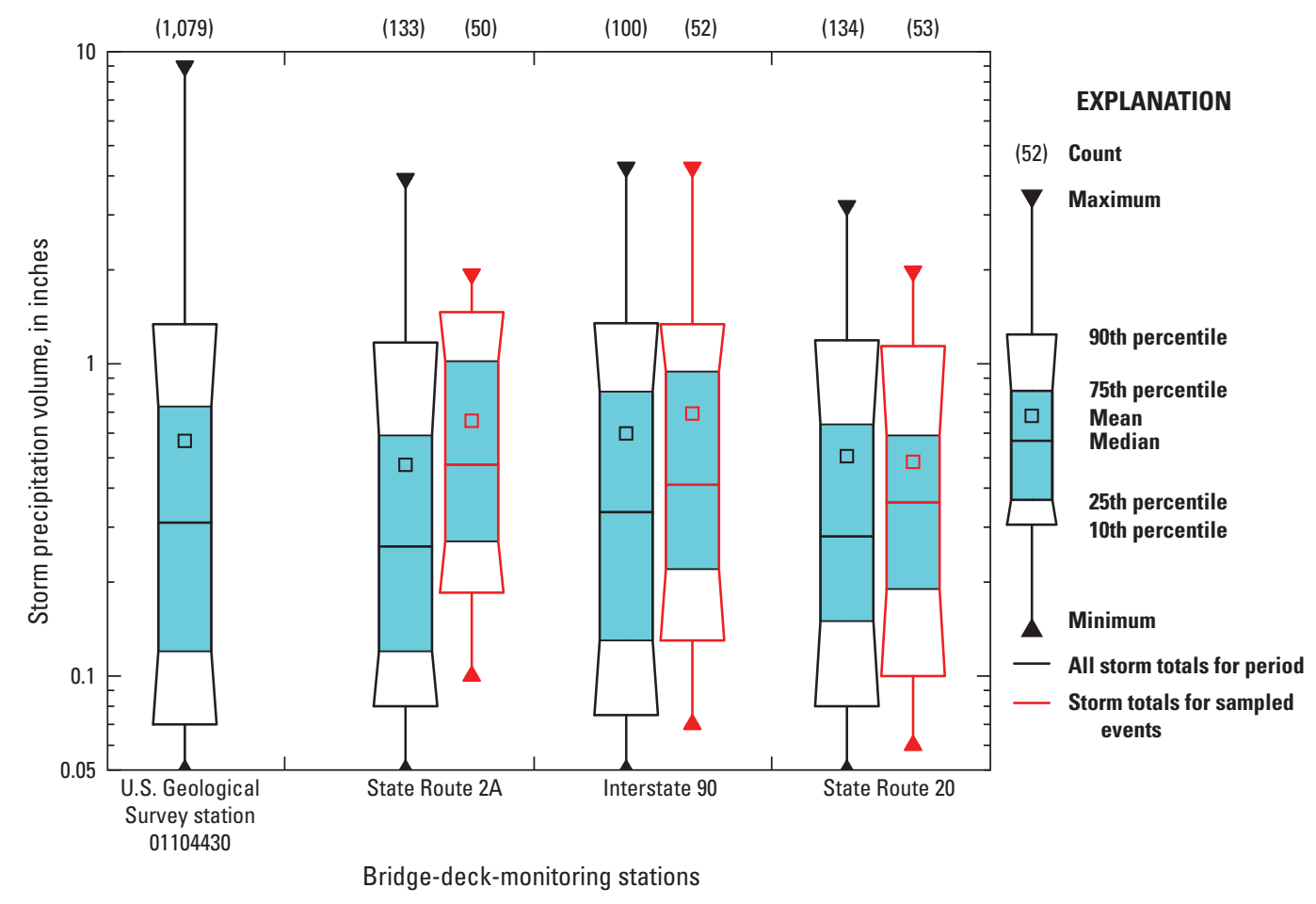

Figure 6. Distribution of storm totals equal to or greater than 0.05 inch recorded at U.S. Geological Survey station 01104430 during November 2001 through July 2014 and precipitation totals for storms during which samples were collected at U.S. Geological Survey bridge-deck-monitoring stations on State Route 2A in Boston (422108071052501), Interstate 90 near Weston (422025071154501), and State Route 20 near Quinsigamond Village (421247071470201) in eastern Massachusetts, August 2014 through September 2016. Precipitation totals for State Route $2 \mathrm{~A}$ in Boston were recorded at U.S. Geological Survey station 01104683. Locations of stations are shown on figure 1.

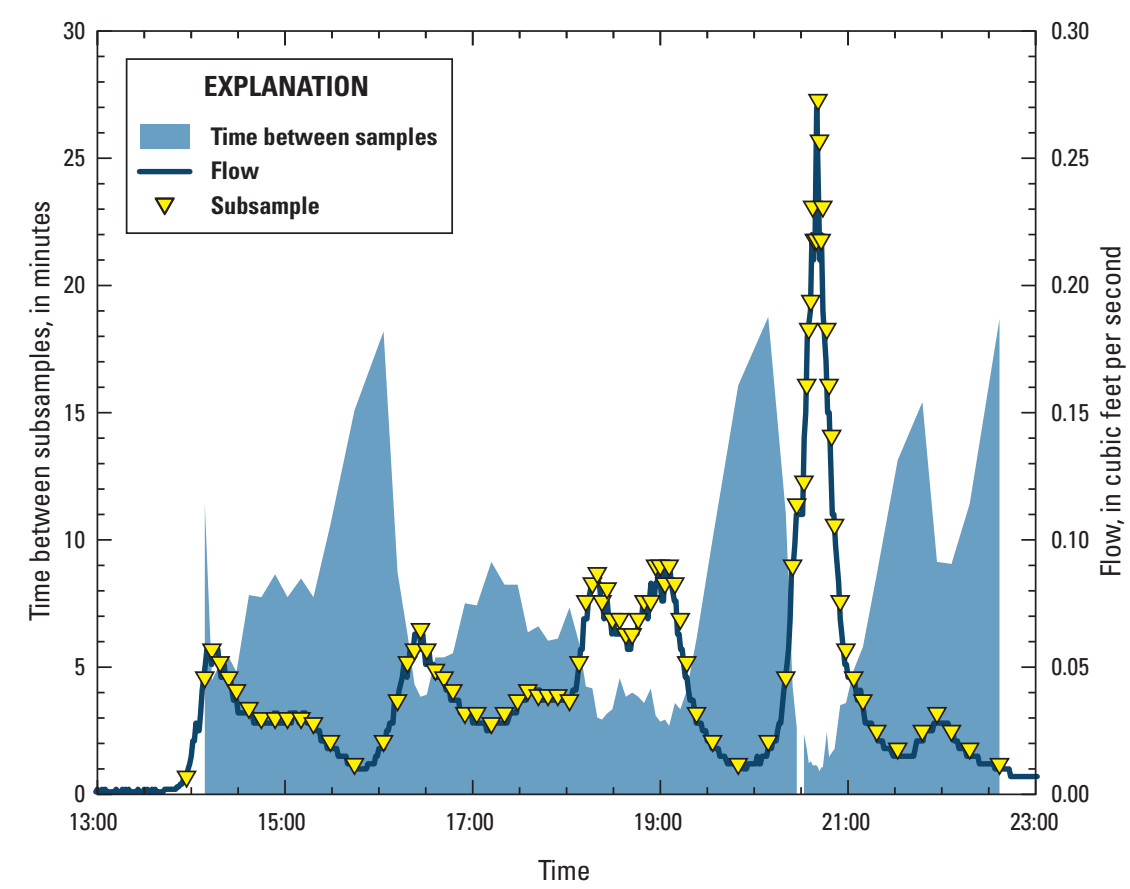

Figure 7. Example of automated flowproportional collection of stormflow subsamples at U.S. Geological Survey bridgedeck-monitoring station at State Route 20 near Quinsigamond Village (421247071470201) in eastern Massachusetts, December 17, 2015. Location of station is shown on figure 1. 


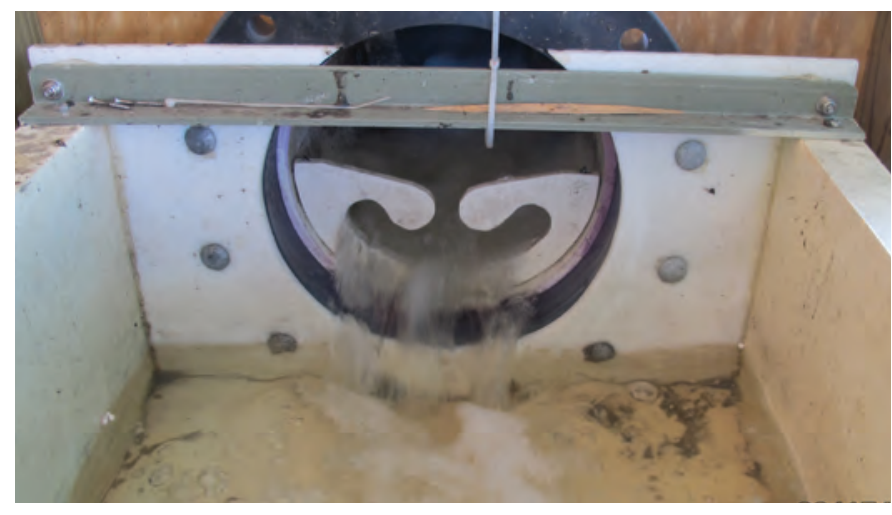

Figure 8. A static mixer assembly at U.S. Geological Survey bridge-deck-monitoring station on State Route 2A in Boston (422108071052501) in eastern Massachusetts, 2014-16. Location of station is shown on figure 1 .

of the routine cleaning practice, lint-free wipes were forced hydraulically through the sampler's tubing to remove internal deposits or films that were difficult to remove by circulating solution alone. Afterward, the sample tubing was purged with $2 \mathrm{~L}$ of deionized water. The sampler's pump-head tubing was routinely replaced with new tubing throughout the project as the tubing performance deteriorated.

\section{Sample Processing}

Water samples were processed in the USGS New England Water Science Center laboratory in Northborough, Mass., typically during the day following the conclusion of the runoff events. The $\mathrm{pH}$ of the entire sample volume was adjusted to be between 1.6 and 1.95 prior to processing to meet preservation requirements for nutrient analysis. Subsamples for the analysis of SS, TP, DN, PN, LOI, and PC were split by pouring the contents of each composite sample bottle fitted with a funnel cap into a Deka port cone splitter (Capel and others, 1995) modified to accept 0.5 -in. tubes. The modification of the cone splitter to accept tubes of the same diameter as the sampler was necessary to ensure that all particles in the runoff samples would pass through the splitting device. Results of experimental tests by the USGS (Capel and others, 1995; Capel and Larson, 1996) indicate that subsamples containing coarse sediment are more precisely processed with a cone splitter compared to other splitting devices. In many cases, it was necessary to split subsamples multiple times to reduce the volume sufficiently to satisfy analytical requirements when the sample volume was large. Sample-water particulates were processed by passing a known volume of sample water through a Teflon ${ }^{\mathrm{TM}}$ filter assembly and a 25 -millimeter $(\mathrm{mm})$ glassmicrofiber filter with a 0.7 -micrometer $(\mu \mathrm{m})$ pore size (U.S. Geological Survey, variously dated). The filters were analyzed for PN, PC, PIC, and POC. The filtrate from this procedure was analyzed for $\mathrm{DN}$.

\section{Sample Analysis}

Samples for analysis of nutrients and carbon constituents were preserved with Optima-grade sulfuric acid 4.5-normal solution and chilled. Other samples only required refrigeration. Samples for the analysis of nutrients and carbon constituents were double bagged after processing and stored on ice for overnight delivery to the USGS National Water Quality Laboratory in Denver, Colorado, where they were analyzed (table 3). Samples were analyzed for SS, distribution of particle size, and LOI at the USGS Kentucky Water Science Center Sediment Laboratory (table 3). Constituent concentrations for the composite samples of bridge-deck runoff are available through the USGS National Water Information System (NWIS; U.S. Geological Survey, 2016).

\section{Samples of Bridge-Deck Sediment}

A composite sample of bridge-deck sediment for analysis of sediment quality was collected directly from the bridge surface, scuppers, or flumes on each bridge. These composite samples were wet sieved into three particle-size ranges (less than $0.0625 \mathrm{~mm}$ in diameter, greater than or equal to 0.0625 to $0.25 \mathrm{~mm}$ in diameter, and greater than $0.25 \mathrm{~mm}$ in diameter), and each size range was analyzed for concentrations of TP and 10 total-recoverable metals (table 4).

\section{Sample Processing}

Samples of bridge-deck sediment for analysis of sediment quality were wet sieved with bridge-deck runoff water specifically collected for this purpose through precleaned $0.25-\mathrm{mm}$ and $0.0625-\mathrm{mm}$ nylon-mesh sieves. The sieves, and polyethylene settling bags, were cleaned by immersing them in a 5-percent solution of hydrochloric acid for a period of about 6 hours and thoroughly rinsing them with deionized water. Sediment greater than or equal to 0.0625 to $0.25 \mathrm{~mm}$ in diameter and sediment greater than $0.25 \mathrm{~mm}$ in diameter for each bridge was set aside in separate clean polyethylene bags. Sediment particles less than $0.0625 \mathrm{~mm}$ in diameter were collected in polyethylene bags with native water and allowed to settle undisturbed in a laboratory refrigerator in the USGS New England Water Science Center laboratory in Northborough, Mass., for at least a week. After the sediment settled, the supernatant was decanted and discarded, and the sediment was retained for chemical analysis.

\section{Sample Analysis}

Samples for sediment quality containing particles less than $0.0625 \mathrm{~mm}$ in diameter, greater than or equal to 0.0625 to $0.25 \mathrm{~mm}$ in diameter, and greater than $0.25 \mathrm{~mm}$ in diameter were submitted to RTI Laboratories, Incorporated in Livonia, Michigan, for analysis of TP and 10 total-recoverable metals (table 4). Concentrations of TP were determined by automated ascorbic acid reduction (Clesceri and others, 1998). Concentrations of total-recoverable metals were determined with the 
use of U.S. Environmental Protection Agency (EPA) digestion method 3050B (U.S. Environmental Protection Agency, 1996) and inductively coupled plasma-atomic emission spectrometry (U.S. Environmental Protection Agency, 2000). Bridge-deck sediment quality data are available through the NWIS database (U.S. Geological Survey, 2016).

\section{Distribution of Bridge-Deck Sediment}

The bridges contain numerous scuppers, and most scupper outlets are over water or are too high to access. As a result, bridge-deck runoff monitoring was limited to a single scupper on each bridge. Characterizing the distribution of the mass of bridge-deck sediment on the surface of the roadway at different points across each bridge is necessary to qualify the results obtained at the monitored scupper.

To determine the distribution of sediment on the bridge decks, samples of sediment along the curb were collected with portable vacuums at five evenly distributed locations across each of the bridges. The nozzle width of the vacuum and the number and lengths of the vacuumed sections were recorded, and samples were returned to the New England Water Science Center laboratory in Northborough, Mass., where they were extracted from the vacuums and a mass per curb length was determined for each set of samples.

\section{Sample Collection and Processing}

Three sampling events were conducted on each bridge deck between April 2015 and September 2016. Samples of bridge-deck sediment were collected at five evenly distributed locations across each bridge deck (table 5). Dedicated hand-held battery-powered vacuums were used to collect bridge-deck sediment samples at each of the five sampling locations. Fixed sampling locations included the center of each bridge and adjacent locations that represent about 10 and 30 percent of the total length of each bridge span. Each of the five samples was a composite of two to five vacuumed strips that were the width of the vacuum nozzle $(0.22 \mathrm{ft}), 3 \mathrm{ft}$ long, and perpendicular to direction of traffic flow from the rightmost curb edge (fig. 9). The number of strips vacuumed at each location was determined by the amount of sediment available on the bridge deck at the time of sample collection. Sediment was removed from pre-tared vacuum tanks and each filter was dried in pre-tared stainless-steel trays at 105 degrees Celsius $\left({ }^{\circ} \mathrm{C}\right)$ to a constant weight, or until the weight change from the previous recorded weight was less than 0.5 milligram (mg) (Clesceri and others, 1998) at the USGS New England Water Science Center laboratory in Northborough, Mass. The resultant bridge-deck sediment mass, in grams, for each bridge and sampling event is listed in table 5. Previous studies have shown that this method of street sediment collection provides good precision and that these sample-collection techniques do not likely introduce additional variability (Pitt, 1979; Bannerman and others, 1983; Selbig and Bannerman, 2007; Sorenson, 2013).

\section{Sample Analysis}

Sediment yield in pounds per curb-mile was estimated from the dry mass of bridge-deck sediment at each sampling location (eq. 1). These estimated yields provide a semiquantitative account of the mass of sediment at fixed points across each bridge. The mass of sediment used to estimate the linear yield was collected within $3 \mathrm{ft}$ of the curb. Data from several studies indicate that between 75 and 90 percent of the street sediment is near the curb (Sartor and Boyd, 1972; Pitt, 1979; Selbig and Bannerman, 2007), and this also was observed on the bridge sites through visual observations during routine sample collection (fig. 9B). Sample composite yields for each bridge are summarized in table 6 .

$$
P=\frac{g \times 0.0022}{W \times N \times M}
$$

where

$\mathrm{P} \quad$ is the mass of the sediment for a bridgedeck sampling location, in pounds per curb-mile;

$\mathrm{g}$ is the total dry mass of sampled bridge-deck sediment, in grams;

0.0022 is the unit conversion factor between grams and pounds;

W is the width vacuumed for each sample strip (vacuum nozzle width), in feet;

$\mathrm{N}$ is the total number of sample strips at each of the bridge-deck sampling location; and

M is the conversion from the width vacuumed, in feet, to miles.

\section{Data Quality}

The accuracy and precision of the data collected in this study were evaluated by making quality-control measurements at each of the monitoring stations and collecting various types of quality-control samples. Quality-control samples include field blanks and replicate-split samples. The identification of random error and systematic bias can be achieved through the collection and analysis of quality-control data. These analyses provided the basis for the interpretation of sediment and chemical data collected in this study.

\section{Bridge-Deck Flow}

Quality-assurance data were collected at each monitoring station to evaluate the accuracy of the theoretical waterlevel/flow relation of each flume. This relation was tested by simultaneously measuring flow from a 9,600-gallon-per-hour centrifugal pump with an in-line flowmeter and measuring the water level in the flume. Pump and theoretical flow values were recorded after pump flow and flume water level were stable across a range of pumping rates. This process was 


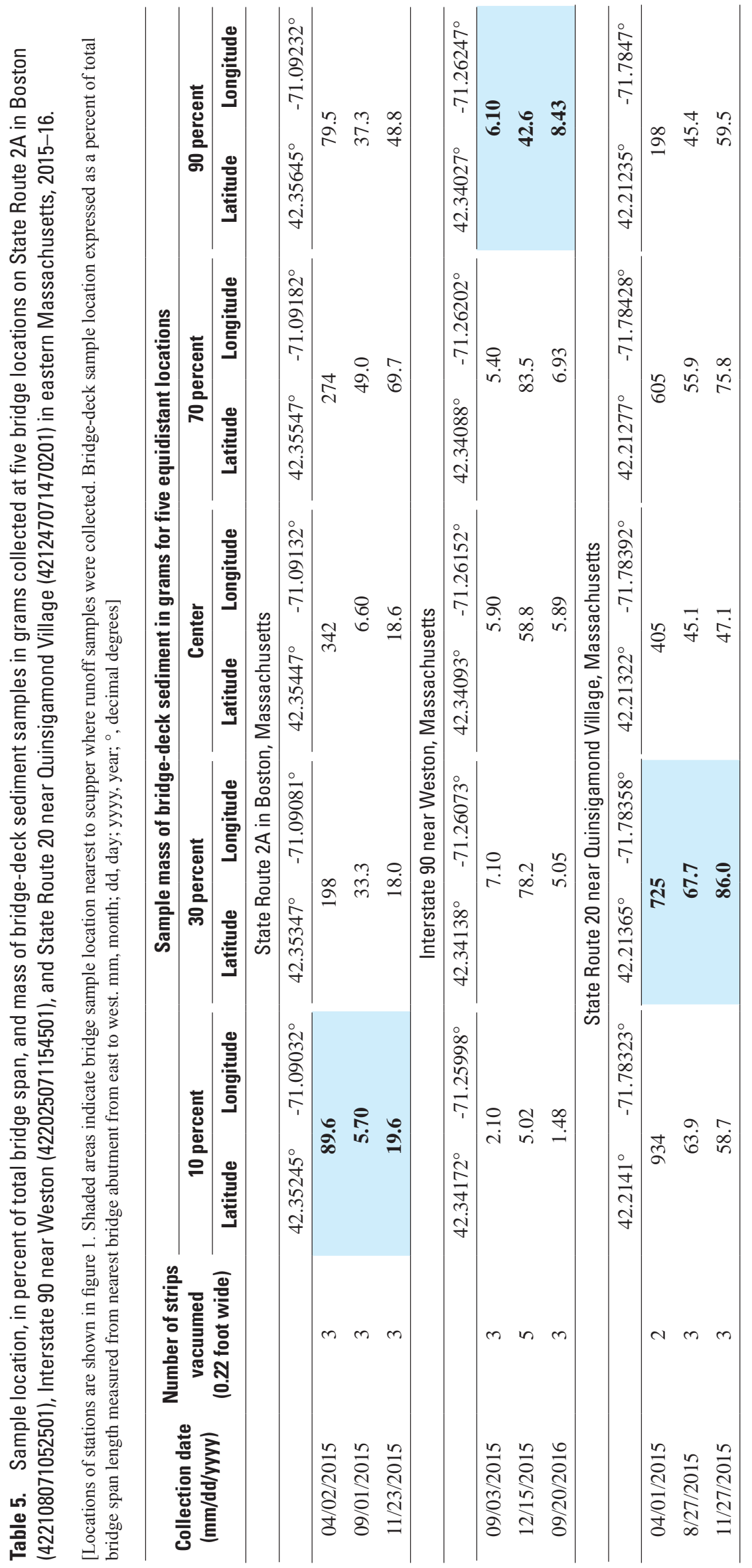




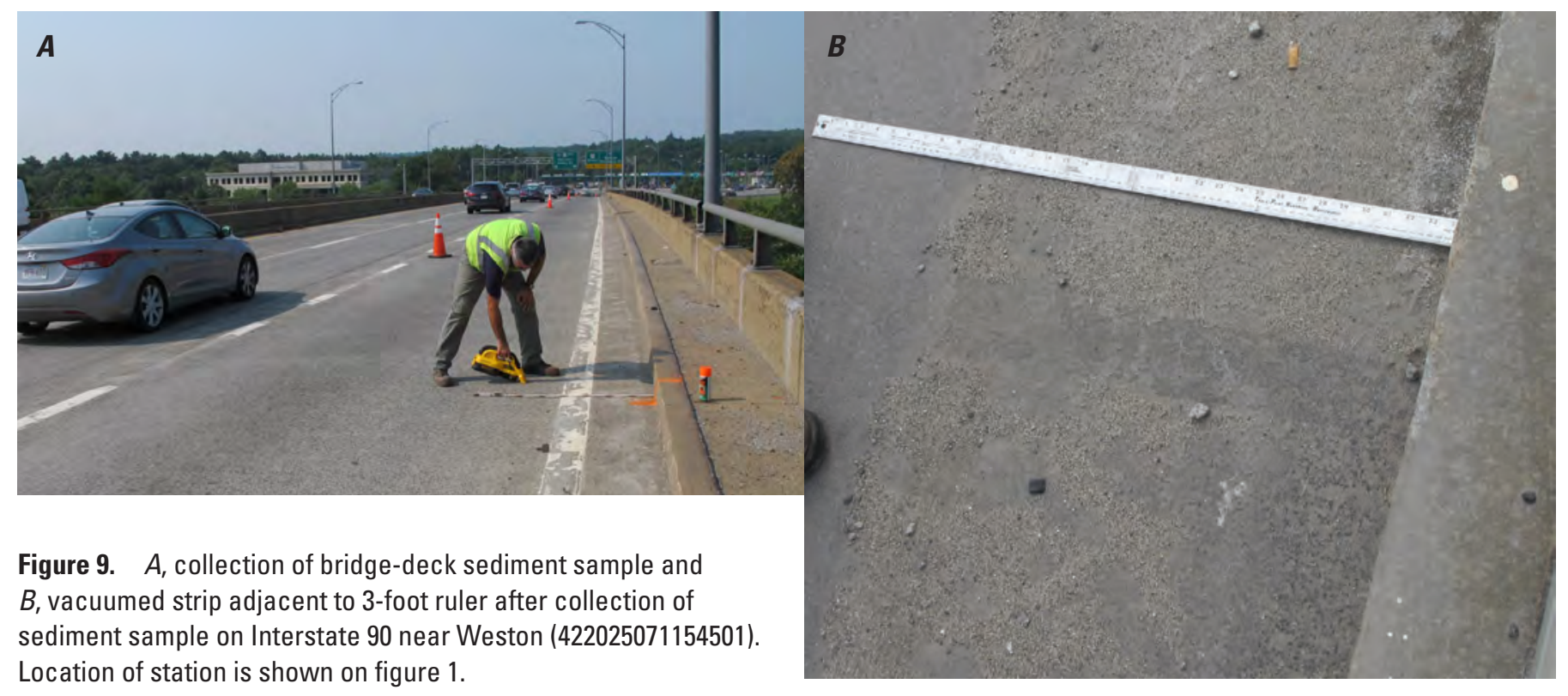

repeated until the pump reached its maximum rate of flow. Pump flow values typically were within the range of flow estimated from a water level of plus or minus $0.01 \mathrm{ft}$ around the theoretical water level-flow relation (fig. 10). This range (plus or minus $0.01 \mathrm{ft}$ ) in water level represents the typical error for the measurement of water levels in the flume. Errors in flow at the low end of the relation may be larger as a result of minor physical imperfections in the flume than that in the theoretical water-level/flow relation. Maximum pump flow values exceeded all peak flows measured during sampled events, except for the monitoring station at State Route 20, which had the largest drainage area. At State Route 20, about 80 percent of the flows measured during sampled events were within the range of flows tested with the pump (fig. 10). Nevertheless, there was no indication that flow greater than the test range deviated from the theoretical level-flow relation at this monitoring station. These water level-flow pump tests indicate that the theoretical relation for each flume provided accurate estimates for flow.

\section{Sediment and Chemical Quality}

Quality-control samples, including field blank and replicate-split samples, were collected to identify potential bias in sampling and processing methods and contamination resulting from the sampling equipment and from the sample-collection, processing, and analysis processes. These quality-control samples are listed in table 7 in the back of the report.

\section{Field Blank Samples}

A field blank is used to test for positive bias that can result from contamination at any stage of sample collection, processing, or analysis, as well as from the sampling equipment itself. Source-solution blanks were prepared from deionized water produced by a laboratory-grade waterpurification system that uses ion-exchange packs and reverse osmosis. The source-solution water was transported to the monitoring stations in precleaned polyethylene cubits. Field blanks were collected throughout the study period and at every monitoring station. These samples were collected by pumping blank water through the automatic sampler tubing and into the collection bottle, and processing it in a manner consistent with the collection of environmental samples of bridge-deck runoff.

During the study period, 10 field blanks were collected and submitted for chemical and sediment analysis. Measurable concentrations for each constituent in field-blank samples were compared to the USGS National Water Quality Laboratory and sediment laboratory reporting limit and environmental concentration data collected during the study (table 8). For analytes not detected in samples, such as PIC, PN, and $\mathrm{TP}$, a concentration equal to the laboratory reporting limit is reported with a "less than" $(<$ remark code in all data tables in this report. Concentrations of SS in field blanks were slightly greater than the laboratory reporting limit in 7 of 10 field blank samples, with the maximum concentration in the field blanks being less than 2 percent of the minimum environmental concentration. Concentrations of LOI, PC, and POC were detected less often in field blank samples, and the maximum concentrations in the field blanks were 11,11 , and 2 percent of minimum environmental concentrations in samples of bridge-deck runoff respectively. Only 1 of the 10 field blanks had a detection of DN at a level that was below the minimum environmental concentration for that constituent. Low levels of contamination may be acceptable if the level of contamination is within the measurement error of the analytical method or is well below the concentrations of the constituent in the environmental samples. For example, the maximum concentration for SS in the field blanks was more than an order of 


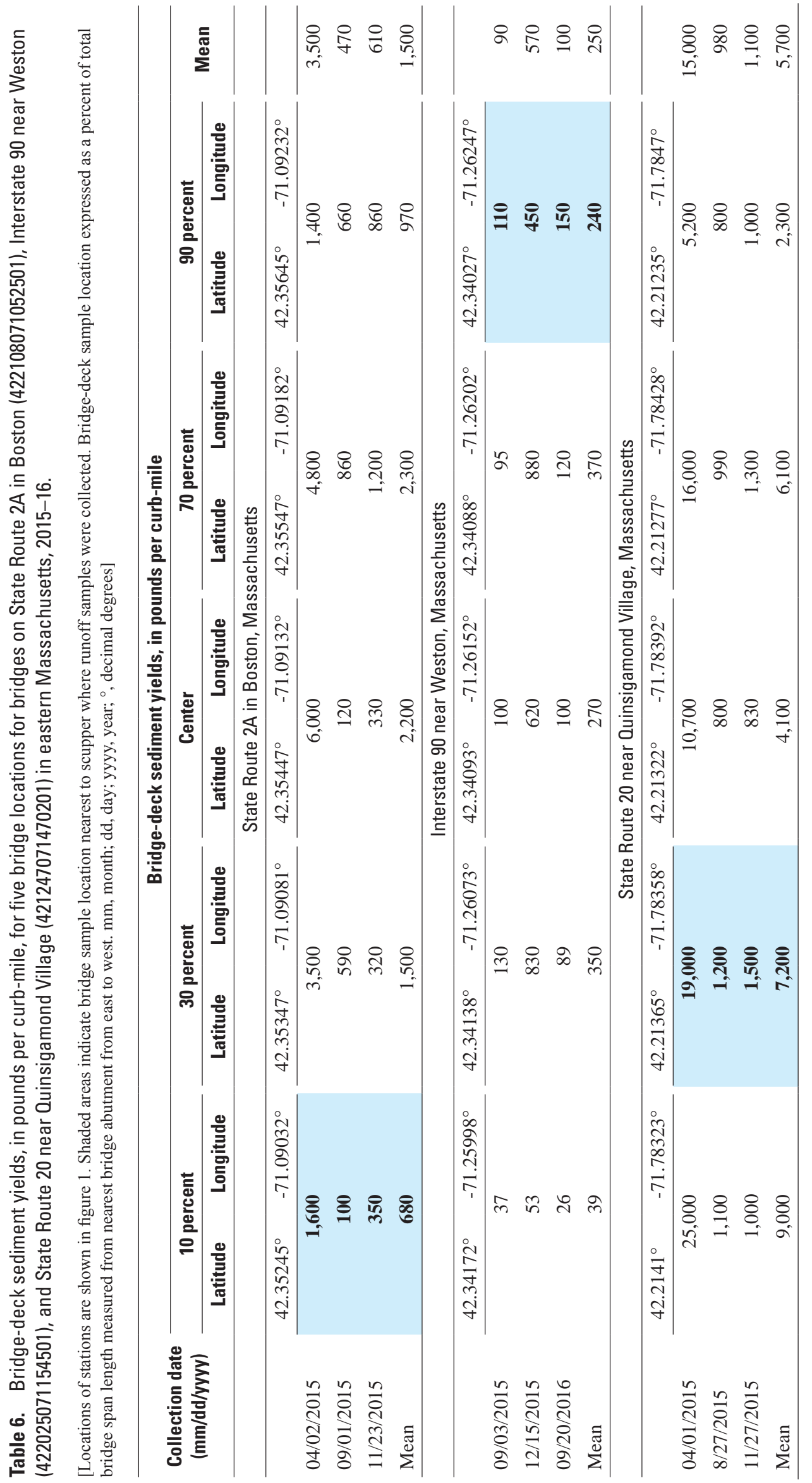




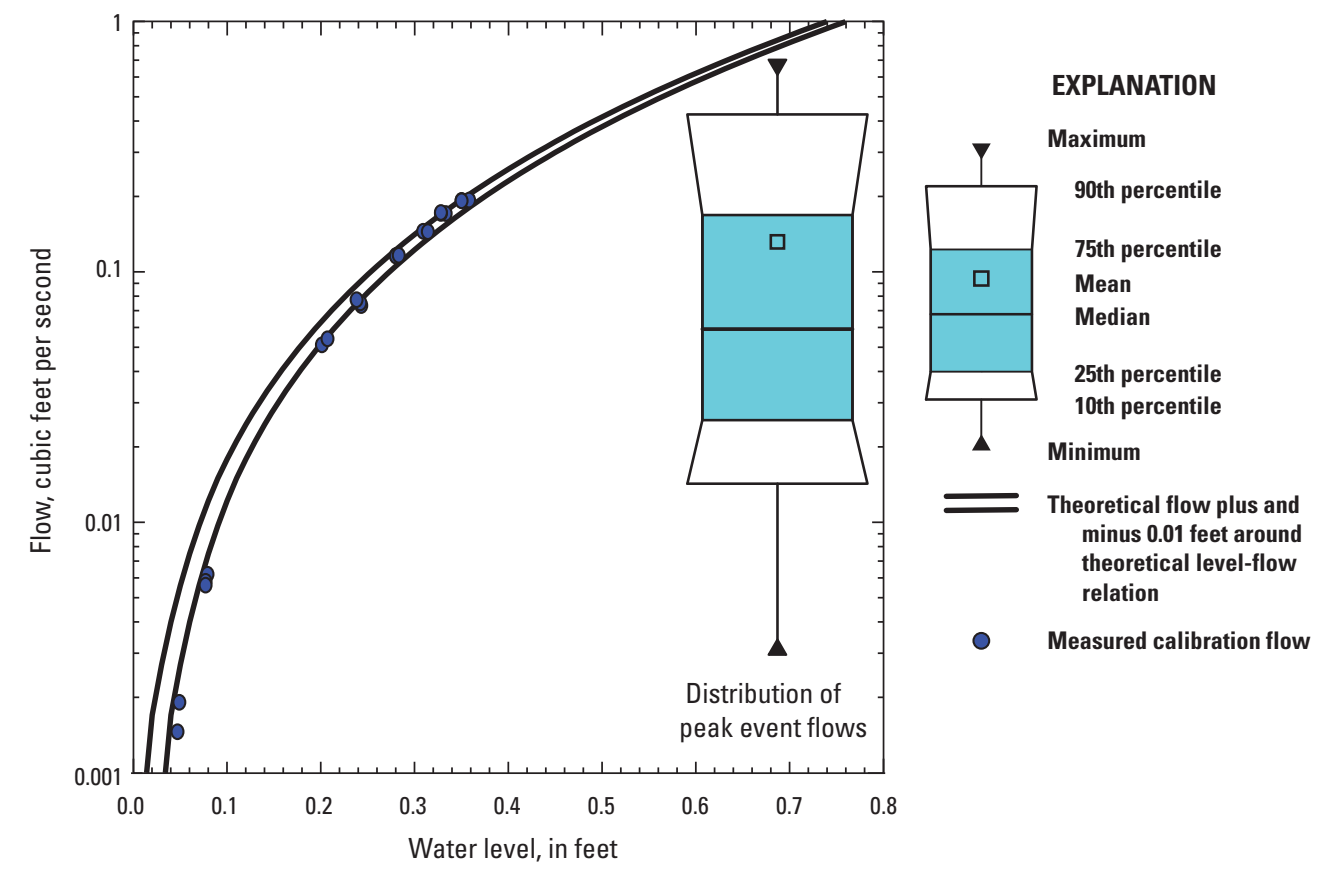

Figure 10. Discrete measurements of pump flow in relation to the theoretical water-level/flow relation (offset by plus or minus 0.01 feet) for the $\mathrm{H}$ flume compared to the distribution of peak flows recorded during sampled events at U.S. Geological Survey bridgedeck-monitoring station on State Route 20 near Quinsigamond Village (421247071470201), eastern Massachusetts, 2015-16. Location of station is shown on figure 1. magnitude lower than the minimum concentration measured in samples of bridge-deck runoff. In general, contamination bias was low for all constituents.

\section{Concurrent Replicate-Split Runoff Samples}

Concurrent replicate-split samples are thought to be identical in composition to the environmental samples and are collected simultaneously during sample processing. Replicatesplit samples provide a measure of bias and variability for the method of sample processing (splitting, filtering, and preservation), laboratory analysis, and effects such as analyte degradation that can happen prior to laboratory analysis. Concurrent replicate-split samples were collected throughout the year and over a range of varying concentrations that occurred during the study (fig. 11).

Concurrent replicate-split samples were collected from 33 bridge-deck composite samples. Bridge-deck composite runoff samples were split into smaller representative aliquots, as described previously, to satisfy the different analytical

Table 8. Summary of field-blank data and comparison to composite bridge-deck runoff samples, in milligrams per liter, collected at U.S. Geological Survey bridge-deck-monitoring stations on State Route 2A in Boston (422108071052501), Interstate 90 near Weston (422025071154501), and State Route 20 near Quinsigamond Village (421247071470201) in eastern Massachusetts, 2014-16.

[Locations of stations are shown in figure 1. USGS, U.S. Geological Survey; NWQL, National Water Quality Laboratory; <, less than]

\begin{tabular}{|c|c|c|c|c|c|c|c|}
\hline Constituent & $\begin{array}{c}\text { USGS } \\
\text { parameter } \\
\text { code }\end{array}$ & $\begin{array}{c}\text { Sample } \\
\text { count }\end{array}$ & $\begin{array}{l}\text { NWQL } \\
\text { reporting } \\
\text { limit }\end{array}$ & $\begin{array}{l}\text { Number of } \\
\text { detections } \\
\text { in field } \\
\text { blanks }\end{array}$ & $\begin{array}{l}\text { Maximum } \\
\text { concentration } \\
\text { in field blank }\end{array}$ & $\begin{array}{c}\text { Minimum } \\
\text { concentration } \\
\text { in bridge- } \\
\text { deck runoff }\end{array}$ & $\begin{array}{c}\text { Maximum } \\
\text { concentration } \\
\text { in bridge- } \\
\text { deck runoff }\end{array}$ \\
\hline Particulate carbon [inorganic plus organic] & 00694 & 10 & 0.05 & 4 & 0.76 & 6.68 & 1,360 \\
\hline Particulate organic carbon & 00689 & 8 & 0.05 & 2 & 0.11 & 6.57 & 1,100 \\
\hline Particulate nitrogen & 49570 & 10 & 0.030 & 0 & $<0.030$ & 0.179 & 26.7 \\
\hline Total phosphorus & 00665 & 10 & 0.01 & 0 & $<0.01$ & 0.09 & 7.02 \\
\hline Total dissolved nitrogen & 62854 & 10 & 0.05 & 1 & 0.07 & 0.18 & 5.63 \\
\hline Suspended sediment & 70331 & 10 & 0.5 & 7 & 2 & 44 & 142,000 \\
\hline
\end{tabular}




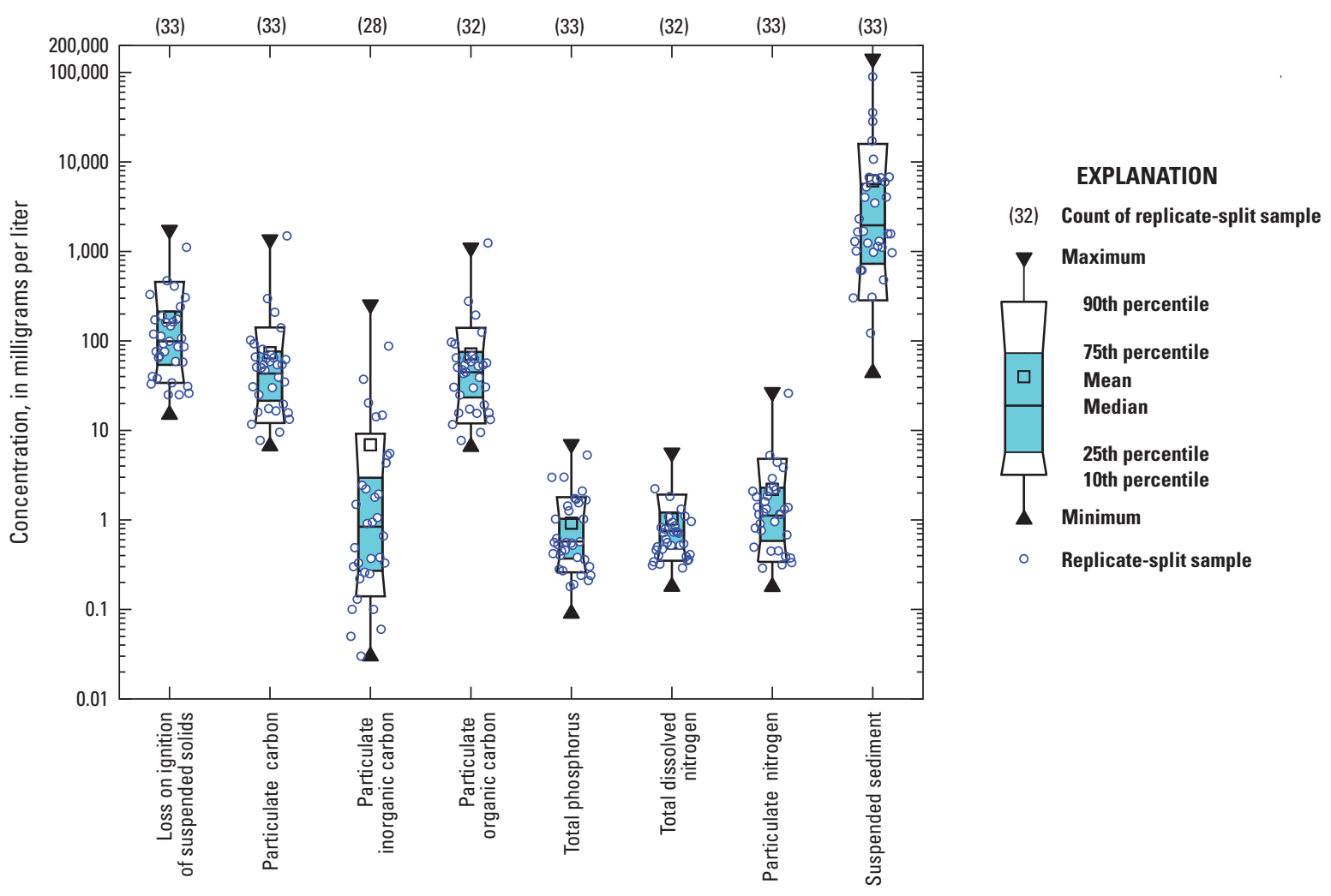

Figure 11. Distribution of concentrations of constituents measured in composite samples of bridge-deck runoff and in concurrent replicate-split samples collected at U.S. Geological Survey bridge-deck-monitoring stations on State Route 2A in Boston (422108071052501), Interstate 90 near Weston (422025071154501), and State Route 20 near Quinsigamond Village (421247071470201) in eastern Massachusetts, 2014-16. Locations of stations are shown on figure 1.

methods. The absolute relative percent difference (RPD) was calculated for each sample pair (concurrent replicate-split sample and composite runoff sample). The median RPD for concentrations of SS- and particle-associated constituents ranged from 10 to 25 percent, except for the median RPD for concentrations of PIC, which was about 65 percent (fig. 12). The maximum RPD for SS and LOI was 59 and 45 percent, respectively; about 75 percent of the RPDs for each constituent were less than 20 percent. The maximum RPD for PC, POC, TP, and PN was about 100 percent for each constituent; about 75 percent of the RPDs for each constituent were less than 42 percent. The RPD for PIC was much greater compared to the RPD for other carbon constituents. Concentrations of PIC were an order of magnitude lower than concentrations of PC and POC (fig. 11) and may explain the higher variability in the RPD values. Dissolved constituents generally are not affected by splitting; however, the low RPD for DN (less than 8 percent for all sample pairs; median less than 2 percent for all sample pairs) also is an indication that the analytical method performance was generally precise.

The collection of representative aliquots from composite samples containing high concentrations of sand-size particles is difficult, and the results are often imprecise (Selbig and others, 2007; Smith and Granato, 2010). Under experimental conditions, the relative standard deviation for concentrations of sand-size particles in aliquots obtained by processing two artificial samples containing known concentrations of SS (50 and 200 milligrams per liter [mg/L]) through a Deka port cone splitter ranged from 12 to 45 percent (Capel and others, 1995). The relative standard deviation for the RPDs of 33 SS pairs in this study was higher at 99 percent. Concentrations of SS in composite samples collected in this study varied by more about three orders of magnitude (fig. 11), and the sediment matrix was dominated by sand-size particles. The lower precision for SS and particle-associated constituent concentrations observed in concurrent replicate-split sample aliquots in this study may be explained, in part, by the variability and high concentrations of SS in composite samples of runoff collected from the bridge decks where the concentration of SS in 96 percent of the sample pairs was substantially greater than the concentrations of SS in the two artificial samples described in the Deka port cone splitter experiment (Capel and others, 1995). Furthermore, sample composite volumes in this study ranged from 1 to $16 \mathrm{~L}$; thus composite samples often were split two or three times to reduce the aliquot volume sufficiently, and this also could have attributed to lower sample splitting precision for SS and particle-associated constituent concentrations. The relation between the RPDs of sample pairs and the associated 


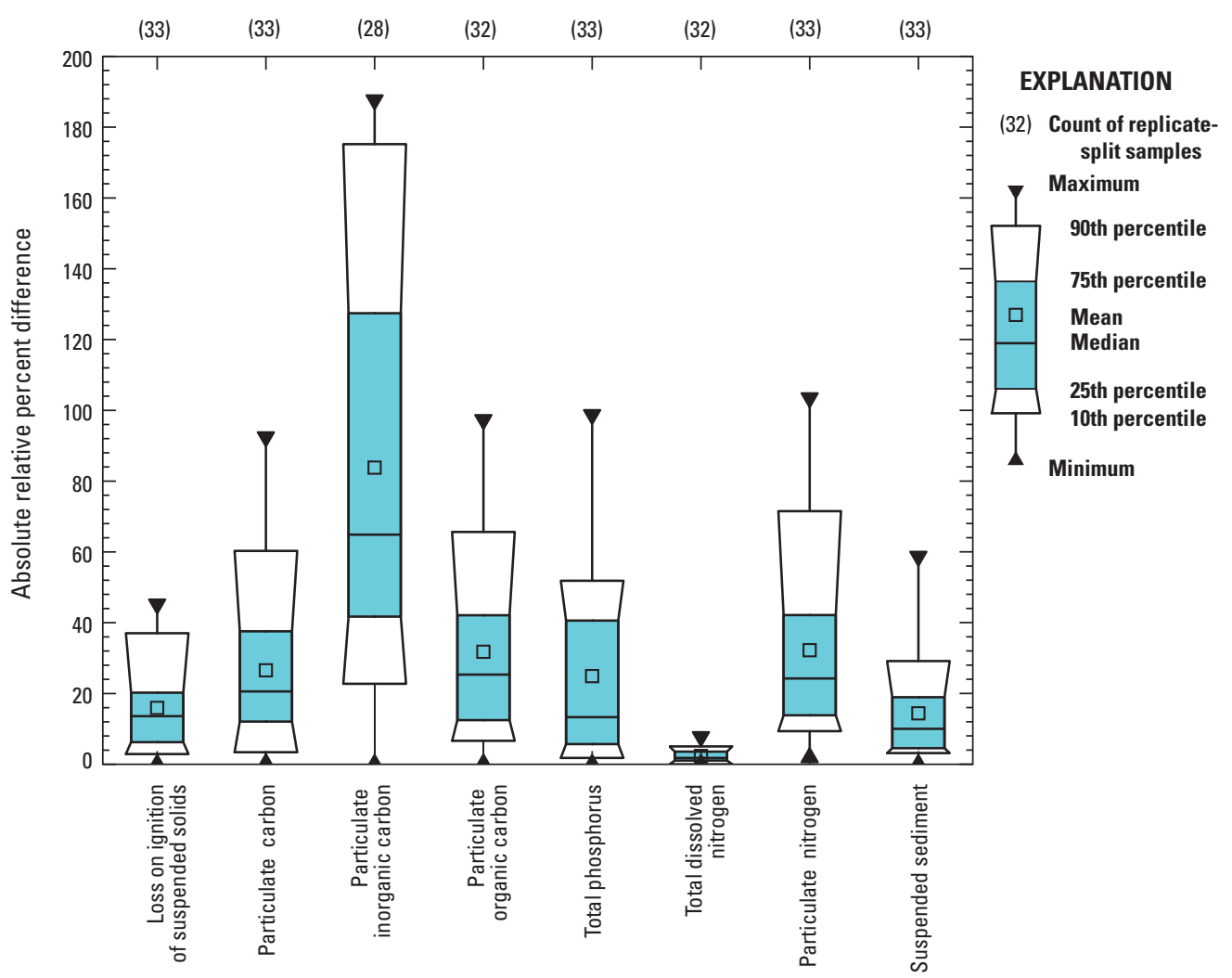

Figure 12. Distribution of absolute relative percent difference values between replicate-split samples and composite samples of bridge-deck runoff collected at U.S. Geological Survey bridge-deck-monitoring stations on State Route 2A in Boston (422108071052501), Interstate 90 near Weston (422025071154501), and State Route 20 near Quinsigamond Village (421247071470201) in eastern Massachusetts, 2014-16. Locations of stations are shown on figure 1. concentrations of SS was poor, indicating the precision was random across the range of concentrations measured in composite samples of bridge-deck runoff.

\section{Replicate Samples of Bridge-Deck Sediment}

One replicate sample, representing one of three particlesize classes of bridge-deck sediment, was collected at each bridge site to determine the precision of the concentration data associated with the particle-size classes less than $0.0625 \mathrm{~mm}$ in diameter, greater than or equal to 0.0625 to $0.25 \mathrm{~mm}$ in diameter, and greater than $0.25 \mathrm{~mm}$ in diameter. The RPD between concentrations of TP and total-recoverable metals in many replicate-split samples and bridge-deck sediment samples tended to be lower (less than 12 percent) in the finesediment fraction and increased with particle-size diameter (table 9). In general, many constituents affiliated with SS tend to be concentrated on the particles less than $0.0625 \mathrm{~mm}$ in diameter, and the relation becomes less homogenous as sediment diameter increases (Breault and others, 2005; Smith, 2005; Smith and Granato, 2010). Aside from arsenic (As) and copper $(\mathrm{Cu})$, the RPD for the other metals in the coarser size fractions ranged from 0 to 64 percent. The RPDs for concentrations of $\mathrm{As}$ and $\mathrm{Cu}$ were the least precise in the two larger size fractions. The RPD for concentrations of chromium (Cr) was the most precise in all three particle-size ranges.

\section{Analysis Methods}

The Anderson-Darling test, which compares the fit of an observed cumulative distribution function to an expected cumulative distribution function, was used to test for normality of each dataset (Minitab, Inc., 2010). The Spearman rho test was used to evaluate monotonic relations between concentrations of constituents collected at the bridges (Helsel and Hirsch, 2002). The Spearman rho test is based on the ranks of the data and, therefore, is resistant to effects caused by outliers (Helsel and Hirsch, 2002). Test results range from -1 (negative relation) through 0 (no relation) to +1 (positive relation). A negative coefficient indicates that one variable tends to increase as the other decreases, and a positive coefficient indicates that the two variables tend to increase together; however, the variables may not necessarily change at a constant rate in a monotonic relation. The absolute value of the correlation coefficient indicates the strength of the relation between variables. For the Anderson-Darling and the Spearman rho test, the significance level $(\alpha)$ was equal to 0.05 . When the attained significance level of the test ( $p$-value) was less than 0.05 , the null hypothesis of "data is normally distributed" (Anderson-Darling) or "no correlation in ranked data" (Spearman) was rejected.

Data collected in this study were analyzed to determine if the quality of bridge runoff differed significantly from bridge to bridge and if the quality of bridge runoff differed 


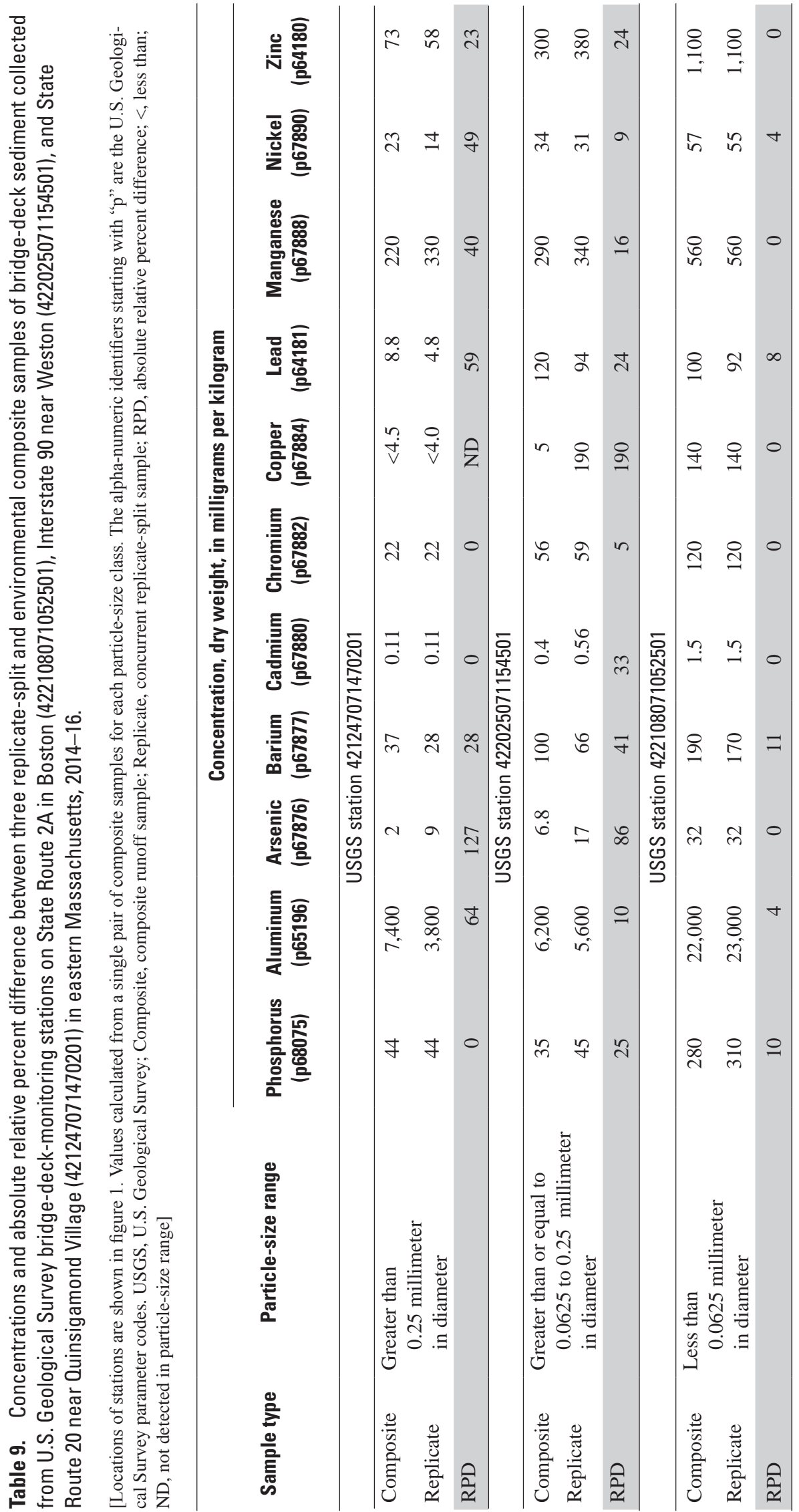


significantly from the quality of highway runoff collected in eastern Massachusetts (Smith and Granato, 2010). Nonparametric rank-based methods were used for comparison of constituent concentrations collected on bridges or highways. Analysis of rank-transformed data is more robust compared to the analysis of raw data that are not normally distributed, and the mean rank represents an estimate of the median (Helsel and Hirsch, 2002). Bridge-deck runoff concentration data were analyzed by using the one-way analysis of variance (ANOVA) test on the ranks of the data (Minitab, Inc., 2010). Subsequently, the Tukey pairwise comparison method test was used to identify statistically significant differences ( $p$-value less than 0.05 ) between datasets from each bridge (Minitab, Inc., 2010).

The Tukey method controls the overall specified error rate (95-percent joint confidence level) for all pairwise comparisons, and it is applicable to the uneven sample sizes (Helsel and Hirsch, 2002). The Mann-Whitney test, also referred to as the rank-sum test, was used to determine whether constituent concentrations collected from bridges differed statistically ( $p$-value less than 0.05) from paired constituent concentrations collected from highways (Helsel and Hirsch, 2002). The Mann-Whitney test is a nonparametric method that makes no assumptions about the distribution of data and is used to determine if groups of data come from the same population or, alternatively, if the median values are different (Helsel and Hirsch, 2002).

\section{Bridge-Deck Runoff Simulations}

Model simulations of runoff quality can provide important information for engineers and managers when choosing BMPs that are most effective in consistently reducing the target. The Stochastic Empirical Loading and Dilution Model (SELDM) was used to simulate bridge-deck runoff quality (Granato, 2013, 2016). These simulations demonstrate waterquality risk analysis and simulate annual bridge-runoff yields with and without use of stormwater control measure BMPs. Standard methods and variables described by Granato (2013) and statistics from the National Weather Service long-term precipitation monitoring sites in ecoregion 59 (the Northeastern Coastal Zone) were used for the hydrologic simulations.

Version 1.0.2 of SELDM was used to perform longterm (29-30-year) simulations of bridge-deck runoff quality. SELDM can be used to model sites with different land uses and sites in different settings because it is a lumped parameter model that simulates runoff by using representative input values for conditions at a site of interest. Although SELDM is primarily designed to indicate the risk for stormwater event-mean composites, flows, and loads to be above userselected water-quality goals for individual storm events, it also calculates annual yields. SELDM is not calibrated by fitting input values to a historical record; it is calibrated by selecting statistics for runoff-quality variables and BMP-treatment variables from robust and representative datasets (Granato, 2013, 2014; Granato and Jones, 2015, 2016, 2017). The input statistics that are selected can have a substantial effect on the potential number of water-quality exceedances in a simulation and the estimated annual yields.

\section{Simulating Bridge-Deck Hydrology}

Although standard methods and variables described by Granato (2013) were used for the simulations in this study, information about the timing of runoff from the highway is not needed for annual-loads analyses. Therefore, the only bridgesite hydraulic variables needed for these analyses were the drainage area and the impervious fraction. A drainage area of 1 acre and an impervious fraction of one (100 percent) were selected so the loads would be computed as annual yields in pounds per acre of pavement per year. The primary hydrologic variables used by SELDM to simulate runoff are the volume, duration, and the number of hours between event midpoints for runoff-generating storm events. Storm events are generated stochastically by using the two-parameter exponential distribution. The numbers of hours between event midpoints for runoff-generating storm events are summed from event to event until the total elapsed time exceeds either 365 or 366 days, and then all the events within this period are lumped into an annual load accounting year. This process continues until the minimum threshold is exceeded and the last full year is simulated (Granato, 2013). The average of statistics from the 31 National Weather Service long-term precipitation monitoring sites in ecoregion 59 (the Northeastern Coastal Zone) were used for the simulations. These average values for stormevent depth, duration, and the number of hours between event midpoints are 0.704 in., 9.69 hours, and 155 hours, respectively (Granato, 2010, 2013). Stochastic variations in precipitation-event values resulted in 8 simulations with 29 annualload accounting years and 3 simulations with 30 annual-load accounting years. SELDM simulates runoff from precipitation by using stochastic runoff coefficients simulated with the Pearson type III distribution (Interagency Advisory Committee on Water Data, 1982; Chow and others, 1988). The stochasticrunoff coefficient statistics used in the analysis were calculated by using the standard SELDM values for the average (0.785), standard deviation (SD; 0.1917), and skew $(-1.19)$ of runoff coefficients for sites that are fully impervious; these statistics were calculated by using rainfall-runoff data from 58 highway-runoff monitoring sites (Granato, 2013).

\section{Simulating Bridge-Deck Runoff Concentrations}

SELDM was used to simulate long-term concentrations and yields of SS, TP, and total nitrogen (TN) in bridge runoff. These values were simulated by using the log-Pearson type III distribution with the average, SD, and skew of the common (base 10) logarithms of SS, TP, and TN concentrations. In this study, these constituents were simulated by using the 
logarithms of concentrations because such data commonly fit a lognormal or log-Pearson type III distribution (Di Toro, 1984; Novotny, 2004; Granato and others, 2009; Granato, 2013). If data were simulated as lognormal, the skew was set equal to zero, which linearized the distribution of generated data with respect to the logarithmic and probability axes. In comparison, datasets with negative skews were concave down, which resulted in lower values at both ends of the distribution than would be produced with a lognormal distribution. Datasets with positive skews were concave up, which resulted in higher values at both ends of the distribution than would be produced with a lognormal distribution. Large positive skew values, when coupled with large SD values, may produce unrealistic concentrations, flows, and loads if an extreme random number is generated. Because monitoring data were limited, with many datasets commonly having fewer than 20 events per site, generating a long-term record set of many events (usually more than 1,600 in the Northeastern Coastal Zone) required extrapolation beyond the percentiles of the original data; therefore, careful selection of representative statistics was warranted.

Three methods for estimating sample statistics were used to evaluate input values for these long-term simulations. The first method was to use the traditional statistics for estimating the average, SD, and skew because they are most commonly used in hydrology and statistics (Haan, 1977; Interagency Advisory Committee on Water Data, 1982; Chow and others, 1988; Hosking, 1990; Stedinger and others, 1993; Helsel and Hirsch, 2002). The second method was to use robust regression on order statistics to estimate the average and SD and Pearson's second skew as a robust estimate of skew (Haan, 1977; Helsel and Hirsch, 2002). The third method was to use L-moments, which also are considered robust estimates of sample statistics (Hosking, 1990; Stedinger and others, 1993).

The traditional methods for estimating the average, SD, and skew have some limitations when these statistics calculated from limited datasets are used to simulate more values than are available (Haan, 1977; Interagency Advisory Committee on Water Data, 1982; Chow and others, 1988; Hosking, 1990; Stedinger and others, 1993; Helsel and Hirsch, 2002). Although the average is the best estimate of the center of the distribution, the value of the average can be substantially biased by either high or low outliers in small datasets. Estimates of the average values tend to stabilize more rapidly with each additional sample and are less biased by outliers than the SD or skew because these statistics are calculated by using the sum of squared differences between each value and the average and the sum of cubed differences between each value and the average, respectively.

Robust regression on order statistics and Pearson's second skew were used to estimate sample statistics because values calculated by using these methods may be less biased by outliers than values calculated by using traditional methods (Haan, 1977; Helsel and Hirsch, 2002). If the logarithms of data are plotted against the normal quantiles of the plotting position of each data point, then the intercept and slope of a regression line based on these points are estimates of the average and SD of a lognormal distribution of these data (Haan, 1977; Helsel, 2004; National Institute of Standards and Technology, 2012). For this study, the Kendall-Theil Robust Line software (Granato, 2006) was used to obtain the estimates of the average and SD with the composite sample runoff data because this regression method is resistant to outliers. The TP concentrations from composite runoff samples from the State Route 20 bridge-deck-monitoring station are presented in figure 13 as an example. The average was estimated by adding the median error to the intercept because the intercept of the Kendall-Theil Robust Line is an estimate of the median not the average (Granato, 2006). Pearson's second skew was used to estimate the value of skew because it is less affected by outliers than the traditional measure of skewness. The traditional equation for skewness is calculated by using the sum of cubed differences from the mean and the cubed SD; therefore, a few extreme values can have a substantial effect on this estimate of skew (Haan, 1977; Stedinger and others, 1993; Helsel and Hirsch, 2002; National Institute of Standards and Technology, 2012). Pearson's second skew, however, is calculated by subtracting the median from the mean, multiplying the difference by 3 , and dividing by the SD, which avoids the use of cubed values (Haan, 1977; Stedinger and others, 1993; Helsel and Hirsch, 2002; National Institute of Standards and Technology, 2012).

L-moments also were used to estimate sample statistics for potential use in SELDM simulations. L-moments are linear combinations of probability-weighted moments (Hosking, 1990; Stedinger and others, 1993). The average L-moment statistic is calculated by using the same equation as the traditional average; however, the L-moments statistics which are analogous to the SD and skew statistics are considered unbiased estimators of sample statistics because these L-moment statistics are not calculated by using the squared or cubed differences from the average value. Calculation of these statistics is described by Stedinger and others (1993).

Selecting runoff-quality statistics from monitored sites to represent runoff quality at an unmonitored site is not a welldefined process. Although AADT counts have been reported as a predictive variable, such relations commonly are categorical, and the differences among sites may be attributable to the increasing development of surrounding areas that is associated with increasing traffic counts (Driscoll and others, 1990; Smith and Granato, 2010; Wagner and others, 2011; Taylor and others, 2014). Differences in monitoring statistics among sites may not be meaningful without availability of extremely large datasets (for example, 25 to 100 events) because of the variability of highway and urban runoff quality (Burton and Pitt, 2002; California Department of Transportation, 2009; Granato, 2013).

Robust methods are needed to use available data from monitored sites to estimate potential effects of runoff at unmonitored sites. In this study, the three monitored bridges constitute only about 0.16 percent of MassDOT-owned bridges over water in Massachusetts. Similarly, the 15 bridge decks 


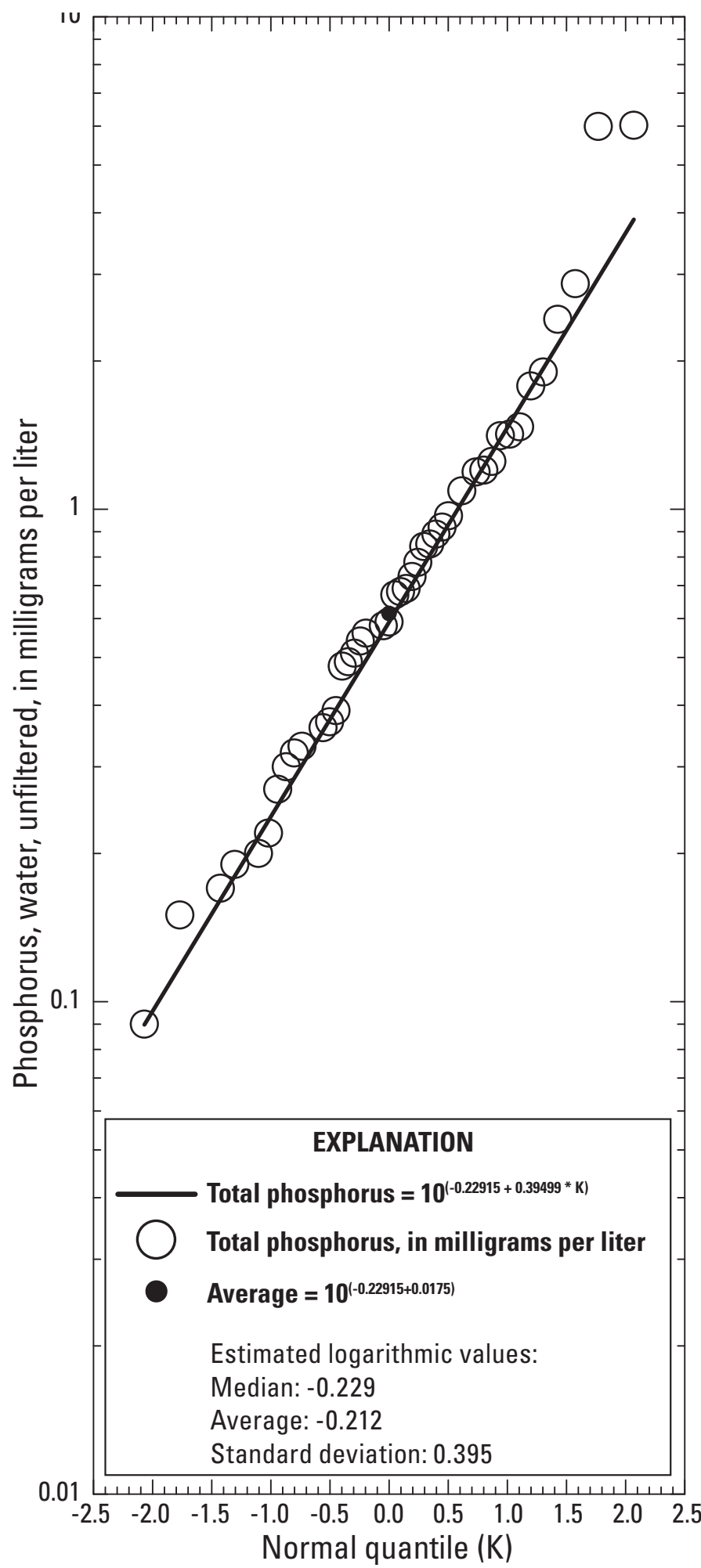

Figure 13. An example of the estimation of the average and standard deviation of total phosphorus concentrations in runoff composite samples collected from U.S. Geological Survey bridge-deck-monitoring station State Route 20 near Quinsigamond Village (421247071470201) by using the robust regression on order statistics method. Location of station is shown on figure 1. in North Carolina in a larger study by Wagner and others (2011) constitute only about 0.1 percent of the 13,500 bridges maintained by North Carolina Department of Transportation (2017). Granato and Jones (2015) examined use of statistics from the same 15 bridge-runoff monitoring sites to estimate the risks for adverse effects of total phosphorus in receiving streams from bridge-deck runoff in North Carolina. They determined that correlations of concentrations to AADT counts (using both Pearson's R and Spearman's rho) were small and not statistically significant at the 95-percent confidence limits. Granato and Jones (2015) also determined a lack of significant correlation among statistics indicating that the average, $\mathrm{SD}$, and skew of the common logarithms of concentration do not covary. They concluded that statistics may vary randomly from site to site, and the median of each concentration statistic may be representative for simulating runoff quality at unmonitored sites. Similarly, Risley and Granato (2014) examined potential effects of runoff-quality statistics on simulated concentrations and the potential for simulated water-quality excursions in receiving waters in Oregon. They concluded that using the median of statistics from hydrologically similar sites provided robust concentration estimates. Therefore, the median of statistics from the three bridge sites were used to simulate planning-level yield estimates for all bridges in eastern Massachusetts.

\section{Simulating Runoff Treatment}

Runoff treatment was analyzed to examine the potential effects of flow reductions and concentration reductions by stormwater BMPs on concentrations and annual yields from bridges. The BMP effluent concentrations and discharge volumes were simulated by using the BMP-treatment module in SELDM (Granato, 2013, 2014). The SELDM BMPtreatment module has provisions for stochastic modeling of three stormwater treatments: volume reduction, hydrograph extension, and water-quality treatment. Hydrograph extension is an important variable for dilution analyses, but the durations of BMP discharges do not substantially affect the total-annual yield from the highway. The SELDM BMP module uses the trapezoidal distribution and the rank correlation with the associated highway-runoff variable to provide a stochastic transfer function to approximate the quantity and quality of BMP effluent given the associated inflow values in a simulation. SELDM uses rank correlation to preserve the structure of inflow and outflow data commonly present in BMP studies. Correlations between the ratio of outflow to inflow volumes and the magnitude of inflows commonly are positive because it would be difficult for BMPs built with commonly used designs to retain or infiltrate a large proportion of flow from a large runoff event. The small positive correlation between highway inflow volumes and the outflow ratios reduces the average effectiveness of flow reduction by the BMP. Correlations between the concentration ratio and inflow concentrations are negative because BMP-monitoring datasets indicate that BMPs are more effective for substantially reducing large 
inflow concentrations than small inflow concentrations. The negative correlation between highway inflow concentrations and the outflow ratios increases the average effectiveness of concentration reduction by the BMP. In many studies, BMP outflow concentrations can exceed low inflow concentrations (Granato, 2014; Taylor and others, 2014). To represent this phenomenon, SELDM simulates the effect of the minimum irreducible concentration (MIC), which is the lowest expected BMP effluent concentration (Granato, 2013, 2014). SELDM substitutes the MIC for BMP effluent concentrations that are less than the MIC.

For these analyses, a generic BMP was simulated by using the median of treatment statistics for flow reductions, concentration reductions, and MICs from nine BMP categories with data from the 2012 International BMP database (Granato, 2014). The BMP categories and associated performance statistics for flow and concentration treatment from which the median values were derived and used for simulations in these analyses are shown in table 10 . The categories bioretention, composite BMPs, detention basin, biofilter (swale), media filter, retention pond, wetland basin, and wetland channel were selected because flow statistics, concentration statistics, and MIC statistics were available from multiple BMP monitoring sites for these categories (Granato, 2014). The MIC values that were chosen for these simulations were based on the 25th percentile of MIC estimates from available sites for each category.

\section{Quality of Bridge-Deck Runoff}

Concentrations of SS, sediment particle size, nutrients, LOI, and PC were measured in more than 160 flow-proportional composite samples (about 50 or more per monitoring station) of bridge-deck runoff collected from the three bridge-deck-monitoring stations between 2014 and 2016 (U.S. Geological Survey, 2016). In addition to NWIS, the data also are available in the HRDB (version 1.0.0b) (Granato, 2017) that was developed by USGS in cooperation with the Federal Highway Administration (Granato and Cazenas, 2009). Summary statistics and statistical tests are presented to characterize and contrast the datasets for each bridge (table 11). The concentrations of constituents in composite samples of bridgedeck runoff varied considerably from storm to storm; however, concentration statistics for many constituents were similar for each bridge.

\section{Suspended Sediment}

Suspended sediment, especially the fine sediment fraction, is an important transport mechanism for many constituents in stormwater runoff. Several recent studies in Massachusetts have documented the affiliation of phosphorus and metals with sediment and the corresponding effect of concentration with specific particle sizes from samples of sediment collected from oil-grit separators (Smith, 2002), streambeds (Smith, 2005), street sweepings (Breault and others, 2005; Sorenson, 2013), and highway runoff (Smith and Granato, 2010). Metal concentrations associated with sediment tend to increase with a decrease in sediment particle size because as sediment particle size decreases the sediment surface area increases, allowing metals to bond to the sediment surface. Understanding the relation between sediment quality and particle size is important for the selection and implementation of structural and nonstructural BMPs to improve the quality of water discharged from bridge decks.

Concentrations of SS in composite samples of bridgedeck runoff ranged from 44 to 142,000 mg/L; however, most concentrations were less than 23,000 mg/L (maximum value for the 90th percentile for the three stations; table 11). Median concentrations of SS were nearly identical in samples collected from State Route $2 \mathrm{~A}$ and Interstate 90 bridge-deckmonitoring stations (2,010 and 2,020 mg/L, respectively); the median concentration of SS in samples from State Route 20 bridge-deck-monitoring station was lower at 1,490 mg/L. The particle-size distribution of SS at each monitoring station was highly skewed towards the coarse size fraction (size fraction greater than $0.25 \mathrm{~mm}$ in diameter) (fig. 14). At each bridgedeck-monitoring station, the median concentration for the coarse size fraction was about an order of magnitude greater than the finer two size fractions $(0.0625$ to $0.25 \mathrm{~mm}$ and less than $0.0625 \mathrm{~mm}$ in diameter). The median distribution of particles in the fine size fraction (less than $0.0625 \mathrm{~mm}$ in diameter) ranged from 4 to 8 percent at each monitoring station (table 11). The median distribution of particles less than $0.25 \mathrm{~mm}$ in diameter was less than or equal to 26 percent for each bridge. The percentage of finer particles tended to increase with a decrease in concentration of SS (fig. 15), which is likely attributed to dissimilar buildup rates or roadway surface load capacity for the different particle sizes; that is, silt and clay size particles are easily dispersed by wind or vehicular turbulence, whereas coarse sand deposits tend to not disperse easily (less mobile) and increase in place between runoff events.

\section{Loss on Ignition of Suspended Solids and Particulate Carbon}

Concentrations of SS include organic particles in addition to mineral sediments. The organic fraction of the SS concentration is represented by LOI (or volatile suspended solids) and PC concentration data. Concentrations of LOI are generally considered a crude estimate of PC because other constituents, such as volatile salts, organic compounds, sulfide oxidation, inorganic carbon, and hydroxide compounds, also may be volatilized or otherwise diminished during the analytical method (Brown and Dykstra, 1995; Veres, 2002) and result in concentrations that are greater than those determined by methods for PC. Concentrations of LOI in composite samples of bridge-deck runoff generally were about 2.5 times greater than concentrations of PC in the same samples (fig. 16). 
Table 10. Stormwater control measure best-management practice performance statistics for flow and concentration treatment used in the Stochastic Empirical Loading and Dilution Model.

[The concentration-reduction and flow-reduction statistics are for the trapezoidal distribution of the ratio of outflow to inflow concentration or flow volume. The Spearman's rho correlation coefficients are calculated by using the ranks of the inflow concentrations or flows and the associated ratios of outflow to inflow concentrations or flows. The minimum irreducible concentration (MIC) estimates for the suspended sediment concentrations were developed with total suspended solids concentrations but are considered applicable for estimating the MIC of suspended sediment concentrations because differences in the results of these analytical methods are small once the large grain-size fractions are removed within the best-management practice. LBMPV, lower bound of the most probable value; UBMPV, upper bound of the most probable value; Spearman's rho, Spearman's correlation coefficient; N, nitrogen; P, phosphorus; --, insufficient data; NA, not applicable]

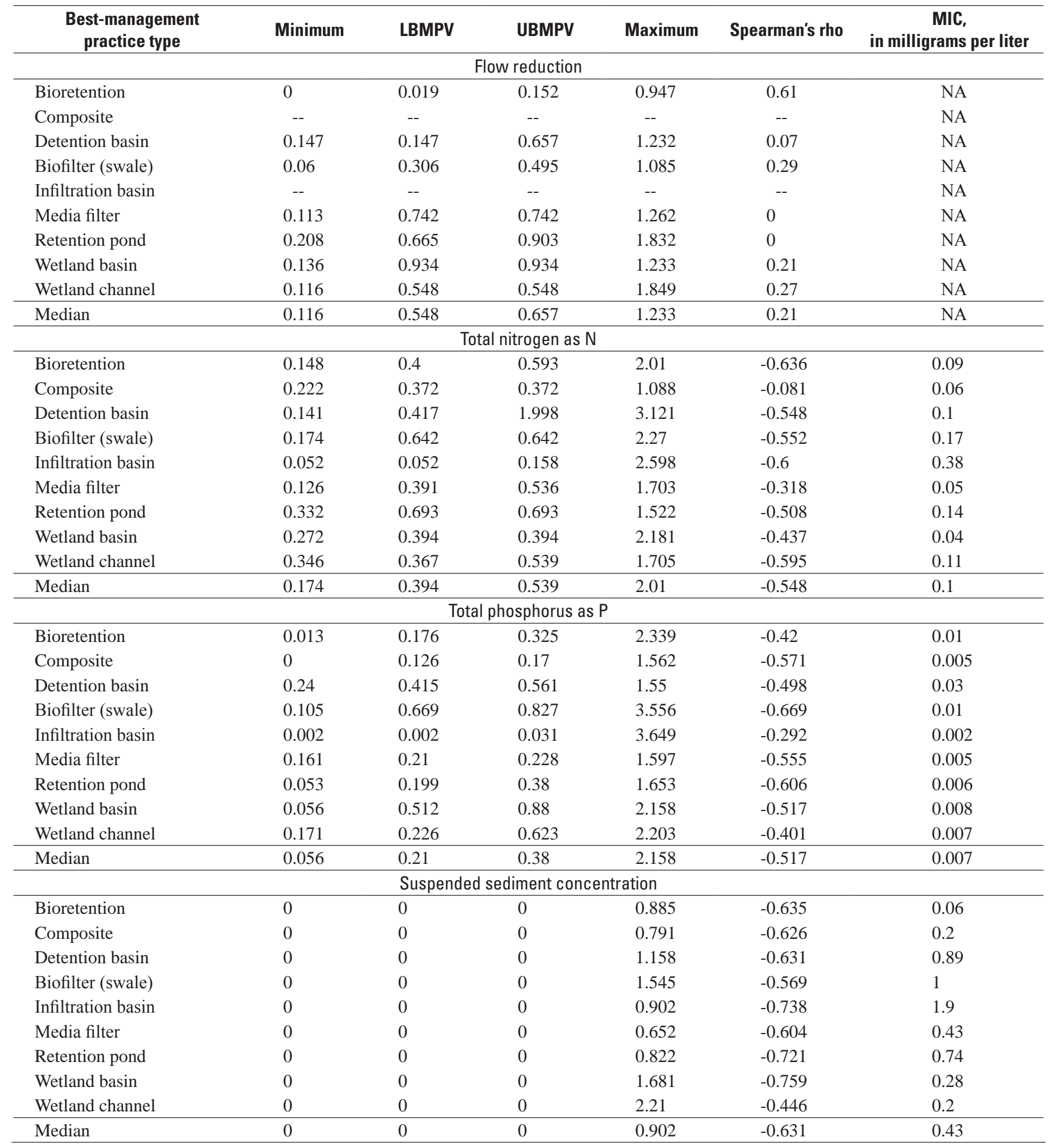




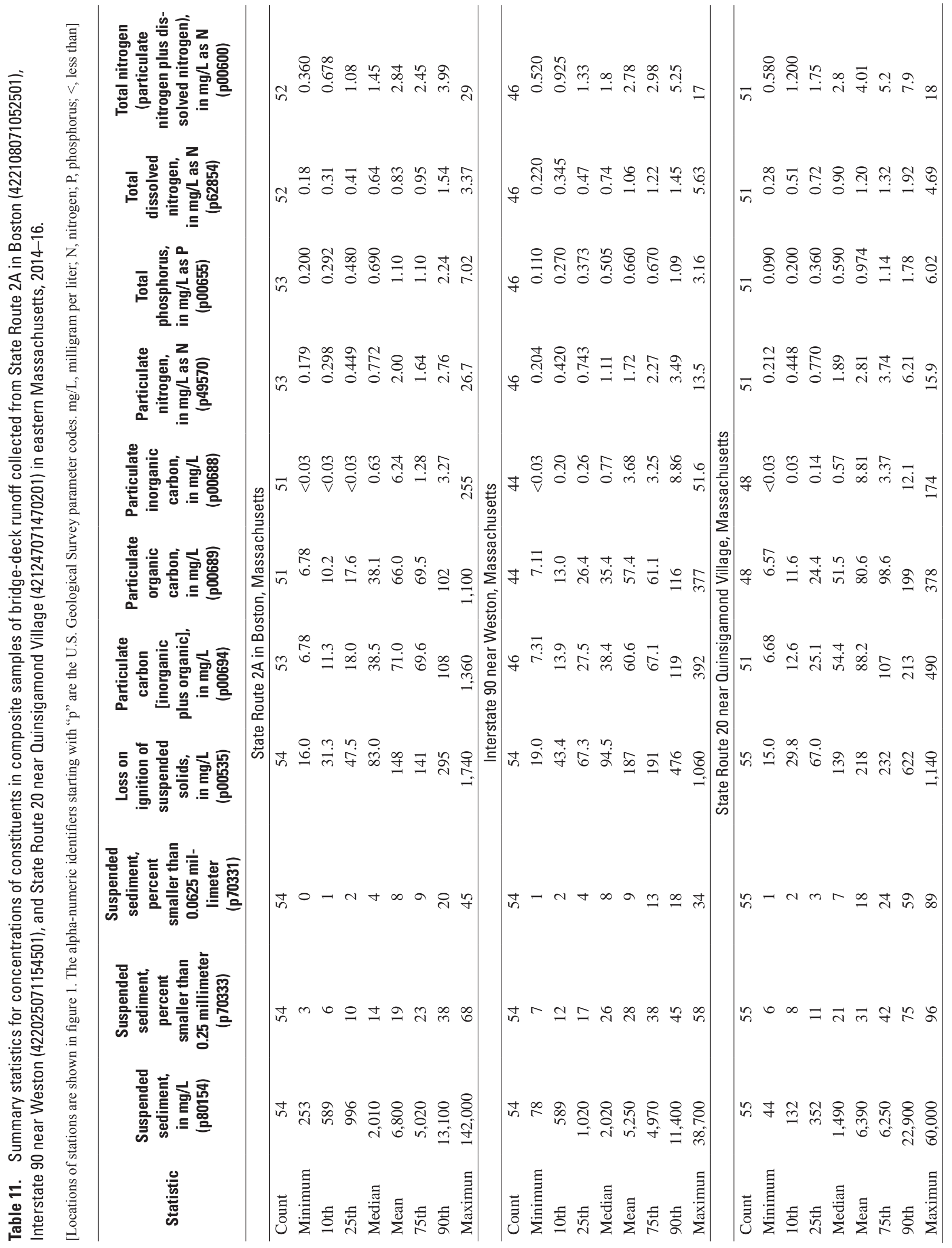




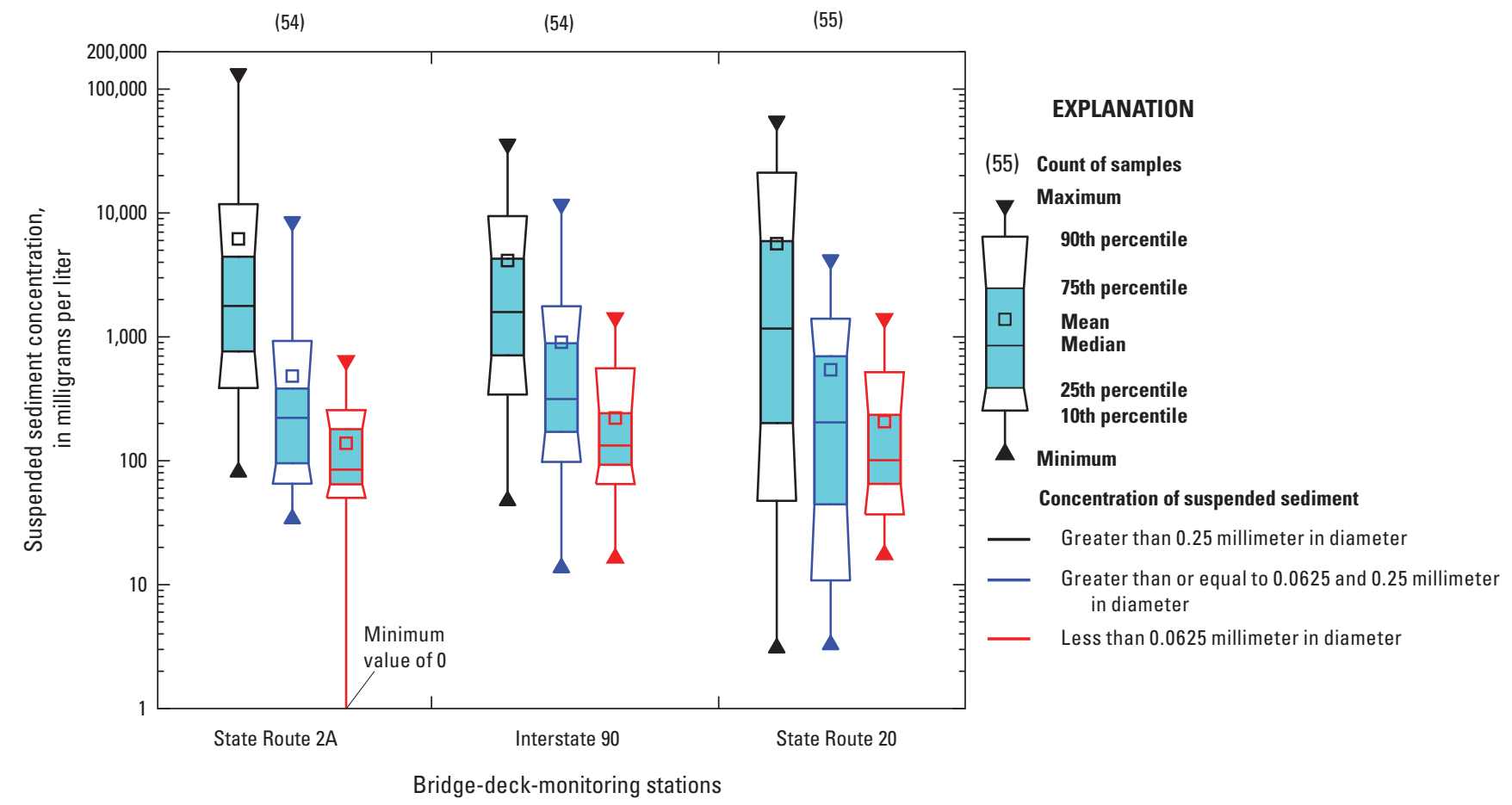

Figure 14. Distribution of three particle-size classes for suspended sediment in composite samples of bridge-deck runoff collected at U.S. Geological Survey bridge-deck-monitoring stations on State Route 2A in Boston (422108071052501), Interstate 90 near Weston (422025071154501), and State Route 20 near Quinsigamond Village (421247071470201) in eastern Massachusetts, 2014-16. Locations of stations are shown on figure 1 .

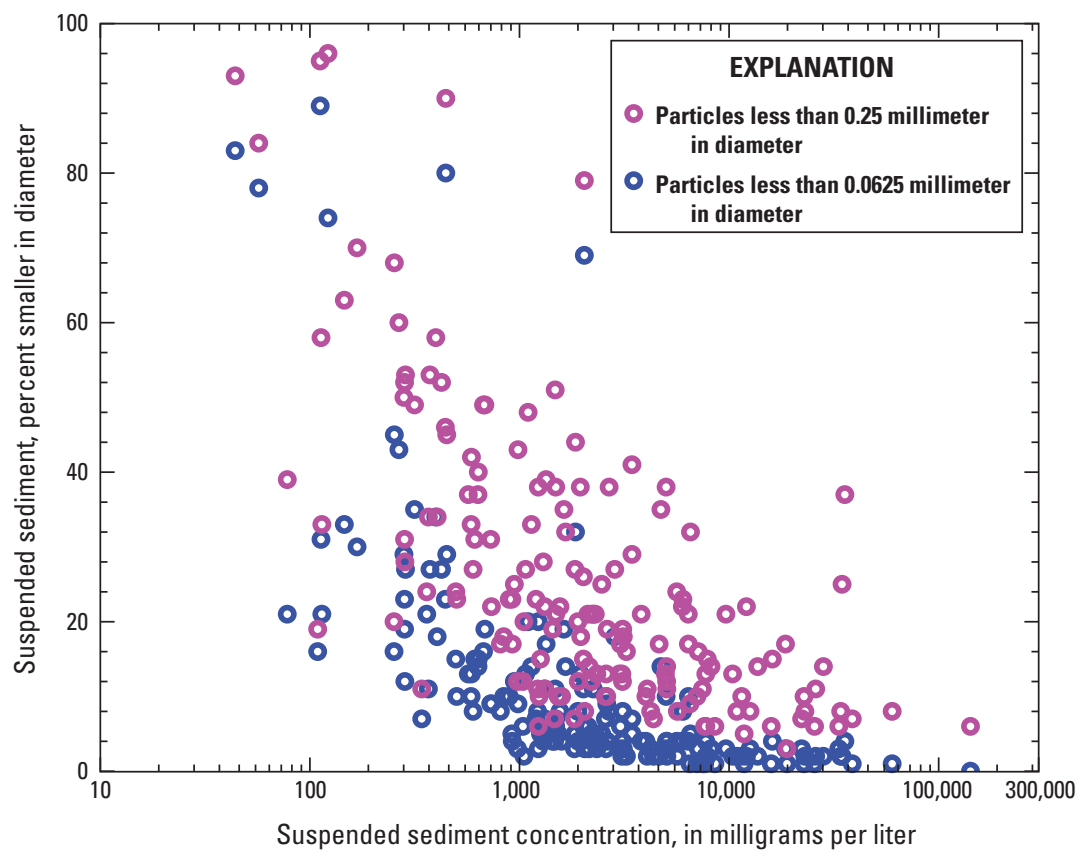

Figure 15. The relation between particles size less than 0.0625 millimeter in diameter and particles size less than 0.25 millimeter in diameter to concentrations of suspended sediment in composite samples of bridgedeck runoff collected at U.S. Geological Survey bridge-deck-monitoring stations on State Route 2A in Boston (422108071052501), Interstate 90 near Weston (422025071154501), and State Route 20 near Quinsigamond Village (421247071470201) in eastern Massachusetts, 2014-16. Locations of stations are shown on figure 1. 


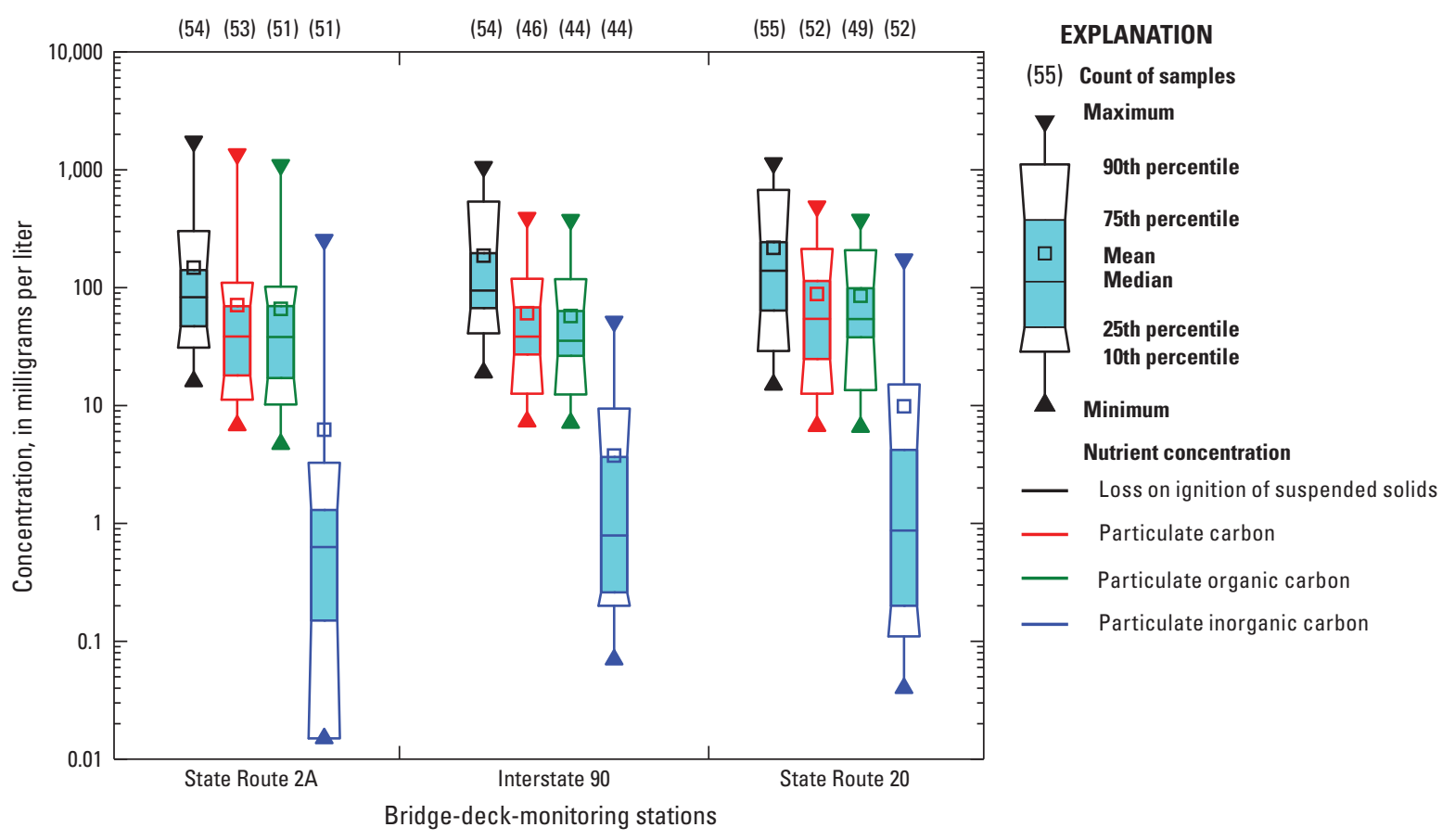

Figure 16. Distribution of concentrations of loss on ignition of suspended solids, particulate carbon, particulate organic carbon, and particulate inorganic carbon in composite samples of bridge-deck runoff collected at U.S. Geological Survey bridge-deck-monitoring stations on State Route 2A in Boston (422108071052501), Interstate 90 near Weston (422025071154501), and State Route 20 near Quinsigamond Village (421247071470201) in eastern Massachusetts, 2014-16. Locations of stations are shown on figure 1.

Concentrations of LOI and PC in composite samples ranged from 15.0 to $1,740 \mathrm{mg} / \mathrm{L}$ and 6.68 to $1,360 \mathrm{mg} / \mathrm{L}$, respectively (table 11). Median values representing the proportion of LOI and PC to SS were less than 10 and 3 percent in composite samples collected at the three bridge-deck-monitoring stations, respectively. Concentrations of PC were primarily organic in content (table 11; fig. 16). Less than about 12 percent of the total PC was inorganic in 90 percent of the samples collected at each bridge-deck-monitoring station.

\section{Nutrients}

Many studies have shown that stormwater runoff can be a source of nutrients (Davenport, 1990; Breault and Granato, 2000; Smith, 2002; Kayhanian and others, 2003; Smith and Granato, 2010). Phosphorus is somewhat insoluble and tends to be associated with sediment, including local soils and even maintenance sand used to increase traction on roads during winter storms (Smith and Granato, 2010). As previously noted in the "Site Selection" section, maintenance sand was not applied to any of the bridges in this study but may have been used on roadways in the vicinity of the monitoring stations and tracked onto the bridge decks. Natural organic material also is a source of TP and PN in stormwater runoff (Breault and others, 2005; Smith, 2005; Smith and Granato, 2010; Sorenson, 2013). Although each bridge is elevated and contains little or no adjacent vegetation, leaves and other natural organic matter were frequently observed in water samples. Concentrations of TP and TN in composite samples of bridge-deck runoff ranged from 0.09 to $7.02 \mathrm{mg} / \mathrm{L}$ and 0.36 to $29.0 \mathrm{mg} / \mathrm{L}$, respectively (table 11). The distribution of TP concentrations was similar at each bridge-deck-monitoring station, whereas median concentrations ranged from 0.505 to $0.690 \mathrm{mg} / \mathrm{L}$

(fig. 17). Highest observed median concentrations of TP were in composite samples of bridge-deck runoff collected on State Route 2A in Boston (table 11). The distribution of PN and DN concentrations also was somewhat similar at each bridge; however, the concentrations of DN and PN were highest at the State Route 20 monitoring station. Approximately 40 percent of the TN concentration at each monitoring station consisted of DN. Annual precipitation-weighted mean concentrations of DN (inorganic forms of ammonia plus nitrate) during 2015 and 2016 were 0.625 and $0.859 \mathrm{mg} / \mathrm{L}$ in Boston, respectively (National Atmospheric Deposition Program, 2017a), and were 0.735 and $0.773 \mathrm{mg} / \mathrm{L}$ in central Massachusetts, respectively (National Atmospheric Deposition Program, 2017b), which are near the median DN concentrations in composite samples of bridge-deck runoff at each monitoring station (0.64 to 


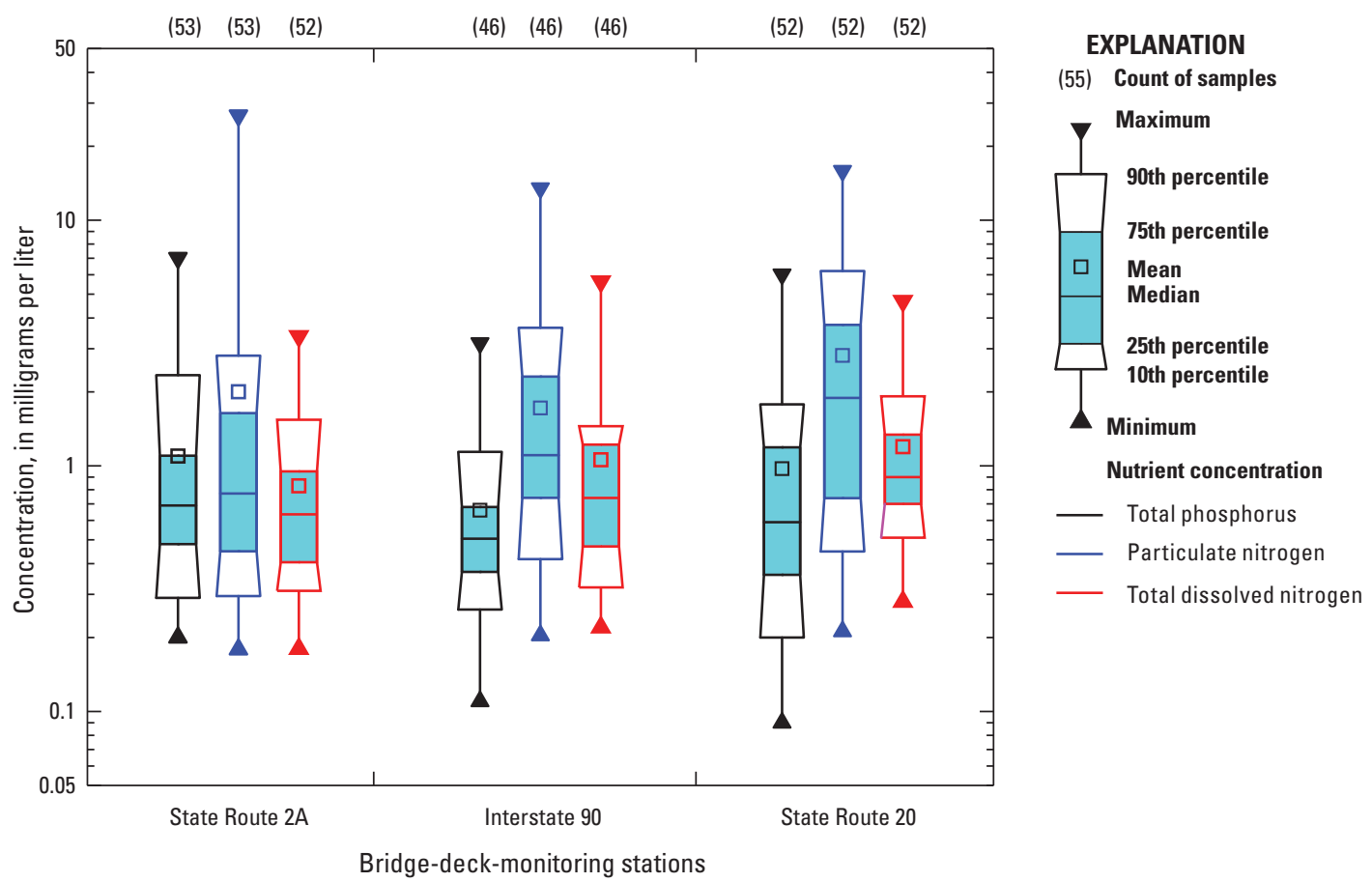

Figure 17. Distribution of concentrations of total phosphorus, particulate nitrogen, and total dissolved nitrogen in composite samples of bridge-deck runoff collected at U.S. Geological Survey bridgedeck-monitoring stations on State Route 2A in Boston (422108071052501), Interstate 90 near Weston (422025071154501), and State Route 20 near Quinsigamond Village (421247071470201) in eastern Massachusetts, 2014-16. Locations of stations are shown on figure 1.

$0.90 \mathrm{mg} / \mathrm{L}$ ) (table 11). Traffic volume (table 1) and available land-use data (table 2) showed no consistent trend that might indicate why nitrogen concentrations in samples collected from the State Route 20 and Interstate 90 bridge locations seemed to differ from nitrogen concentrations in samples collected from the State Route 2A bridge location in Boston.

\section{Correlation Between Constituents}

Results for all Anderson-Darling tests were significant (p-value less than 0.05) (table 12) for sample sets at each bridge, indicating that concentration data for composite samples of bridge-deck runoff were not normally distributed. Right-skewed distributions for highway and urban runoff data are not unusual because concentration data are highly variable and often include high-concentration outliers (Driscoll and others, 1990; Smith, 2002; Smith and Granato, 2010). Because the bridge-deck runoff concentration data were not normally distributed, nonparametric statistical methods were used for analysis of all data.

Results for Spearman rho tests on the datasets indicated that the concentration data were positively correlated with each other (table 13). The relation between concentrations of SS and other particulate constituents (LOI, PC, POC, PIC, and $\mathrm{PN}$ ) were significant and in many cases, the relations were moderately strong (Spearman rho coefficient greater than 0.7). Spearman rho test results indicated that the relations between concentrations of $\mathrm{PN}$ and LOI (coefficients ranging from 0.772 to 0.908 ) and PC (coefficients ranging from 0.906 to 0.942 ) were stronger than the relation between PN and SS (coefficients ranging from 0.595 to 0.640 ). Conversely, relations between concentrations of TP and LOI, PC, and SS were similar at each bridge, although the relations were consistently weaker at Interstate 90 (table 13). These data indicated that concentrations of organic constituents (LOI and PC) were better correlated with concentrations of TN compared to concentrations of SS, and these organic constituents seem to have relations of similar strength with TP compared to concentrations of SS, implying that natural organic materials are likely an important source for total nutrients.

\section{Interbridge Comparison of Constituent Concentrations}

Concentration data collected from each bridge were compared to the respective concentration data collected from each of the other bridges to determine if the datasets were significantly different. Results for the ANOVA and 
Table 12. Results and attained significance levels for Anderson-Darling tests for concentrations of selected constituents in composite samples of bridge-deck runoff collected at U.S. Geological Survey bridge-deck-monitoring stations on State Route 2A in Boston (422108071052501), Interstate 90 near Weston (422025071154501), and State Route 20 near Quinsigamond Village (421247071470201) in eastern Massachusetts, 2014-16.

[Locations of stations are shown in figure 1. The alpha-numeric identifiers starting with "p" are the U.S. Geological Survey parameter codes. p-value, significance level; P, phosphorus; N, nitrogen; <, less than.]

\begin{tabular}{|c|c|c|c|c|c|}
\hline \multirow{2}{*}{ Constituent } & \multicolumn{5}{|c|}{ Anderson-Darling test results } \\
\hline & Count & Average & Standard deviation & Anderson-Darling statistic & $p$-value \\
\hline \multicolumn{6}{|c|}{ State Route $2 \mathrm{~A}$ in Boston, Massachusetts } \\
\hline Total phosphorus as P (p00655) & 53 & 1.096 & 1.304 & 6.812 & $<0.005$ \\
\hline Total nitrogen as $\mathrm{N}(\mathrm{p} 00600)$ & 52 & 2.839 & 4.72 & 10.020 & $<0.005$ \\
\hline Total dissolved nitrogen as N (p62854) & 52 & 0.829 & 0.643 & 3.694 & $<0.005$ \\
\hline Particulate nitrogen as N (p49570) & 53 & 2.003 & 4.418 & 11.782 & $<0.005$ \\
\hline Suspended sediment (p80154) & 54 & 6,795 & 19,486 & 12.299 & $<0.005$ \\
\hline Particulate carbon (p00694) & 53 & 71.03 & 184.6 & 12.616 & $<0.005$ \\
\hline Loss on ignition of suspended solids (p00535) & 54 & 147.4 & 246.1 & 8.312 & $<0.005$ \\
\hline \multicolumn{6}{|c|}{ Interstate 90 near Weston, Massachusetts } \\
\hline Total phosphorus as $\mathrm{P}$ (p00655) & 46 & 0.660 & 0.571 & 4.622 & $<0.005$ \\
\hline Total nitrogen as $\mathrm{N}(\mathrm{p} 00600)$ & 46 & 2.785 & 2.848 & 4.990 & $<0.005$ \\
\hline Total dissolved nitrogen as N (p62854) & 46 & 1.059 & 1.088 & 5.561 & $<0.005$ \\
\hline Particulate nitrogen as N (p49570) & 46 & 1.72 & 2.097 & 4.919 & $<0.005$ \\
\hline Suspended sediment (p80154) & 54 & 5,251 & 8,700 & 8.777 & $<0.005$ \\
\hline Particulate carbon (p00694) & 46 & 60.62 & 68.16 & 4.956 & $<0.005$ \\
\hline Loss on ignition of suspended solids (p00535) & 54 & 186.6 & 214 & 6.247 & $<0.005$ \\
\hline \multicolumn{6}{|c|}{ State Route 20 near Quinsigamond Village, Massachusetts } \\
\hline Total phosphorus as P (p00655) & 51 & 0.974 & 1.179 & 5.809 & $<0.005$ \\
\hline Total nitrogen as N (p00600) & 51 & 4.013 & 3.395 & 2.734 & $<0.005$ \\
\hline Total dissolved nitrogen as N (p62854) & 51 & 1.197 & 0.937 & 4.719 & $<0.005$ \\
\hline Particulate nitrogen as N (p49570) & 51 & 2.815 & 3.048 & 3.873 & $<0.005$ \\
\hline Suspended sediment (p80154) & 55 & 6,393 & 11,368 & 8.062 & $<0.005$ \\
\hline Particulate carbon (p00694) & 51 & 88.24 & 95.84 & 3.973 & $<0.005$ \\
\hline Loss on ignition of suspended solids (p00535) & 55 & 217.6 & 237 & 4.723 & $<0.005$ \\
\hline
\end{tabular}

accompanying Tukey pairwise comparison tests performed on the rank-transformed data are reported in table 14. Results for the ANOVA test indicate if the differences among the datasets are significant. The subsequent Tukey pairwise comparison tests are necessary to determine which datasets differ from one another; datasets that share the same letter are not significantly different ( $p$-value 0.05).

Results of the ANOVA tests indicated that concentrations of SS, LOI, PC, and TP in datasets for each bridge pair were not significantly different (table 14). Test results for the fine sediment-size fraction (less than $0.0625 \mathrm{~mm}$ in diameter), intermediate sediment-size fraction (greater than or equal to 0.0625 to $0.25 \mathrm{~mm}$ in diameter), $\mathrm{TN}, \mathrm{PN}$, and $\mathrm{DN}$ were significant, indicating that the dataset from at least one bridge may be different compared to the datasets from the other bridges. Results for the post hoc Tukey pairwise comparison test, however, did not indicate that there was a significant difference between the fine sediment-size fraction in composite samples collected at the three bridges. Test results for the Tukey pairwise comparison test did indicate that datasets for the intermediate sediment-size fraction, TN, PN, and DN were significantly different at one or more bridges. Grouping information indicated that the mean of the rank-transformed data for the intermediate sediment-size fraction collected on Interstate 90 was significantly higher than the means of the ranktransformed data for the other bridges (table 14). The higher 
Table 13. Results and attained significance levels for Spearman rho tests for concentrations of selected constituents in composite samples of bridge-deck runoff collected at U.S. Geological Survey bridge-deck-monitoring stations on State Route 2A in Boston (422108071052501), Interstate 90 near Weston (422025071154501), and State Route 20 near Quinsigamond Village(421247071470201) in eastern Massachusetts, 2014-16.

[Locations of stations are shown in figure 1. Shaded areas indicate values that are significant at a 95-percent confidence interval. The alpha-numeric identifiers starting with "p" are the U.S. Geological Survey parameter codes. P, phosphorus; N, nitrogen; $p$-value, significance level; <, less than]

\begin{tabular}{|c|c|c|c|c|c|c|c|c|c|}
\hline Constituent & Statistic & $\begin{array}{l}\text { Loss on } \\
\text { ignition } \\
\text { of sus- } \\
\text { pended } \\
\text { solids } \\
\text { (p00535) }\end{array}$ & $\begin{array}{l}\text { Particulate } \\
\text { carbon } \\
\text { [inor- } \\
\text { ganic plus } \\
\text { organic] } \\
\text { (p00694) }\end{array}$ & $\begin{array}{c}\text { Par- } \\
\text { ticulate } \\
\text { organic } \\
\text { carbon } \\
\text { (p00689) }\end{array}$ & $\begin{array}{c}\text { Par- } \\
\text { ticulate } \\
\text { inorganic } \\
\text { carbon } \\
\text { (p00688) }\end{array}$ & $\begin{array}{c}\text { Total } \\
\text { dis- } \\
\text { solved } \\
\text { nitrogen } \\
\text { (p62854) }\end{array}$ & $\begin{array}{c}\text { Par- } \\
\text { ticulate } \\
\text { nitrogen } \\
\text { (p49570) }\end{array}$ & $\begin{array}{l}\text { Total } \\
\text { phos- } \\
\text { phorus } \\
\text { as } P \\
\text { (p00655) }\end{array}$ & $\begin{array}{c}\text { Total } \\
\text { nitrogen } \\
\text { as N } \\
\text { (p00600) }\end{array}$ \\
\hline \multicolumn{10}{|c|}{ State Route 2A in Boston, Massachusetts } \\
\hline \multirow{2}{*}{$\begin{array}{l}\text { Particulate carbon [inorganic } \\
\text { plus organic] (p00694) }\end{array}$} & \multirow{2}{*}{$\begin{array}{l}\text { Spearman rho } \\
\text { p-value }\end{array}$} & 0.897 & & & & & & & \\
\hline & & $<0.001$ & & & & & & & \\
\hline \multirow{2}{*}{$\begin{array}{l}\text { Particulate organic carbon } \\
\text { (p00689) }\end{array}$} & \multirow{2}{*}{$\begin{array}{l}\text { Spearman rho } \\
\text { p-value }\end{array}$} & 0.884 & 0.998 & & & & & & \\
\hline & & $<0.001$ & $<0.001$ & & & & & & \\
\hline \multirow{2}{*}{$\begin{array}{l}\text { Particulate inorganic carbon } \\
\quad \text { (p00688) }\end{array}$} & \multirow{2}{*}{$\begin{array}{l}\text { Spearman rho } \\
\text { p-value }\end{array}$} & 0.676 & 0.511 & 0.483 & & & & & \\
\hline & & $<0.001$ & $<0.001$ & 0.001 & & & & & \\
\hline \multirow{2}{*}{$\begin{array}{l}\text { Total dissolved nitrogen as } \mathrm{N} \\
\quad \text { (p62854) }\end{array}$} & \multirow{2}{*}{$\begin{array}{l}\text { Spearman rho } \\
\text { p-value }\end{array}$} & 0.298 & 0.283 & 0.375 & 0.252 & & & & \\
\hline & & 0.032 & 0.042 & 0.01 & 0.098 & & & & \\
\hline \multirow{2}{*}{$\begin{array}{l}\text { Particulate nitrogen as } \mathrm{N} \\
\quad \text { (p49570) }\end{array}$} & \multirow{2}{*}{$\begin{array}{l}\text { Spearman rho } \\
\text { p-value }\end{array}$} & 0.908 & 0.942 & 0.938 & 0.546 & 0.398 & & & \\
\hline & & $<0.001$ & $<0.001$ & $<0.001$ & $<0.001$ & 0.003 & & & \\
\hline \multirow[t]{2}{*}{ Total phosphorus as $\mathrm{P}$ (p00655) } & \multirow{2}{*}{$\begin{array}{l}\text { Spearman rho } \\
\text { p-value }\end{array}$} & 0.780 & 0.665 & 0.602 & 0.563 & 0.119 & 0.682 & & \\
\hline & & $<0.001$ & $<0.001$ & $<0.001$ & $<0.001$ & 0.400 & $<0.001$ & & \\
\hline \multirow[t]{2}{*}{ Total nitrogen as $\mathrm{N}(\mathrm{p} 00600)$} & \multirow{2}{*}{$\begin{array}{l}\text { Spearman rho } \\
\text { p-value }\end{array}$} & 0.739 & 0.748 & 0.800 & 0.522 & 0.737 & 0.859 & 0.502 & \\
\hline & & $<0.001$ & $<0.001$ & $<0.001$ & $<0.001$ & $<0.001$ & $<0.001$ & $<0.001$ & \\
\hline \multirow[t]{2}{*}{ Suspended sediment (p80154) } & \multirow{2}{*}{$\begin{array}{l}\text { Spearman rho } \\
\text { p-value }\end{array}$} & 0.769 & 0.658 & 0.627 & 0.735 & 0.045 & 0.640 & 0.799 & 0.417 \\
\hline & & $<0.001$ & $<0.001$ & $<0.001$ & $<0.001$ & 0.752 & $<0.001$ & $<0.001$ & 0.002 \\
\hline \multicolumn{10}{|c|}{ Interstate 90 near Weston, Massachusetts } \\
\hline \multirow{2}{*}{$\begin{array}{l}\text { Particulate carbon [inorganic } \\
\text { plus organic] (p00694) }\end{array}$} & \multirow{2}{*}{$\begin{array}{l}\text { Spearman rho } \\
\text { p-value }\end{array}$} & 0.845 & & & & & & & \\
\hline & & $<0.001$ & & & & & & & \\
\hline \multirow{2}{*}{$\begin{array}{l}\text { Particulate organic carbon } \\
\quad \text { (p00689) }\end{array}$} & \multirow{2}{*}{$\begin{array}{l}\text { Spearman rho } \\
\text { p-value }\end{array}$} & 0.852 & 0.995 & & & & & & \\
\hline & & $<0.001$ & $<0.001$ & & & & & & \\
\hline \multirow{2}{*}{$\begin{array}{l}\text { Particulate inorganic carbon } \\
\quad \text { (p00688) }\end{array}$} & \multirow{2}{*}{$\begin{array}{l}\text { Spearman rho } \\
\text { p-value }\end{array}$} & 0.680 & 0.660 & 0.614 & & & & & \\
\hline & & $<0.001$ & $<0.001$ & $<0.001$ & & & & & \\
\hline \multirow{2}{*}{$\begin{array}{l}\text { Total dissolved nitrogen as } \mathrm{N} \\
\quad \text { (p62854) }\end{array}$} & \multirow{2}{*}{$\begin{array}{l}\text { Spearman rho } \\
\text { p-value }\end{array}$} & 0.434 & 0.427 & 0.404 & 0.203 & & & & \\
\hline & & 0.003 & 0.003 & 0.007 & 0.192 & & & & \\
\hline \multirow{2}{*}{$\begin{array}{l}\text { Particulate nitrogen as N } \\
\text { (p49570) }\end{array}$} & Spearman rho & 0.772 & 0.906 & 0.905 & 0.618 & 0.507 & & & \\
\hline & $p$-value & $<0.001$ & $<0.001$ & $<0.001$ & $<0.001$ & $<0.001$ & & & \\
\hline Total phosphorus as $\mathrm{P}(\mathrm{p} 00655)$ & Spearman rho & 0.579 & 0.497 & 0.485 & 0.423 & 0.251 & 0.543 & & \\
\hline & $\mathrm{p}$-value & $<0.001$ & $<0.001$ & 0.001 & 0.005 & 0.093 & $<0.001$ & & \\
\hline Total nitrogen as N (p00600) & Spearman rho & 0.750 & 0.818 & 0.808 & 0.529 & 0.748 & 0.927 & 0.512 & \\
\hline & $p$-value & $<0.001$ & $<0.001$ & $<0.001$ & $<0.001$ & $<0.001$ & $<0.001$ & $<0.001$ & \\
\hline Suspended sediment (p80154) & Spearman rho & 0.840 & 0.739 & 0.733 & 0.739 & 0.250 & 0.595 & 0.413 & 0.557 \\
\hline & p-value & $<0.001$ & $<0.001$ & $<0.001$ & $<0.001$ & 0.094 & $<0.001$ & 0.004 & 0.001 \\
\hline
\end{tabular}


Table 13. Results and attained significance levels for Spearman rho tests for concentrations of selected constituents in composite samples of bridge-deck runoff collected at U.S. Geological Survey bridge-deck-monitoring stations on State Route 2A in Boston (422108071052501), Interstate 90 near Weston (422025071154501), and State Route 20 near Quinsigamond Village(421247071470201) in eastern Massachusetts, 2014-16.-Continued

[Locations of stations are shown in figure 1. Shaded areas indicate values that are significant at a 95 -percent confidence interval. The alpha-numeric identifiers starting with "p" are the U.S. Geological Survey parameter codes. P, phosphorus; N, nitrogen; p-value, significance level; <, less than]

\begin{tabular}{|c|c|c|c|c|c|c|c|c|c|}
\hline Constituent & Statistic & $\begin{array}{l}\text { Loss on } \\
\text { ignition } \\
\text { of sus- } \\
\text { pended } \\
\text { solids } \\
\text { (p00535) }\end{array}$ & $\begin{array}{l}\text { Particulate } \\
\text { carbon } \\
\text { [inor- } \\
\text { ganic plus } \\
\text { organic] } \\
\text { (p00694) }\end{array}$ & $\begin{array}{l}\text { Par- } \\
\text { ticulate } \\
\text { organic } \\
\text { carbon } \\
\text { (p00689) }\end{array}$ & $\begin{array}{c}\text { Par- } \\
\text { ticulate } \\
\text { inorganic } \\
\text { carbon } \\
\text { (p00688) }\end{array}$ & $\begin{array}{c}\text { Total } \\
\text { dis- } \\
\text { solved } \\
\text { nitrogen } \\
\text { (p62854) }\end{array}$ & $\begin{array}{c}\text { Par- } \\
\text { ticulate } \\
\text { nitrogen } \\
\text { (p49570) }\end{array}$ & $\begin{array}{c}\text { Total } \\
\text { phos- } \\
\text { phorus } \\
\text { as P } \\
\text { (p00655) }\end{array}$ & $\begin{array}{c}\text { Total } \\
\text { nitrogen } \\
\text { as N } \\
\text { (p00600) }\end{array}$ \\
\hline \multicolumn{10}{|c|}{ State Route 20 near Quinsigamond Village, Massachusetts } \\
\hline \multirow{2}{*}{$\begin{array}{l}\text { Particulate carbon [inorganic } \\
\text { plus organic] (p00694) }\end{array}$} & \multirow{2}{*}{$\begin{array}{l}\text { Spearman rho } \\
\text { p-value }\end{array}$} & 0.874 & & & & & & & \\
\hline & & $<0.001$ & & & & & & & \\
\hline \multirow{2}{*}{$\begin{array}{l}\text { Particulate organic carbon } \\
\text { (p00689) }\end{array}$} & \multirow{2}{*}{$\begin{array}{l}\text { Spearman rho } \\
\text { p-value }\end{array}$} & 0.830 & 0.993 & & & & & & \\
\hline & & $<0.001$ & $<0.001$ & & & & & & \\
\hline \multirow{2}{*}{$\begin{array}{l}\text { Particulate inorganic carbon } \\
\text { (p00688) }\end{array}$} & \multirow{2}{*}{$\begin{array}{l}\text { Spearman rho } \\
\text { p-value }\end{array}$} & 0.677 & 0.659 & 0.624 & & & & & \\
\hline & & $<0.001$ & $<0.001$ & $<0.001$ & & & & & \\
\hline \multirow{2}{*}{$\begin{array}{l}\text { Total dissolved nitrogen as } \mathrm{N} \\
\text { (p62854) }\end{array}$} & \multirow{2}{*}{$\begin{array}{l}\text { Spearman rho } \\
\text { p-value }\end{array}$} & 0.343 & 0.450 & 0.524 & 0.152 & & & & \\
\hline & & 0.015 & 0.001 & $<0.001$ & 0.330 & & & & \\
\hline \multirow{2}{*}{$\begin{array}{l}\text { Particulate nitrogen as } \mathrm{N} \\
\text { (p49570) }\end{array}$} & \multirow{2}{*}{$\begin{array}{l}\text { Spearman rho } \\
\text { p-value }\end{array}$} & 0.834 & 0.937 & 0.931 & 0.558 & 0.548 & & & \\
\hline & & $<0.001$ & $<0.001$ & $<0.001$ & $<0.001$ & $<0.001$ & & & \\
\hline \multirow[t]{2}{*}{ Total phosphorus as P (p00655) } & \multirow{2}{*}{$\begin{array}{l}\text { Spearman rho } \\
\text { p-value }\end{array}$} & 0.762 & 0.733 & 0.678 & 0.725 & 0.214 & 0.658 & & \\
\hline & & $<0.001$ & $<0.001$ & $<0.001$ & $<0.001$ & 0.131 & $<0.001$ & & \\
\hline \multirow[t]{2}{*}{ Total nitrogen as N (p00600) } & \multirow{2}{*}{$\begin{array}{l}\text { Spearman rho } \\
\text { p-value }\end{array}$} & 0.729 & 0.843 & 0.888 & 0.497 & 0.750 & 0.925 & 0.572 & \\
\hline & & $<0.001$ & $<0.001$ & $<0.001$ & 0.001 & $<0.001$ & $<0.001$ & $<0.001$ & \\
\hline \multirow[t]{2}{*}{ Suspended sediment (p80154) } & \multirow{2}{*}{$\begin{array}{l}\text { Spearman rho } \\
\text { p-value }\end{array}$} & 0.783 & 0.735 & 0.661 & 0.827 & 0.082 & 0.621 & 0.831 & 0.484 \\
\hline & & $<0.001$ & $<0.001$ & $<0.001$ & $<0.001$ & 0.572 & $<0.001$ & $<0.001$ & $<0.001$ \\
\hline
\end{tabular}

proportion of sediment in this size fraction on the Interstate 90 may be related to the effect of concrete particles transported in runoff from the degradation of the bridge surface and median barriers that were not present at the other bridges (fig. 18). The mean of the rank-transformed data for TN collected on State Route 20 was significantly higher than the means of the rank-transformed data for the other bridges. Median concentrations of TN were about 93 and 55 percent lower at State Route 2A in Boston and at Interstate 90 near Weston, respectively, compared to the median concentrations of TN at State Route 20 near Quinsigamond Village (table 11). The means of the rank-transformed data for DN and PN for bridge pairs State Route 2A and Interstate 90, and Interstate 90 and State Route 20 were not statistically different; however, test results for the bridge pair State Route 2A and State Route 20 were significant and indicated that the fractional portions of TN were significantly higher at the State Route 20 bridge compared to State Route 2A.

\section{Spatial Distribution of Bridge-Deck Sediment}

Differences in wind current across the bridge, the slope of the bridge, sediment source, and depositional decay of vehicle tracking all can affect the distribution of sediment and associated constituents across each bridge. Samples of sediment were collected from the deck surface of each bridge to determine if sediment transported to the instrumented scupper inlets were representative of sediment mass across the entire bridge-deck surface. Samples of bridge-deck sediment were collected at five evenly distributed locations the entire length of each bridge deck three times between April 2015 and September 2016. These data represent a semiquantitative assessment of the distribution of bridge surface sediment on each bridge at the time of sampling.

Yields of bridge-deck sediment for each of the five sampling locations (table 6) ranged from 26 to 25,000 pounds per curb-mile (lbs/curb-mi). Yields were greatest in April 2015 at the bridge on State Route 2A and State Route 20. The bridge 


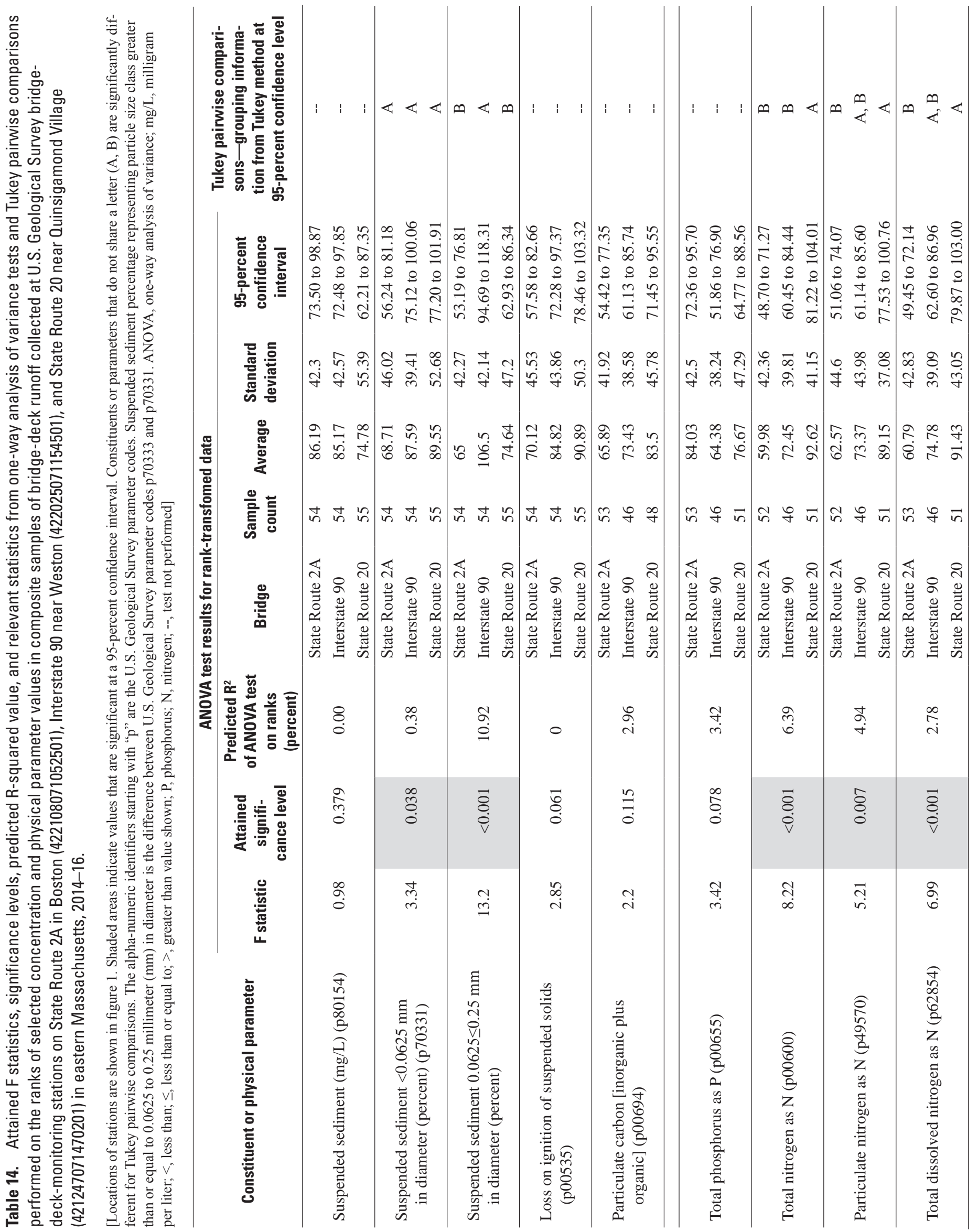



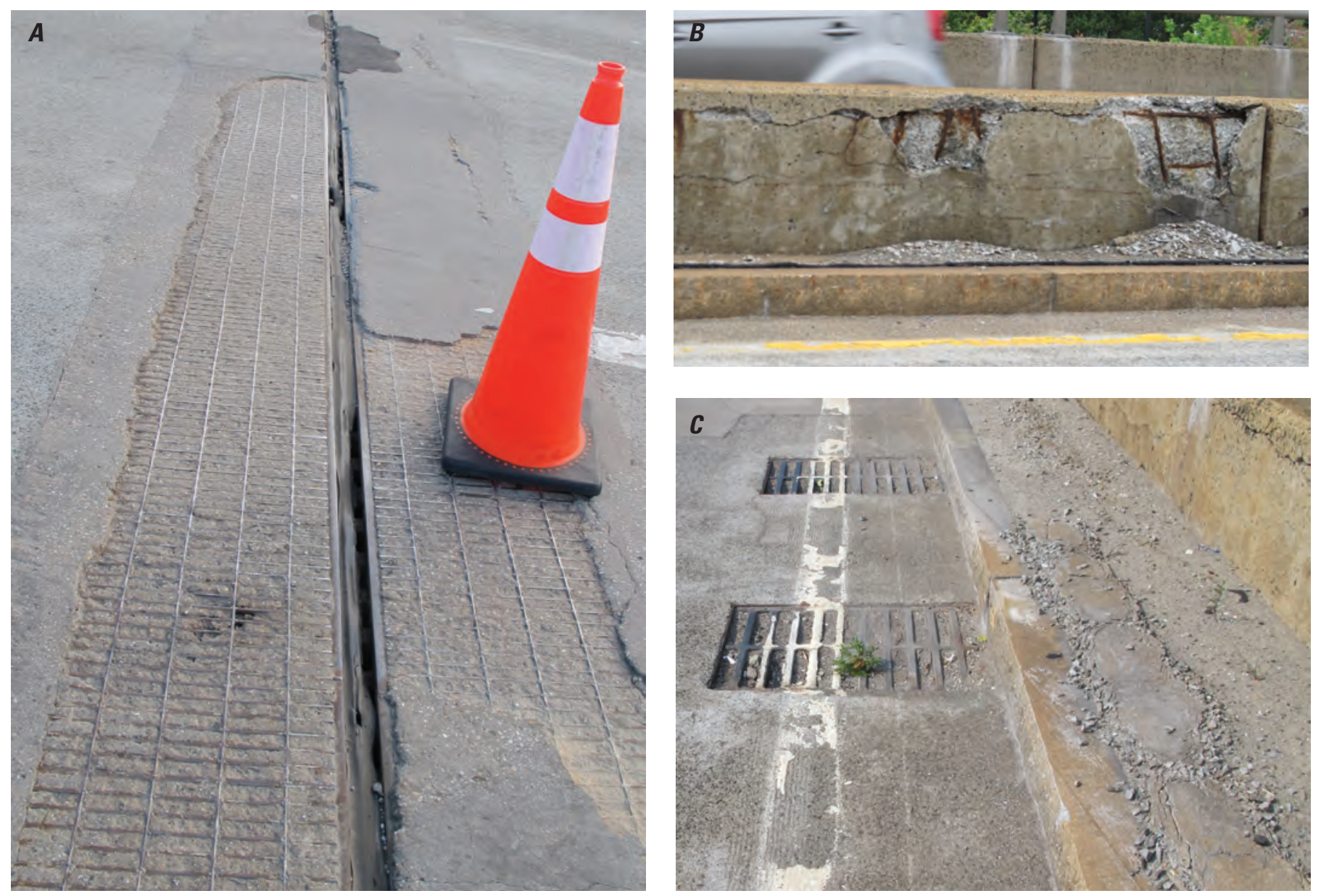

Figure 18. Sediment sources from deterioration of the $A$, bridge-deck surface; $B$, median barrier; and $C$, shoulder area that contributed to the sediment yield on the Interstate 90 bridge near Weston, Massachusetts, 2015-16. Location of bridge is shown on figure 1.

on Interstate 90 was not sampled at this time, but the greatest yields were measured in December 2015. High fluctuations in the sediment mass and yields on the bridge decks were similar to those seen on other types of streets and highway surfaces in the region (Smith, 2002; Breault and others, 2005; Smith and Granato, 2010; Sorenson, 2013).

The mean yields of bridge-deck sediment were 1,500 , 250, and 5,700 lbs/curb-mi for State Route 2A, Interstate 90, and State Route 20, respectively (table 6). The mean yields were only calculated from three events and were heavily affected by the April and December values. Nevertheless, the yields of bridge-deck sediment in this study were similar to those reported in other studies. Mean yields of material on streets in Cambridge, Mass., ranged from 522 to 740 lbs/ curb-mi, and end-of-winter yields ranged from 2,609 to 4,788 lbs/curb-mi (Sorenson, 2013). Selbig and Bannerman (2007) reported residential street-dirt yields of 614 and $569 \mathrm{lbs} /$ curb-mi; Law and others (2008) reported mean streetsolid yields of $645 \mathrm{lbs} / \mathrm{curb}$-mi within an area routinely swept and 1,100 lbs/curb-mi for a control area within their study; and the Seattle Public Utilities and Herrera Environmental Consultants (2009) reported median yields of street solids that ranged from 69 to 2,200 lbs/curb-mi on streets swept twice per month. Yields of bridge-deck sediment (table 6) at each sampling location were normalized to the yield of bridge-deck sediment measured proximate to the monitoring station at each bridge (fig. 19) for greater comparison of the sediment distribution across each bridge.

The State Route $2 \mathrm{~A}$ bridge is the only convex bridge in this study where the center of the bridge is higher in elevation than either side of approach. Although the bridge-deck yields were often variable, normalized bridge-deck sediment yields indicated that the sediment mass often was lower at the fixed sampling location proximate to the monitoring station compared to the other fixed sampling locations (fig. 19A). The mean yield of bridge-deck sediment measured proximate to the monitoring station (680 lbs/curb-mi) on the eastern end (Boston) of the bridge (fig. 1) was 55 percent lower than the mean yield of bridge-deck sediment represented by the sampling locations (1,500 lbs/curb-mi) (table 6). The lower 


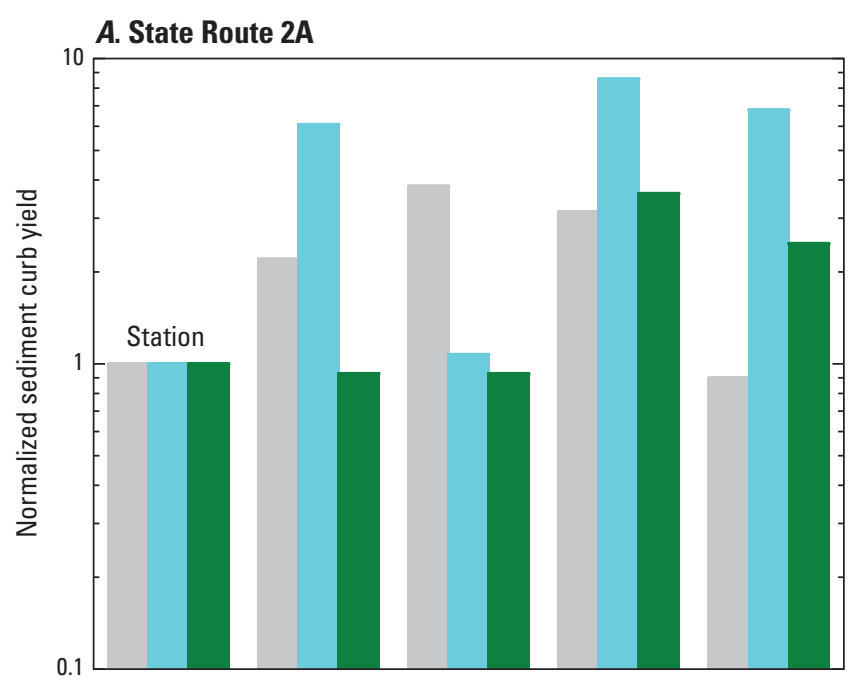

EXPLANATION

Station: location proximate to

bridge-deck-monitoring station

Month and year

April 2015

September 2015

November 2015

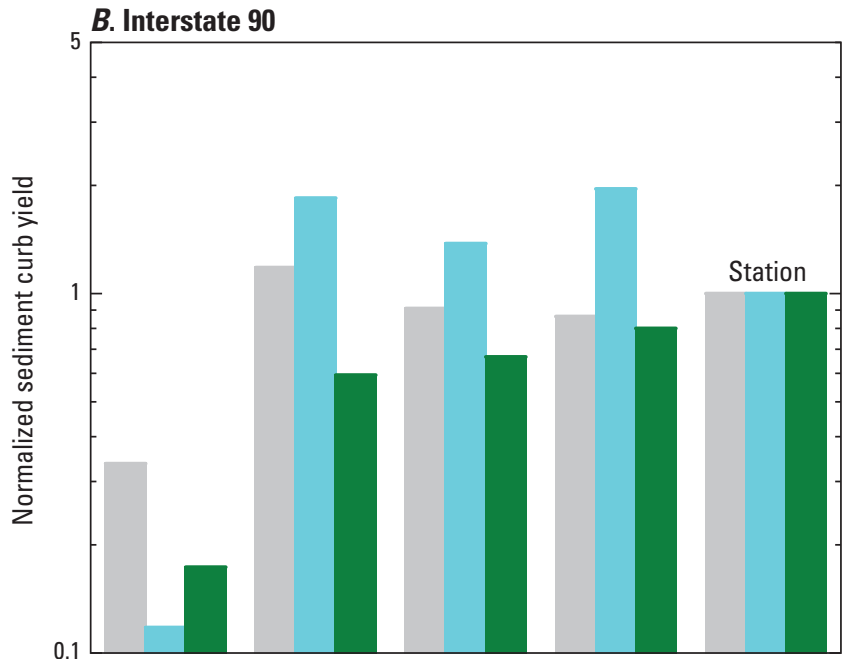

\section{EXPLANATION}

Station: location proximate to bridge-deck-monitoring station

Month and year

September 2015

December 2015

September 2016

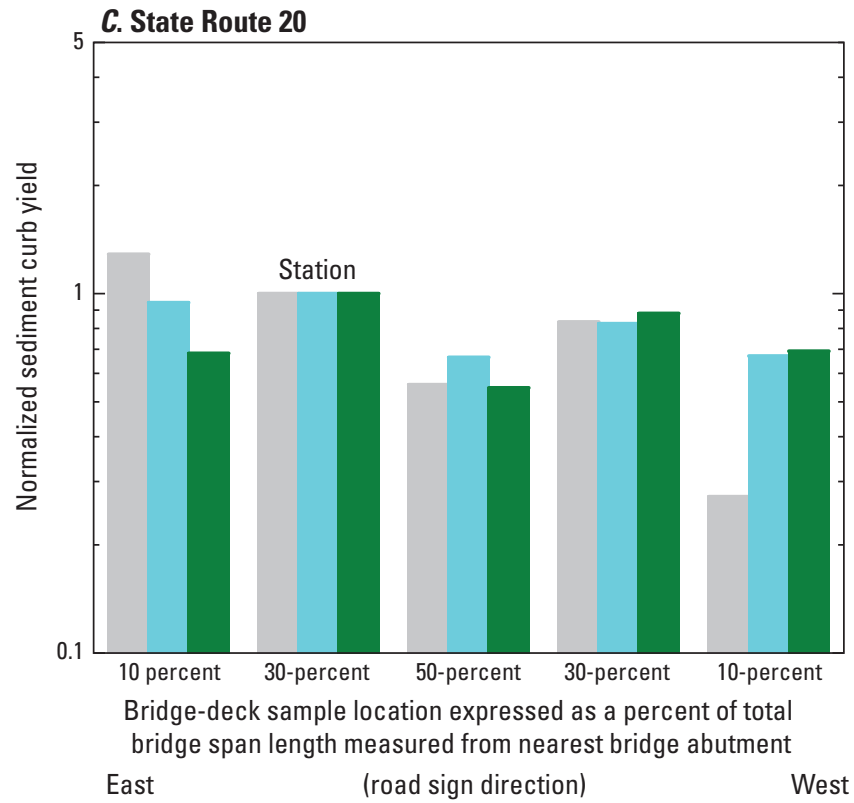

\section{EXPLANATION}

Station: location proximate to

bridge-deck-monitoring station

Month and year

April 2015

August 2015

November 2015

Figure 19. Normalized bridge-deck sediment yields at five fixed locations on three bridges monitored by the U.S. Geological Survey on $A$, State Route 2A in Boston (422108071052501); $B$, Interstate 90 near Weston (422025071154501); and C, State Route 20 near Quinsigamond Village (421247071470201) in eastern Massachusetts, 2015-16. Locations of stations are shown on figure 1. 
bridge-deck sediment yields measured near the monitoring station might be related to depositional decay of vehicle tracking because the traffic flow at the fixed sampling locations is from west to east (city of Cambridge to the city of Boston).

Normalized bridge-deck sediment yields for Interstate 90 were similar for much of the bridge, except for the easternmost location, which was lower in comparison to the four other sampling locations (fig. 19B). The mean yield of bridge-deck sediment measured proximate to the monitoring station on Interstate 90 (240 lbs/curb-mi), located on the most western section of the bridge (fig. 1), was similar to the mean yield of bridge-deck sediment represented by the sampling locations (250 lbs/curb-mi). The distribution of the sediment mass across this bridge was largely related to the contribution of solids from the deterioration of the bridge-deck surface, median barrier, and shoulder area (fig. 18). The elevation of the Interstate 90 bridge decreased from east to west causing the mass of bridge sediments to migrate westward with traffic and runoff and resulting in higher deposits in the western sampling locations. Scupper inlets were often blocked (fig. 18C) on the bridge, which can contribute to the migration of sediments westward.

Normalized bridge-deck sediment yields for State Route 20 near Quinsigamond Village seemed to indicate that the sediment mass decreased from east to west, especially for the April and August 2015 sampling events (fig. 19C). The monitoring station was about one-third of the way across the bridge from the eastern side (fig. 1). The mean yield of bridgedeck sediment proximate to the monitoring station on State Route 20 (7,200 lbs/curb-mi) was about 26 percent higher than the mean yield of bridge-deck sediment representing the sampling locations (5,700 lbs/curb-mi) (table 6). This bridge was constructed in 2005 (Massachusetts Department of Transportation, 2017b) and showed no signs of deterioration that might contribute to the sediment mass on the bridge deck. The roadway approach and the bridge both decreased in elevation from east to west. The distribution of the sediment mass across this bridge likely was the result of wash-on from the roadway upgradient of the bridge (fig. 20). Unlike the Interstate 90 bridge, the materials from the State Route 20 bridge did not seem to substantially contribute to the sediment mass, but sediment yields did diminish westward as the sediment was captured in the scuppers. Similar to Interstate 90, the scupper inlets often were blocked on State Route 20, which caused the sediment mass to propagate farther onto the bridge than it might otherwise if the scupper inlets were always open.

The results from this study and from studies in other areas of the United States discussed previously in this section indicate that street-surface sediment masses and yields can vary widely. The distribution of sediment measured three times at each bridge during this study does not represent a quantitative assessment; however, plausible explanations are described above for the likely causes of the general distribution of the sediment yields measured and observed during this study on each bridge.

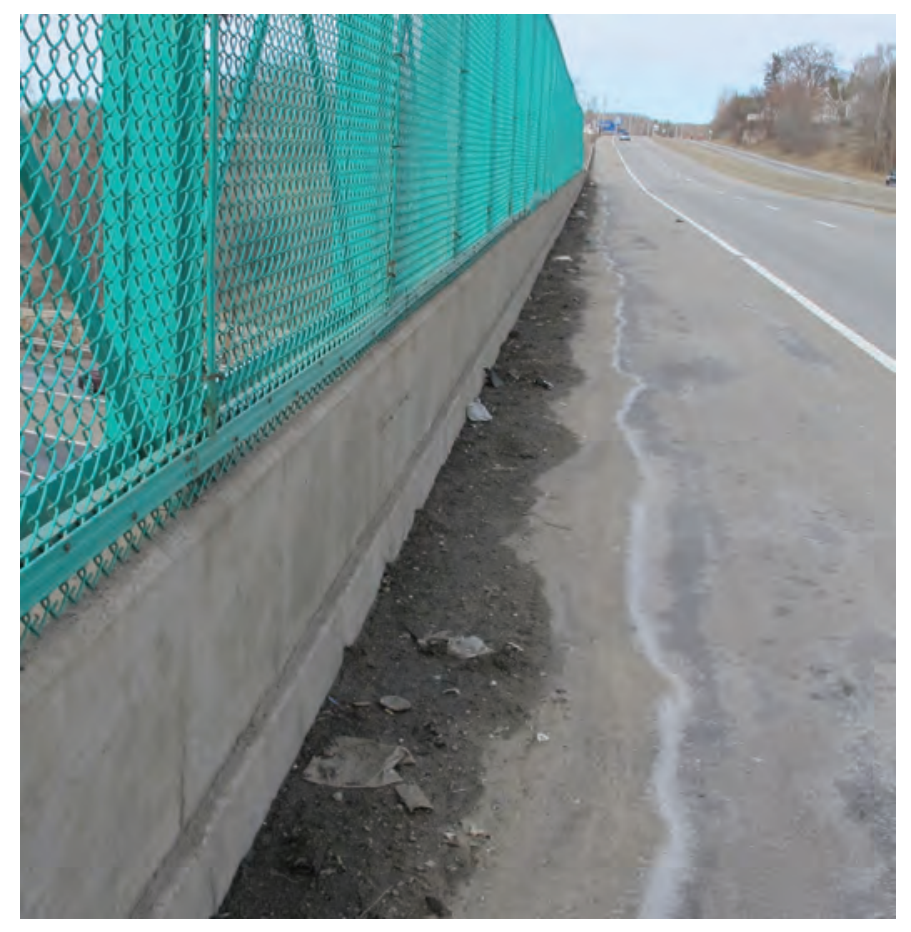

Figure 20. Sediment buildup propagating westward onto the State Route 20 bridge from the upgradient roadway, near Quinsigamond Village, Massachusetts, 2016. Location of bridge is shown on figure 1.

\section{Chemical Analysis of Sediment}

Many trace metals are associated with roadway sediments (Gupta and others, 1981; Smith, 2002; Breault and others, 2005; Smith and Granato, 2010; Sorenson, 2013). An analysis of the particulate fraction of SS in samples of bridge-deck runoff indicated that PC represents about 3 percent of the SS and about 60 percent of TN is associated with the sediment fraction (U.S. Geological Survey, 2016). Natural plant matter, which is directly associated with the PC, also is a source of TP and TN and may contain a greater amount of these nutrients per unit mass compared to mineral sediment alone (Smith and Granato, 2010).

Results of laboratory analysis of sieved sediment samples indicated that bridge-deck sediment contained high concentrations of TP and various metals and that in many cases, the two fractions of sediment less than $0.25 \mathrm{~mm}$ in diameter were more enriched compared to the coarse sediment fraction (table 15). Concentrations of TP in the fine sediment fraction (less than $0.0625 \mathrm{~mm}$ in diameter) were about 6 times greater than in the coarse sediment fraction (greater than or equal to $0.25 \mathrm{~mm}$ in diameter), but concentrations of TP in the intermediate sediment fraction (greater than or equal to 0.0625 to less than $0.25 \mathrm{~mm}$ in diameter) were similar to concentrations in the coarse sediment fraction. Total-recoverable $\mathrm{Cu}$ was not detected at the reporting limit concentration, 7.5 milligrams 


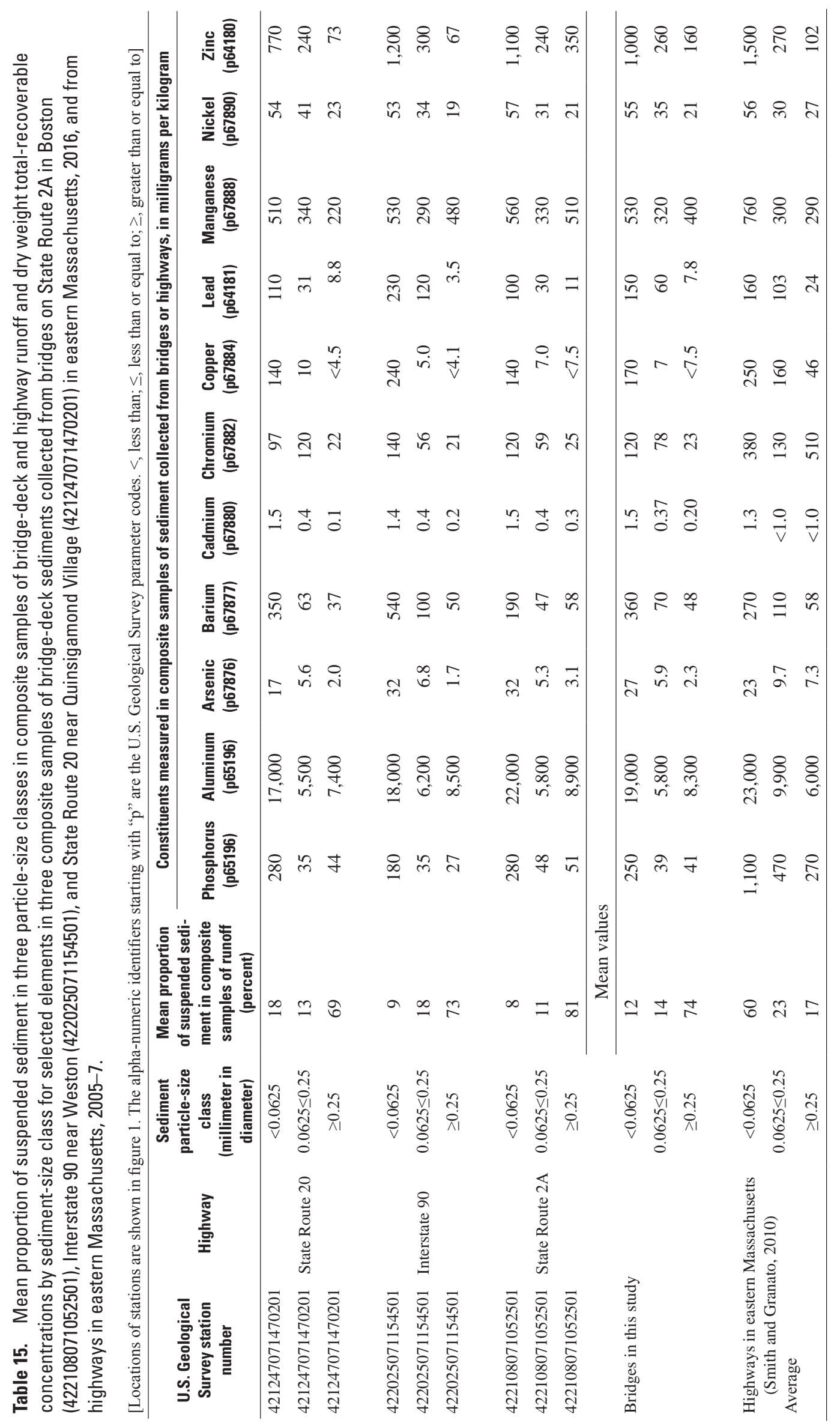


per kilogram or less, in the coarse sediment fraction of samples of bridge-deck sediment collected from any of the bridges. Concentrations of $\mathrm{Cu}$ in the fine sediment fraction were 13 to 47 times more concentrated than concentrations in the intermediate sediment fraction. Total-recoverable concentrations of aluminum (Al), manganese $(\mathrm{Mn})$, and nickel (Ni) were only slightly higher in the fine sediment fraction (less than 2 times higher) than concentrations in the coarse sediment fraction, which were similar or slightly higher than concentrations in the intermediate sediment fraction. Totalrecoverable concentrations for arsenic (As), barium $(\mathrm{Ba})$, cadmium (Cd), Cr, and zinc (Zn) were about 2 to 17 times greater in the fine sediment fraction than concentrations in the coarse sediment fraction. Total-recoverable concentrations of As, $\mathrm{Ba}$, $\mathrm{Cd}, \mathrm{Cr}$, and Zn were generally higher (about 1 to 4 times) in the intermediate sediment fraction than in the coarse sediment fraction. Similar to total-recoverable concentrations of $\mathrm{Cu}$, concentrations of lead $(\mathrm{Pb})$ also were highly associated with the finer sediment fractions where the concentration of $\mathrm{Pb}$ in the fine sediment fraction and the intermediate sediment fraction were about 8 to 65 times greater and about 2 to 33 times greater than the concentration in the coarse sediment fraction, respectively.

These data demonstrate that the proportion of sediment in each particle-size class and sediment chemistry associated with each of these particle-size classes can have a substantial effect on the overall concentration of the various constituents, including TP, in aggregate samples of bridge-deck sediment and in composite samples of bridge-deck runoff containing $\mathrm{SS}$. The overall concentration for a given sample can be estimated from the sum of the product of each sediment particlesize class and associated chemistry (eq. 2). On the basis of the mean proportion of SS in each particle-size class for all three bridges and the mean chemical concentration of each particlesize fraction for the three bridges (table 15), about 54 percent of the estimated sediment-associated TP was associated with the two larger sediment fractions (fig. 21). The cumulative proportion of the concentration of 6 of 10 metals (As, Ba, $\mathrm{Cd}, \mathrm{Cu}, \mathrm{Pb}$, and $\mathrm{Zn}$ ) in the intermediate and coarse sediment fractions was less than 56 percent. About 66 to 84 percent of the concentration of the other 4 of 10 metals (Al, Cr, Mn, and $\mathrm{Ni}$ ) was associated with the intermediate and coarse sediment fractions. Only about 5 percent of the $\mathrm{Cu}$ concentration was associated with the intermediate and coarse sediment fraction.

$$
C=\sum_{i=1}^{n}\left(c_{1}^{*} p_{i}\right)
$$

where
C is the concentration of the selected constituent, in milligrams per kilogram;
$\mathrm{n} \quad$ is the total number of particle-size classes (three in the present study);
i is an index to each particle-size class; c is the mean concentration of the selected

constituent associated with the particle-size class, in milligrams per kilogram; and

$\mathrm{p} \quad$ is the mean proportion of sediment in each particle-size class.

Although the fine sediment fraction generally contains higher concentrations of TP and metals, the proportion of the fine sediment in composite samples of runoff was relatively small in comparison to the two larger sediment fractions (fig. 14). As a result, more than 50 percent of the estimated sediment-associated TP and various metals ( 8 of the 10) may be directly related to the larger mass of the intermediate and coarse sediment fractions (fig. 21) and can potentially be remediated by nonstructural BMPs (such as street sweeping) and by various structural BMPs that operate through settling (Waschbusch, 1999; Smith, 2002). Removal of the finer sediment fraction, though often more difficult, also may be achieved with other structural BMPs (Shoemaker and others, 2000) and high-efficiency street sweepers (Breault and others, 2005; Sorenson, 2013). Unlike structural BMPs that operate during each event, assuming proper maintenance, street sweeping is only a periodic method for removing sediment from the roadway. The State Route 2A bridge in Boston was reported to be swept weekly (weather permitting); however, concentrations of SS were not significantly different compared to the other two bridges that were swept infrequently. This is not an indication that the sweeping practice on the State Route $2 \mathrm{~A}$ bridge is ineffective, but perhaps the bridge-deck sediment buildup or recovery occurs quickly. Breault and others (2005) estimated a street-sediment accumulation rate of about 50 pounds per curb-mile per day and indicated that the coarser size fractions between 0.25 and $2.0 \mathrm{~mm}$ seemed to accumulate most rapidly in New Bedford, Mass., which is similar to the measured conditions at this bridge.

\section{Comparisons of Highway and Bridge- Deck Constituent Concentrations}

The USGS, in cooperation with Federal Highway Administration and the MassDOT, conducted a field study during 2005-7 to characterize the quality of highway runoff for a wide range of constituents throughout Massachusetts (Smith and Granato, 2010). These data included concentrations of SS, TP, and TN collected from catch-basin outlets on highway segments with 100-percent impervious drainage areas. Sample concentrations from highway-monitoring stations on State Route 2 (USGS stations 423027071291301, 423027071291302), Interstate 190 (USGS station 423016071431501), Interstate 495 (USGS stations 422821071332001, 422716071343901), Interstate 95 (USGS stations 422420071153302, 422620071153301), and Interstate 93 (USGS station 421647071024703) (fig. 1), which are in eastern Massachusetts and have similar AADT volumes, were compared to constituent concentrations collected in 


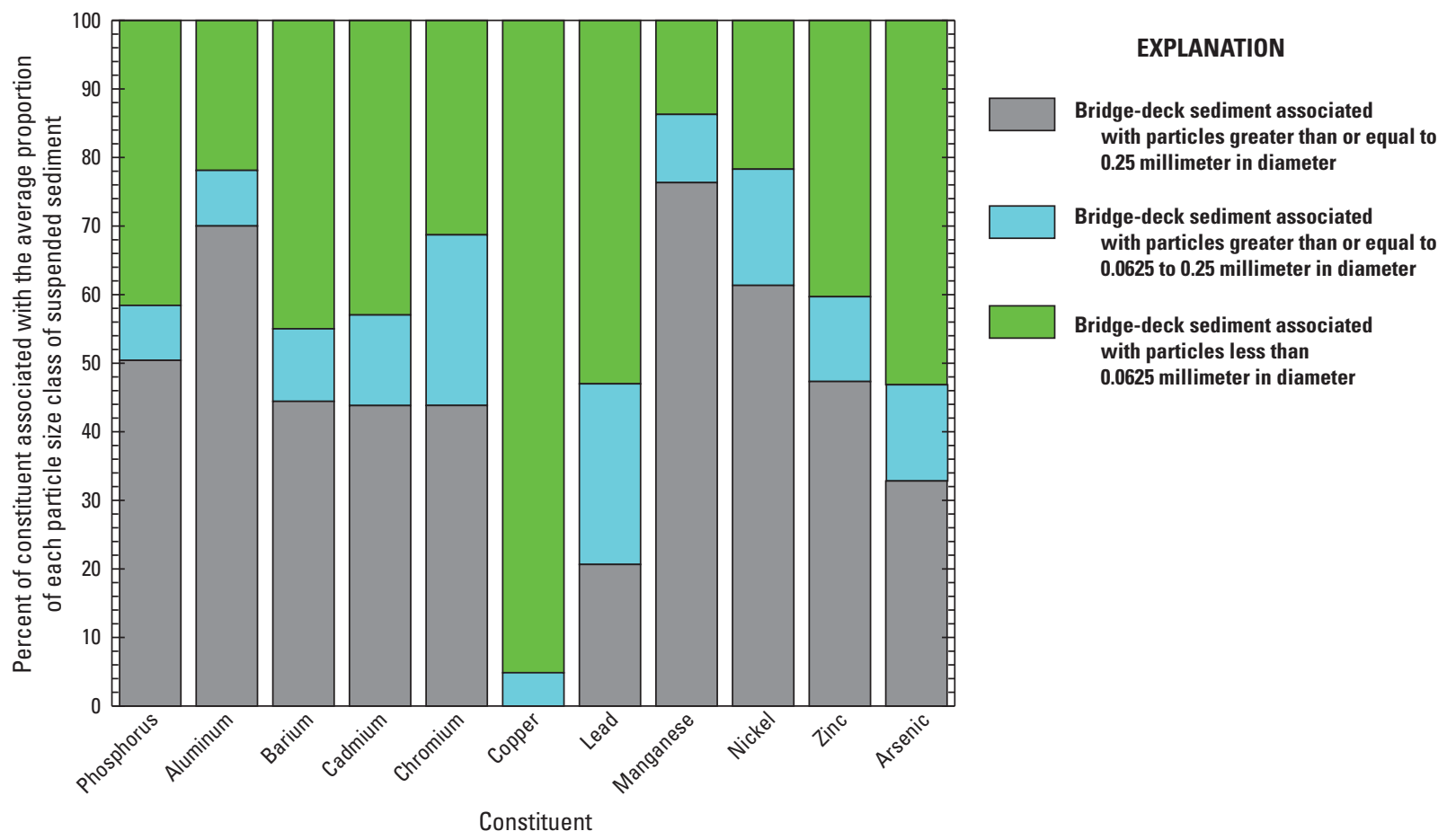

Figure 21. Showing the percentage of the concentration estimated for selected constituents associated with the mean particle size of suspended sediment collected from three bridges monitored by the U.S. Geological Survey on State Route $2 A$ in Boston (422108071052501), Interstate 90 near Weston (422025071154501), and State Route 20 near Quinsigamond Village (421247071470201) in eastern Massachusetts, 2014-16. Locations of stations are shown on figure 1.

the present study. Concentrations of total-recoverable metals in samples of sediment collected from highways in Massachusetts and the bridges in this study also were compared to determine if the 2005-7 total-recoverable metals data are transferable and can be used to expand the number of constituents measured in bridge-deck runoff in Massachusetts.

\section{Suspended Sediment}

Concentrations of SS in samples of bridge-deck runoff were significantly higher (Mann-Whitney test results $p$-values $<0.001$ ) than those collected from the selected highwaymonitoring stations in eastern Massachusetts (table 16). Much of this difference was likely the result of the collection of runoff downstream from catch basins on highways where some portion of the SS was reduced in the runoff, particularly coarse sediments (Smith, 2002), whereas the bridge scuppers provided no SS reduction within the stormwater flow train. Other factors such as high bridge walls adjacent to the roadway (figs. 9A and 20) and median barriers (fig. 18B) may more effectively trap sediment on the bridges compared to highways with low curbing; deterioration of bridge components (fig. 18) and bridge wash-on (fig. 20) also may have contributed to higher concentrations of SS in samples of bridge-deck runoff. The proportion of fine and coarse particle-size fractions also was significantly different ( $p$-values $<0.001$ ) in samples collected from the bridge-deck-monitoring stations compared to the highway-monitoring stations (table 16; fig. 22); however, the proportion of the intermediate sediment-size fraction in bridge-deck runoff was not statistically different than in highway-runoff composite samples. Although the percentage of the fine particle-size fraction of SS in composite samples of bridge-deck runoff (median of 6 percent) was statistically different than in composite samples of highway runoff (median of 60 percent), the range in the concentrations of the fine fraction of SS was not substantially higher than that in the highway dataset compared to the range in concentrations for the two larger sediment-size fractions where the median values were separated by an order of magnitude or more (fig. 22).

Concentrations of SS varied widely in the highwayrunoff dataset, but sample sets generally were statistically similar from highway to highway (Smith and Granato, 2010). Data collected from the bridges in this study indicated that concentrations of SS in all particle-size fractions in untreated bridge-deck runoff were generally higher, particularly in the two larger sediment-size fractions, than concentrations of SS for the respective particle-size fractions in samples collected from highways with catch-basin treatment. Although treatment on par with catch-basin performance may reduce the bridgerunoff SS concentration substantially, such treatment may have little effect on the reduction of fine-grained SS. 
Table 16. Results and attained significance levels ( $p$-values) from Mann-Whitney tests for paired sample sets of constituent concentrations in bridge-deck runoff collected at U.S. Geological Survey bridge-deck-monitoring stations on State Route 2A in Boston (422108071052501), Interstate 90 near Weston (422025071154501), and State Route 20 near Quinsigamond Village (421247071470201) during 2014-16 and in highway runoff collected from U.S. Geological Survey monitoring stations on State Route 2 (USGS stations 423027071291301, 423027071291302), Interstate 190 (USGS station 423016071431501), Interstate 495 (USGS stations 422821071332001, 422716071343901), Interstate 95 (USGS stations 422420071153302, 422620071153301), and Interstate 93 (USGS station 421647071024703) in eastern Massachusetts, 2005-7.

[Locations of stations are shown in figure 1. Shaded areas indicate values that are significant at a 95-percent confidence interval. The alpha-numeric identifiers starting with "p" are the U.S. Geological Survey parameter codes. Suspended sediment percentage representing particle size class greater than or equal to 0.0625 to 0.25 millimeter $(\mathrm{mm})$ in diameter is the difference between U.S. Geological Survey parameter codes p70333 and p70331. Suspended sediment percentage representing particle size class greater than or equal to $0.25 \mathrm{~mm}$ in diameter is the difference greater than U.S. Geological Survey parameter code p70333. mg/L, milligram per liter; $<$, less than; $\leq$, less than or equal to; $\geq$, greater than or equal to; P, phosphorus; N, nitrogen]

\begin{tabular}{|c|c|c|c|c|c|c|c|c|}
\hline \multirow{2}{*}{ Constituent } & \multicolumn{2}{|c|}{ Highway } & \multicolumn{2}{|c|}{ Bridge } & \multirow{2}{*}{$\begin{array}{l}\text { Point } \\
\text { estimate }\end{array}$} & \multirow{2}{*}{$\begin{array}{c}\text { 95-percent } \\
\text { confidence interval }\end{array}$} & \multirow{2}{*}{ W statistic } & \multirow{2}{*}{$p$-value } \\
\hline & Count & Median & Count & Median & & & & \\
\hline Suspended sediment (mg/L) (p80154) & 94 & 87 & 163 & 1,960 & $-1,810$ & $-2,230$ to $-1,320$ & 5,442 & $<0.001$ \\
\hline $\begin{array}{l}\text { Suspended sediment } 0.0625 \leq 0.25 \\
\text { mm in diameter (percent) }\end{array}$ & 94 & 13.5 & 163 & 12.0 & 1.00 & -1.00 to 3.99 & 12,700 & 0.318 \\
\hline $\begin{array}{l}\text { Total phosphorus (mg/L as P) } \\
\quad \text { (p00655) }\end{array}$ & 96 & 0.130 & 150 & 0.575 & 0.450 & -0.530 to -0.380 & 5,642 & $<0.001$ \\
\hline Total nitrogen (mg/L as N) ${ }^{1}(\mathrm{p} 00600)$ & 96 & 1.24 & 103 & 2.10 & -0.720 & -1.10 to 0.380 & 7,777 & $<0.001$ \\
\hline Total nitrogen (mg/L as N)² (p00600) & 96 & 1.24 & 46 & 1.80 & -0.560 & -0.910 to -0.250 & 6,041 & $<0.001$ \\
\hline
\end{tabular}

${ }^{1}$ Bridge data inclusive of State Route $2 \mathrm{~A}$ and Interstate 90.

${ }^{2}$ Bridge data inclusive of State Route 20.

\section{Nutrients}

Concentrations of TP and TN in samples of bridge-deck runoff also were higher compared to the concentrations in samples collected from the selected highway-monitoring stations in eastern Massachusetts (fig. 23). Concentrations of TP in sample sets collected at each of the bridges were significantly higher ( $p$-values $<0.001$ ) than those collected from the highway-monitoring stations (table 16). High concentrations of TP in bridge-deck runoff samples were not unexpected given the high concentrations of SS in the samples. Chemical analysis of bridge-deck sediment indicated that TP was closely associated with the sediments, particularly the fine sediment fraction (table 15).

Concentrations of TN in sample sets collected at each bridge were significantly higher ( $p$-values $<0.001$ ) than those collected from the highway-monitoring stations (table 16). The difference in TN concentrations between the highway and bridge datasets may, in part, be somewhat overstated and affected by analytical method bias. Whole-water concentrations of TN in highway-runoff samples were analyzed by alkaline persulfate digestion (Patton and Kryskalla, 2003). Experimental evidence has since indicated that a negative bias in concentrations of $\mathrm{TN}$ is present across a range of sediment concentrations and increases as SS concentration increases (Rus and others, 2012). As a result, concentrations of TN in the prior highway dataset (Smith and Granato, 2010), particularly samples with high SS concentrations, were likely underestimated. Concentrations of TN in this study were calculated as the sum of DN and PN (table 3), and therefore the negative bias was eliminated. The alkaline persulfate digestion method, when used for samples absent of SS (filtered samples), has a reported precision of 2.3 percent (Rus and others, 2012). The RPDs between concentrations of DN in environment and replicate samples in this study (fig. 12) generally were within this reported precision, indicating that the performance of the method also was acceptable for the sample matrix in this study.

Concentrations of TN in the highway dataset may exhibit a negative bias as a result of method performance during the earlier study (Smith and Granato, 2010); however, this bias may not fully explain the difference in TN concentrations for each study. The substantial difference between concentrations of SS in samples of bridge-deck runoff and highway runoff (fig. 22) also may explain part of the difference in TN concentrations. In this study, most of the TN concentration in samples of bridge-deck runoff consisted of PN, and thus it is likely that the particulate concentration of nitrogen in the highway 


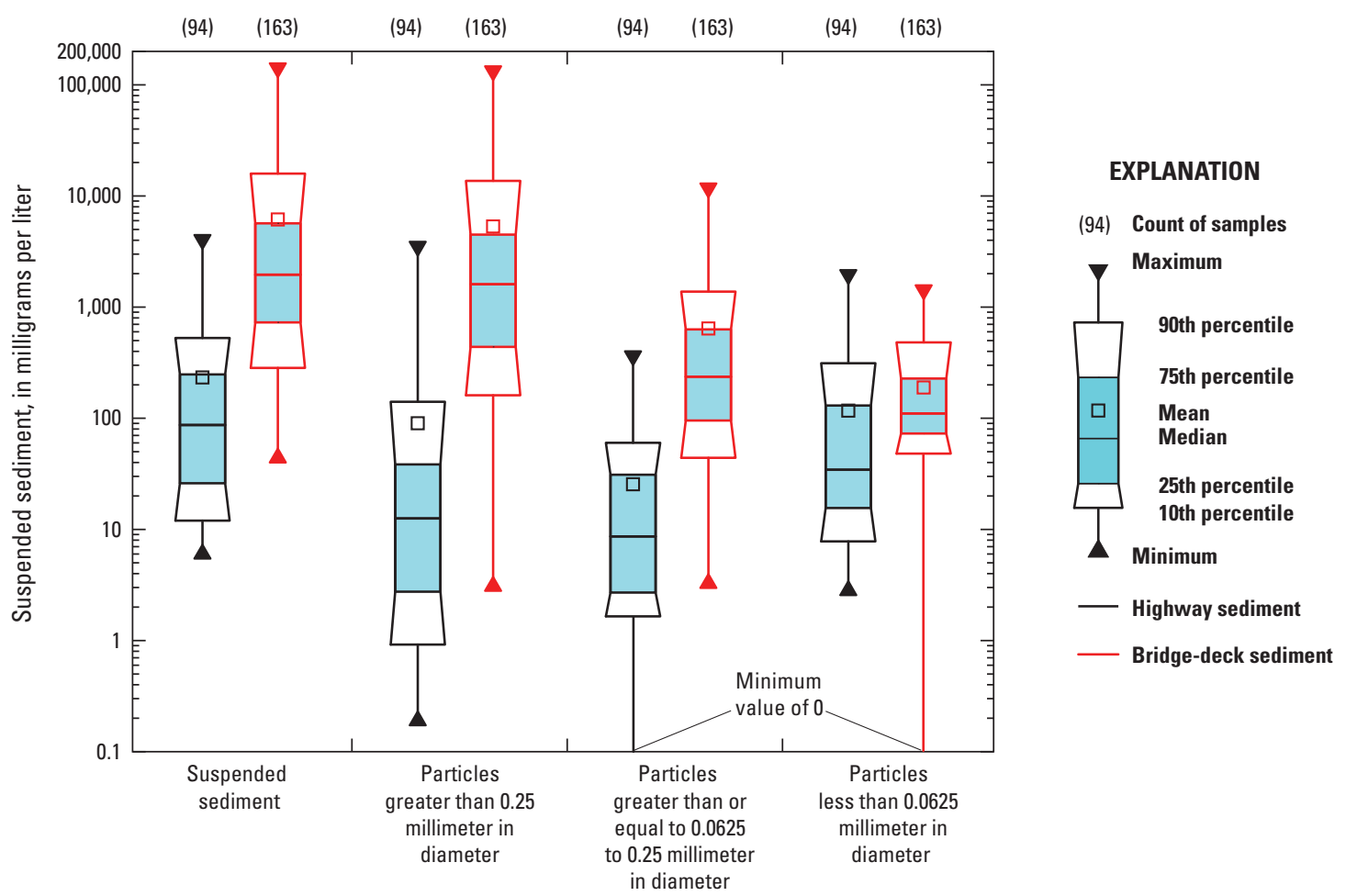

Figure 22. Distribution of concentrations of suspended sediment and the distribution of concentrations of three particle-size classes for suspended sediment in composite samples of highway runoff collected at USGS stations 423027071291301, 423027071291302, 423016071431501, 422821071332001, 422716071343901, 422420071153302, 422620071153301, and 421647071024703 in eastern Massachusetts, 2005-7 (Smith and Granato, 2010), and from three bridge-deck-monitoring stations (422108071052501, 422025071154501, and 421247071470201) in this study, eastern Massachusetts, 2014-16. Locations of stations are shown on figure 1.

samples, which have significantly lower concentrations of SS, also was proportionally lower than the concentrations of PN in the bridge-runoff samples. Therefore, much of the difference between concentrations of TN in the highway and bridge datasets may in fact be realistic.

\section{Sediment Quality}

The quality of bridge-deck sediment from State Route 2A in Boston, Interstate 90 near Weston, and State Route 20 near Quinsigamond Village was compared to the sediment quality measured in three composite samples of highway sediment collected from monitoring stations on State Route 2 in Littleton (USGS stations 423027071291301, 423027071291302), Interstate 495 in Boxborough (USGS stations 422821071332001, 422716071343901), and Interstate 495 in Waltham, Mass. (USGS stations 422420071153302, 422620071153301) (Smith and Granato, 2010) (fig. 1). For each of the three particle-size fractions, concentrations of TP in bridge sediment were lower than concentrations measured in highway sediment (fig. 24). Concentrations of TP in highway sediment were 3 to 5 times greater in the fine fraction and 6 to 40 times greater in the intermediate and coarse fractions compared to concentrations in the same size fractions of bridge-deck sediment. Except for concentrations of $\mathrm{Cr}$, concentrations of total-recoverable metals in the fine fraction of bridge-deck sediment were similar (within 50 percent) to the concentration in the same size fraction of highway sediment (fig. 24A). Concentrations of $\mathrm{Cr}$ were 5 to 17 times greater in the intermediate and coarse fraction of highway sediment in comparison to concentrations in the same respective size fractions in bridge sediment samples (figs. 24B-C). Concentrations of $\mathrm{Cu}$ were as much as 49 times greater in the intermediate fraction of highway sediment in comparison to concentrations in the bridge sediment samples (fig. 24B); Cu was not detected in samples containing the coarse size fraction of bridge sediment.

Although the quality of sediment for each size fraction is important, it is necessary to consider the proportion of sediment in each particle-size fraction within the sample. As was previously discussed in the "Suspended Sediment" section, the concentration of SS, as well as the particle-size distribution, in samples of bridge-deck runoff was significantly different compared to the SS concentration and particle-size distribution in composite samples of highway runoff. To better illustrate the relation, a 1-kilogram synthetic sample was estimated on the basis of the mean SS particle-size distribution and mean 


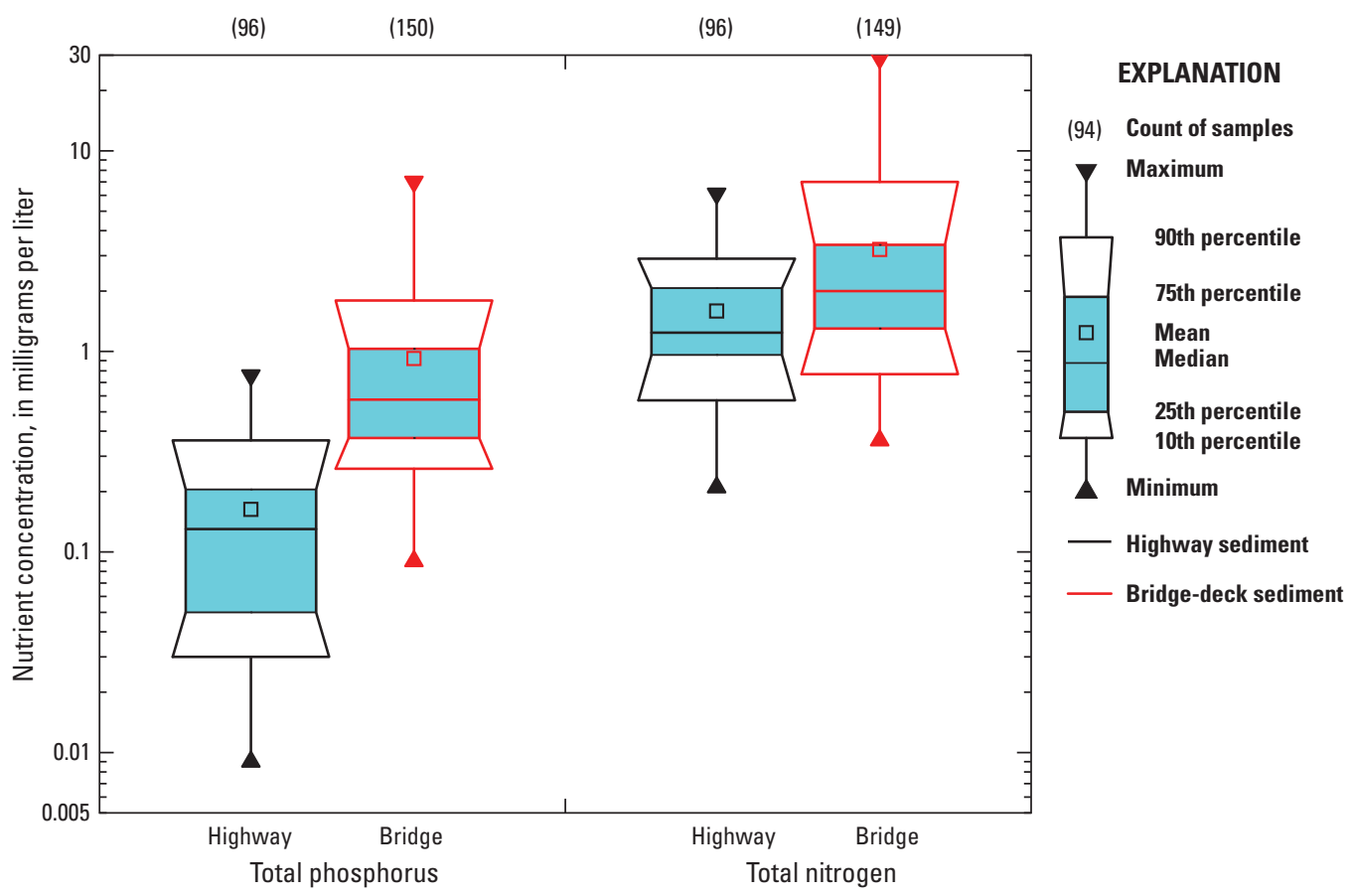

Figure 23. Distribution of total phosphorus and total nitrogen in composite samples of highway runoff collected at USGS stations 423027071291301, 423027071291302, 423016071431501, 422821071332001, 422716071343901, 422420071153302, 422620071153301, and 421647071024703 in eastern Massachusetts, 2005-7 (Smith and Granato, 2010), and from three bridge-deck-monitoring stations (422108071052501, 422025071154501, and 421247071470201) in this study, eastern Massachusetts, 2014-16. Locations of stations are shown on figure 1.

associated constituent concentration for each size fraction (eq. 2; table 15) for bridge deck and highway SS (fig. 25). This simulated sample indicated that the concentrations of TP and trace metals associated with SS in highway runoff were higher than concentrations in the same mass of bridge-deck sediment. The higher concentrations of TP and trace metals (except for $\mathrm{Al}$ ) associated with the highway sediment were the result of a higher proportion of fine to coarse sediment compared to that in bridge-deck sediment and the greater affinity for phosphorus and trace metals to associate with the fine size fraction (fig. 24).

These data demonstrated that the distribution of sediment particle size and associated chemical concentrations in bridge-deck sediment was different compared to highway sediment quality, and that Massachusetts highway-runoff data cannot reliably be used to estimate constituent concentrations and yields of nutrients and trace metals from bridge decks. Where bridge-deck runoff is treated by catch basins or other BMPs that provide similar sediment removal characteristics as present in the highway setting, some trace metal yields for both highway and bridge decks may be similar. As discussed earlier, concentrations associated with specific particle-size classes for many constituents, except for TP, $\mathrm{Cd}, \mathrm{Cr}$, and $\mathrm{Cu}$, were similar in highway and bridge sediments. Therefore, reasonable planning-level concentrations for many trace metals in bridge-deck runoff can be derived from known concentrations of specific trace metals associated with sediments from both studies (Smith and Granato, 2010) and from the average gradated concentrations of SS in the composite samples of runoff collected from the bridges in this study in the absence of site-specific data.

\section{Example Bridge-Deck Runoff Simulations}

SELDM was developed to indicate the risk for stormwater concentrations, flows, and loads to be larger than userselected water-quality goals, the potential need for mitigation measures, and the potential effectiveness of such measures for reducing these risks (Granato, 2013). SELDM is a stochastic model because it uses Monte Carlo methods to produce the random combinations of input variable values needed to generate the stochastic population of values for each component variable. Results are ranked and plotting positions are calculated to indicate the level of risk as a probability of occurrence. SELDM is designed to provide long-term planning-level estimates, which are defined as the results of analyses used to evaluate alternative management measures. 

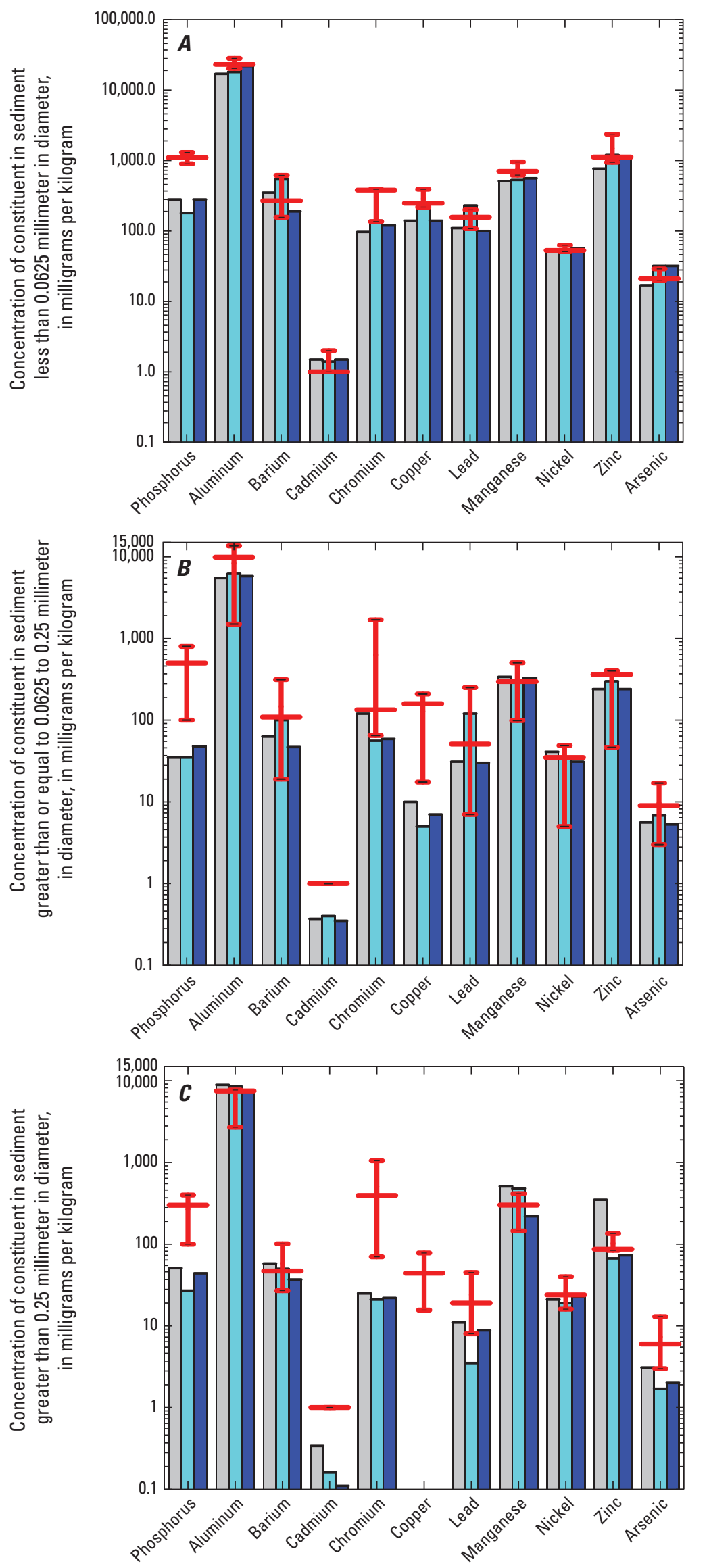

Figure 24. Concentrations of selected elements associated with sediment $A$, less than 0.0625 millimeter $(\mathrm{mm})$ in diameter; $B$, greater than or equal to $0.0625 \mathrm{~mm}$ to $0.25 \mathrm{~mm}$ in diameter; and $C_{\text {, }}$ greater than $0.25 \mathrm{~mm}$ in diameter in three bridgedeck composite samples collected on State Route $2 A$ in Boston (422108071052501), Interstate 90 near Weston (422025071154501), and State Route 20 near Quinsigamond Village (421247071470201) in eastern Massachusetts, 2015-16, in relation to the range of concentrations of selected elements associated with the same grain sizes in highway-runoff sediment from USGS stations 423027071291301 , 423027071291302, 422821071332001, 422716071343901, 422420071153302, and 422620071153301 in eastern Massachusetts, 2005-7 (Smith and Granato, 2010). Locations of stations are shown on figure 1. 


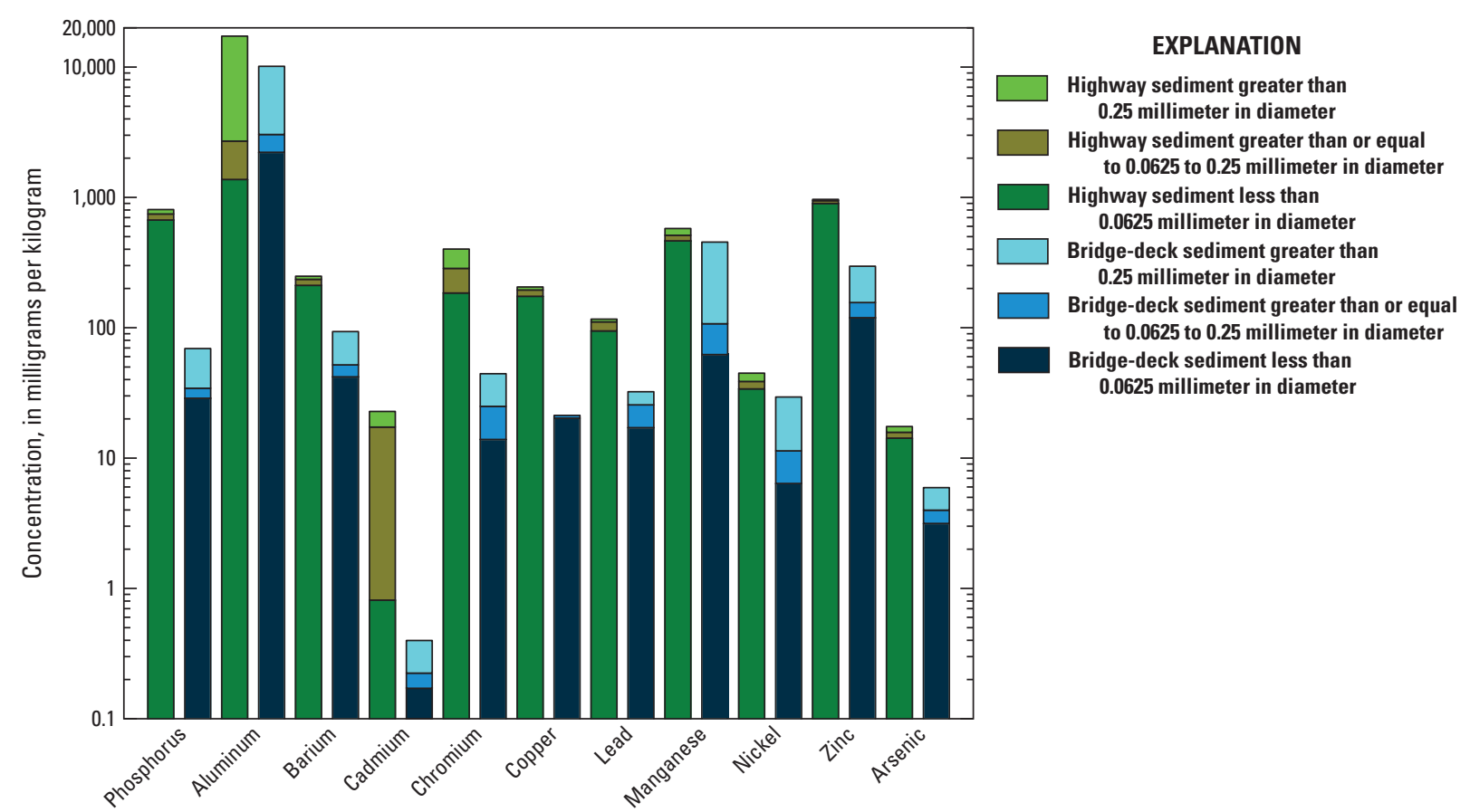

Figure 25. The distribution of concentrations of selected constituents in 1 kilogram of sediment estimated on the basis of the mean concentration of each constituent associated with three particle-size ranges in highway sediment collected from USGS stations 423027071291301, 423027071291302, 422821071332001, 422716071343901, 422420071153302, and 422620071153301 in eastern Massachusetts in 2005-7 (Smith and Granato, 2010) and from bridges on State Route 2A (422108071052501) in Boston, Interstate 90 near Weston (422025071154501), and State Route 20 near Quinsigamond Village (421247071470201) in eastern Massachusetts, 2015-16, and from the mean particle-size distribution of suspended sediment in composite samples of runoff collected at each location. Locations of stations are shown on figure 1.

Planning-level estimates are recognized to include substantial uncertainties, commonly of orders of magnitude (Barnwell and Krenkel, 1982; Marsalek, 1991; Granato, 2013). These uncertainties are especially applicable to stormwater issues because measured flows and concentrations commonly vary by several orders of magnitude, even within monitoring studies with few samples. The SELDM analyses for this study documents the results of simulations that can be used to assess the potential effects of various input concentration statistics on simulated concentrations, provide an example concentration risk analysis, and produce estimates of long-term yields of SS, $\mathrm{TP}$, and TN.

\section{Representativeness of Selected Statistics}

Runoff-concentration statistics are used by SELDM to perform the long-term simulations. The dataset collected for this study has more event-mean composites than most other datasets (Granato and Cazenas, 2009; Smith and Granato, 2010), but generating the long-term simulated record dataset required extrapolation beyond the percentiles of the original data. Concentrations of TP, TN, and SS in bridge-deck samples collected in this study ranged by about 2 orders of magnitude for TP and TN (ranged from 0.09 to $7.02 \mathrm{mg} / \mathrm{L}$ and 0.36 to $29 \mathrm{mg} / \mathrm{L}$, respectively) and almost 4 orders of magnitude for SS (ranged from 44 to 142,000 mg/L) (table 11). Examples of maximum or typical concentrations of phosphorus, nitrogen, and sediment species in environmental samples recorded in the literature also are shown in table 17.

Concentrations of various species of nitrogen and sediment are shown in table 17 because these other species are more commonly measured in highway- and urban-runoff studies. For example, the National Stormwater Quality Database (Pitt and others, 2015) contains 6,156 total Kjeldahl nitrogen (TKN) measurements but only 694 TN concentrations. Similarly, the International BMP Database contains 21,964 total suspended solids measurements but only 1,384 SS concentrations. The maximum TN and TP concentrations measured in this study were comparable to maximum nitrogen and phosphorus concentrations in other highway and urban runoff studies and to weak (low-level) human wastewater concentrations (table 17). The maximum SS concentrations, however, were 2 to 17 times the maximum concentrations measured in other highway and urban runoff studies.

In SELDM, concentrations are simulated by using the frequency-factor method (eq. 3). The frequency factor is calculated using the following equation: 
Table 17. Examples of maximum or typical concentrations of phosphorus, nitrogen, and sediment species in environmental samples recorded in the literature.

[The count in the dataset is provided to compare availability of different water-quality parameters. Precise constituent name parameter codes are not provided because several of the sources provide commonly used constituent names but do not specify the exact definitions. The alpha-numeric identifiers starting with "p" are the U.S. Geological Survey parameter codes. mg/L, milligram per liter; N, nitrogen; total nitrogen (p00600), nitrate plus nitrite (p00631); total Kjeldahl nitrogen (p00625); P, phosphorus; total phosphorus (p00665); SSC, suspended sediment concentration (p80154); TSS, total suspended solids (p00530); EPA, U.S. Environmental Protection Agency; NA, not applicable; HRDB, Highway-Runoff Database, version 1.0.0a; BMPDB, International Stormwater Best Management Practices Database, version 2016-11-17; NSQD, National Stormwater Quality Database, version 4.02; SWQDM, Surface-Water Quality Data Miner; EPA, U.S. Environmental Protection Agency]

\begin{tabular}{|c|c|c|c|c|c|}
\hline Constituent & Water-quality matrix & Value type & $\begin{array}{l}\text { Concentration, } \\
\text { in } \mathrm{mg} / \mathrm{L}\end{array}$ & $\begin{array}{l}\text { Count in } \\
\text { Dataset }\end{array}$ & Source of information \\
\hline \multicolumn{6}{|c|}{ Nitrogen as $\mathrm{N}$} \\
\hline Total nitrogen & Highway runoff & $\begin{array}{l}\text { Maximum } \\
\quad \text { (State Route 2A) }\end{array}$ & 29 & 52 & This study \\
\hline Total nitrogen & Highway runoff & $\begin{array}{l}\text { Maximum } \\
\quad \text { (Interstate 90) }\end{array}$ & 17 & 46 & This study \\
\hline Total nitrogen & Highway runoff & $\begin{array}{l}\text { Maximum } \\
\quad \text { (State Route 20) }\end{array}$ & 18 & 51 & This study \\
\hline Total nitrogen & Highway runoff & Maximum & 6.1 & 164 & HRDB, Smith and Granato, 2010 \\
\hline Nitrite plus nitrate & Highway runoff & Maximum & 9 & 412 & HRDB, Smith and Granato, 2010 \\
\hline Total Kjeldahl nitrogen & Highway runoff & Maximum & 36 & 1,410 & HRDB, Smith and Granato, 2010 \\
\hline Total nitrate & Highway runoff & Maximum & 48 & 1,055 & HRDB, Smith and Granato, 2010 \\
\hline Total nitrogen & Urban runoff & Maximum & 53 & 12,001 & BMPDB, http://www.bmpdatabase.org/ \\
\hline Total nitrogen & Urban runoff & Maximum & 90.1 & 694 & NSQD, Pitt and others, 2015 \\
\hline Total Kjeldahl nitrogen & Urban runoff & Maximum & 200 & 16,195 & BMPDB, http://www.bmpdatabase.org/ \\
\hline Total Kjeldahl nitrogen & Urban runoff & Maximum & 940 & 6,156 & NSQD, Pitt and others, 2015 \\
\hline Total nitrogen & Human wastewater & Typical (weak) & 20 & NA & Peavy and others, 1985 \\
\hline Total nitrogen & Human wastewater & Typical (medium) & 40 & NA & Peavy and others, 1985 \\
\hline Total nitrogen & Human wastewater & Typical (strong) & 85 & NA & Peavy and others, 1985 \\
\hline Total nitrogen & Human wastewater & Typical (weak) & 26 & NA & Gross, 2005 \\
\hline Total nitrogen & Human wastewater & Typical (medium) & 60 & NA & Gross, 2005 \\
\hline Total nitrogen & Human wastewater & Typical (strong) & 75 & NA & Gross, 2005 \\
\hline Total nitrogen & Livestock waste slurry & Typical cattle & 3,000 & NA & Hooda and others, 2000 \\
\hline Total nitrogen & Livestock waste slurry & Typical pig & 5,000 & NA & Hooda and others, 2000 \\
\hline Total nitrogen & Livestock liquid manure & Typical hog & 2,645 & NA & Brown, 2013 \\
\hline Total nitrogen & Livestock liquid manure & Typical dairy & 1,601 & NA & Brown, 2013 \\
\hline Total nitrogen & Livestock liquid manure & Typical beef & 1,543 & NA & Brown, 2013 \\
\hline Total nitrogen & Livestock liquid manure & Typical poultry & 5,567 & NA & Brown, 2013 \\
\hline Total nitrogen & Receiving water & Maximum & 1,500 & 50,160 & SWQDM, Granato and others, 2009 \\
\hline Total nitrogen & Receiving water & $\begin{array}{r}\text { Maximum (EPA } \\
\text { Ecoregion 59) }\end{array}$ & 45 & 3,932 & SWQDM, Granato and others, 2009 \\
\hline
\end{tabular}


Table 17. Examples of maximum or typical concentrations of phosphorus, nitrogen, and sediment species in environmental samples recorded in the literature.-Continued

[The count in the dataset is provided to compare availability of different water-quality parameters. Precise constituent name parameter codes are not provided because several of the sources provide commonly used constituent names but do not specify the exact definitions. The alpha-numeric identifiers starting with "p" are the U.S. Geological Survey parameter codes. mg/L, milligram per liter; N, nitrogen; total nitrogen (p00600), nitrate plus nitrite (p00631); total Kjeldahl nitrogen (p00625); P, phosphorus; total phosphorus (p00665); SSC, suspended sediment concentration (p80154); TSS, total suspended solids (p00530); EPA, U.S. Environmental Protection Agency; NA, not applicable; HRDB, Highway-Runoff Database, version 1.0.0a; BMPDB, International Stormwater Best Management Practices Database, version 2016-11-17; NSQD, National Stormwater Quality Database, version 4.02; SWQDM, Surface-Water Quality Data Miner; EPA, U.S. Environmental Protection Agency]

\begin{tabular}{|c|c|c|c|c|c|}
\hline Constituent & Water-quality matrix & Value type & $\begin{array}{l}\text { Concentration, } \\
\text { in } \mathrm{mg} / \mathrm{L}\end{array}$ & $\begin{array}{l}\text { Count in } \\
\text { Dataset }\end{array}$ & Source of information \\
\hline \multicolumn{6}{|c|}{ Phosphorus as $\mathrm{P}$} \\
\hline Total phosphorus & Bridge-deck runoff & $\begin{array}{l}\text { Maximum } \\
\quad \text { (State Route 2A) }\end{array}$ & 7.02 & 53 & This study \\
\hline Total phosphorus & Bridge-deck runoff & $\begin{array}{l}\text { Maximum } \\
\quad \text { (Interstate 90) }\end{array}$ & 3.16 & 46 & This study \\
\hline Total phosphorus & Bridge-deck runoff & $\begin{array}{l}\text { Maximum } \\
\quad \text { (State Route 20) }\end{array}$ & 6.02 & 51 & This study \\
\hline Total phosphorus & Highway runoff & Maximum & 17 & 1,439 & HRDB, Smith and Granato, 2010 \\
\hline Total phosphorus & Urban runoff & Maximum & 80.2 & 7,232 & NSQD, Pitt and others, 2015 \\
\hline Total phosphorus & Urban runoff & Maximum & 80.2 & 20,258 & BMPDB, http://www.bmpdatabase.org/ \\
\hline Total phosphorus & Human wastewater & Typical (weak) & 4 & NA & Peavy and others, 1985 \\
\hline Total phosphorus & Human wastewater & Typical (medium) & 8 & NA & Peavy and others, 1985 \\
\hline Total phosphorus & Human wastewater & Typical (strong) & 15 & NA & Peavy and others, 1985 \\
\hline Total phosphorus & Human wastewater & Typical (weak) & 6 & NA & Gross, 2005 \\
\hline Total phosphorus & Human wastewater & Typical (medium) & 10 & NA & Gross, 2005 \\
\hline Total phosphorus & Human wastewater & Typical (strong) & 12 & NA & Gross, 2005 \\
\hline Total phosphorus & Livestock waste slurry & Typical cattle & 520 & NA & Hooda and others, 2000 \\
\hline Total phosphorus & Livestock waste slurry & Typical pig & 1,310 & NA & Hooda and others, 2000 \\
\hline Total phosphorus & Livestock liquid manure & Typical hog & 814 & NA & Brown, 2013 \\
\hline Total phosphorus & Livestock liquid manure & Typical dairy & 369 & NA & Brown, 2013 \\
\hline Total phosphorus & Livestock liquid manure & Typical beef & 317 & NA & Brown, 2013 \\
\hline Total phosphorus & Livestock liquid manure & Typical poultry & 1,924 & NA & Brown, 2013 \\
\hline Total phosphorus & Receiving water & Maximum & 640 & 246,403 & SWQDM, Granato and others, 2009 \\
\hline Total phosphorus & Receiving water & $\begin{array}{r}\text { Maximum (EPA } \\
\text { Ecoregion 59) }\end{array}$ & 9 & 10,644 & SWQDM, Granato and others, 2009 \\
\hline
\end{tabular}


Table 17. Examples of maximum or typical concentrations of phosphorus, nitrogen, and sediment species in environmental samples recorded in the literature.-Continued

[The count in the dataset is provided to compare availability of different water-quality parameters. Precise constituent name parameter codes are not provided because several of the sources provide commonly used constituent names but do not specify the exact definitions. The alpha-numeric identifiers starting with "p" are the U.S. Geological Survey parameter codes. mg/L, milligram per liter; N, nitrogen; total nitrogen (p00600), nitrate plus nitrite (p00631); total Kjeldahl nitrogen (p00625); P, phosphorus; total phosphorus (p00665); SSC, suspended sediment concentration (p80154); TSS, total suspended solids (p00530); EPA, U.S. Environmental Protection Agency; NA, not applicable; HRDB, Highway-Runoff Database, version 1.0.0a; BMPDB, International Stormwater Best Management Practices Database, version 2016-11-17; NSQD, National Stormwater Quality Database, version 4.02; SWQDM, Surface-Water Quality Data Miner; EPA, U.S. Environmental Protection Agency]

\begin{tabular}{|c|c|c|c|c|c|}
\hline Constituent & Water-quality matrix & Value type & $\begin{array}{l}\text { Concentration, } \\
\text { in } \mathrm{mg} / \mathrm{L}\end{array}$ & $\begin{array}{l}\text { Count in } \\
\text { Dataset }\end{array}$ & Source of information \\
\hline \multicolumn{6}{|c|}{ Suspended sediment and solids } \\
\hline SSC & Highway runoff & $\begin{array}{l}\text { Maximum } \\
\quad \text { (State Route 2A) }\end{array}$ & 60,000 & 55 & This study \\
\hline SSC & Highway runoff & $\begin{array}{l}\text { Maximum } \\
\quad \text { (Interstate 90) }\end{array}$ & 142,000 & 54 & This study \\
\hline SSC & Highway runoff & $\begin{array}{l}\text { Maximum } \\
\quad \text { (State Route 20) }\end{array}$ & 38,700 & 54 & This study \\
\hline SSC & Highway runoff & Maximum & 8,580 & 431 & HRDB, Smith and Granato, 2010 \\
\hline TSS & Highway runoff & Maximum & 5,100 & 2,253 & HRDB, Smith and Granato, 2010 \\
\hline SSC & Urban runoff & Maximum & 8,580 & 1,384 & BMPDB, http://www.bmpdatabase.org/ \\
\hline TSS & Urban runoff & Maximum & 10,505 & 21,964 & BMPDB, http://www.bmpdatabase.org/ \\
\hline TSS & Urban runoff & Maximum & 10,700 & 6,695 & NSQD, Pitt and others, 2015 \\
\hline TSS & Human wastewater & Typical (weak) & 100 & NA & Peavy and others, 1985 \\
\hline TSS & Human wastewater & Typical (medium) & 200 & NA & Peavy and others, 1985 \\
\hline TSS & Human wastewater & Typical (strong) & 350 & NA & Peavy and others, 1985 \\
\hline TSS & Human wastewater & Typical (weak) & 155 & NA & Gross, 2005 \\
\hline TSS & Human wastewater & Typical (medium) & 250 & NA & Gross, 2005 \\
\hline TSS & Human wastewater & Typical (strong) & 330 & NA & Gross, 2005 \\
\hline SSC & Receiving water & $\begin{array}{l}\text { Maximum (post } \\
\text { volcanic erup- } \\
\text { tion) }\end{array}$ & $1,770,000$ & 2,904 & SWQDM, Granato and others, 2009 \\
\hline SSC & Receiving water & $\begin{array}{l}\text { Maximum } \\
\quad \text { (nonvolcanic) }\end{array}$ & 966,000 & 273,046 & SWQDM, Granato and others, 2009 \\
\hline SSC & Receiving water & $\begin{array}{r}\text { Maximum (EPA } \\
\text { Ecoregion 59) }\end{array}$ & 640 & 3,546 & SWQDM, Granato and others, 2009 \\
\hline
\end{tabular}




$$
\log \left(C_{i}\right)=A v g+S D \times K_{i}
$$

where

$\mathrm{i}$ is the individual simulated value, which
ranges from one to the number of
simulated storm events;
$\mathrm{C}_{i}$ is the ith simulated concentration;
Avg is the average of the logarithms of
concentration;
$\mathrm{SD}$ is the standard deviation of the logarithms of
concentration; and
$\mathrm{K}_{\mathrm{i}} \quad$ is the Pearson type III random variate.

The calculated average value (Avg) sets the magnitude of the center of the simulated sample. The magnitude of the SD controls the variation of concentrations above and below the average; larger SD values will result in a larger range in simulated values. The Pearson type III random variate $\left(\mathrm{K}_{\mathrm{i}}\right)$, which is a function of the skew (Interagency Advisory Committee on Water Data, 1982; Chow and others, 1988; Granato, 2013), is the value generated by SELDM. If the skew is equal to zero, then $\mathrm{K}_{\mathrm{i}}$ is a normal random variate. The SELDM simulations that use precipitation statistics from ecoregion 59 (the Northeastern Coastal Zone) result in about 1,680 events. In theory, the associated range of normal $\mathrm{K}_{\mathrm{i}}$ values would be about plus or minus 3.24 for this number of events. SELDM, however, generates $\mathrm{K}_{\mathrm{i}}$ values randomly, and more extreme $\mathrm{K}_{\mathrm{i}}$ values may be generated in any simulation. If the skew is nonzero then the $\mathrm{K}_{\mathrm{i}}$ values will be skewed (Interagency Advisory Committee on Water Data, 1982; Chow and others, 1988), which increases the probability that extreme $\mathrm{K}_{\mathrm{i}}$ values may be generated (Granato, 2013).

To understand why very extreme outliers may not have very extreme percentiles, it is important to understand that the plotting positions written to the output files by SELDM are the sample statistics, calculated from the ranks of the output values rather than the population statistics, which are the percentiles based on the random number that is generated. However, it is the magnitude of SD values that controls the effect of $\mathrm{K}_{\mathrm{i}}$ values on simulated concentrations. Therefore, statistics used for simulation data must be carefully selected because these high concentrations, measured within a 2-year study, will be used to simulate a 29 to 30 year period. If conditions during the study period resulted in uncharacteristically high or low concentrations, then the probability of occurrence based on sample statistics may be inflated in comparison to the actual population statistics. For example, if a streamgage is established and operated for 5 years and the 100-year flood (a flood magnitude with an actual exceedance risk of about 1 percent) occurs, the sample statistics would indicate that that measured flood-flow magnitude would have an exceedance risk of about 17 percent based on the 5 available annual-flood values.

The average, SD, and skew of the common (base 10) logarithms of event-mean concentrations in composite samples of bridge-deck runoff calculated by using the traditional statistics and the robust statistics are shown in table 18. The medians of each statistic, which in theory may be the best estimates of runoff quality from any randomly selected unmonitored bridge in the State, are also shown in table 18. The median of the statistics may include the average from one site, the SD from another, and the skew from the third site; therefore, concentrations simulated by using these statistics may not represent the data from any particular site. Statistics for the lumped data, which may better represent the exceedance risk of the highest and lowest concentrations if the individual site datasets come from the same population of bridge-runoff quality (the samples from different bridges are not statistically different), also are documented in table 18. Concentrations of SS and TP in sample sets for the bridge in this study were not significantly different. Concentrations of nitrogen in samples of bridge-deck runoff were lowest at State Route 2A in Boston and highest at State Route 20 near Quinsigamond Village; concentrations of TN were significantly higher for State Route 20 than for the other two bridges (table 14). As with the median statistics, simulations made by using the lumped statistics may not represent values from a particular site, but if lumping the data represents the probability of exceedance for the highest and lowest concentrations, results may be more realistic than statistics from the individual datasets.

Information about the uncertainty in the sample statistics is also included in table 18. The standard error of the estimate and the 95-percent confidence interval of the average, SD, and skew of the traditional statistics were calculated by using methods specified by the Interagency Advisory Committee on Water Data (1982). The 95-percent confidence intervals for each statistic indicate if the statistics calculated by using the different methods and by using the lumped data are significantly different from the values calculated by using traditional methods. The values of the average and SD calculated by using the robust alternative methods were within the 95-percent confidence intervals of the associated statistics calculated by using traditional methods. The values of Pearson's second skew calculated by using the robust statistics also were within the 95-percent confidence intervals of skews calculated by using traditional methods, except for the second skew of TN and TP for the State Route 2A monitoring station and TN for the lumped data (table 18). Statistics for the median values were within the 95-percent confidence intervals of the other statistics calculated with data from individual sites (table 18). Although the statistics were not significantly different, there were substantial differences among the values that affected the outcomes of long-term simulations.

The effects of selected statistics (table 18) on simulated TN concentrations are shown in figure 26. The effects of the large positive skew of the traditional TN statistics for data from the monitoring stations on State Routes 20 and 2A are evident in the fact that the distribution of simulated concentrations was concave up, which contributed to the high outlier values of 130 and $245 \mathrm{mg} / \mathrm{L}$ (fig. 26A). These values were higher than maximum values of TN in published highway and urban runoff datasets (table 17). The simulated values were comparable to typical values of "strong" human wastewater but were within the maximum values for urban runoff (table 


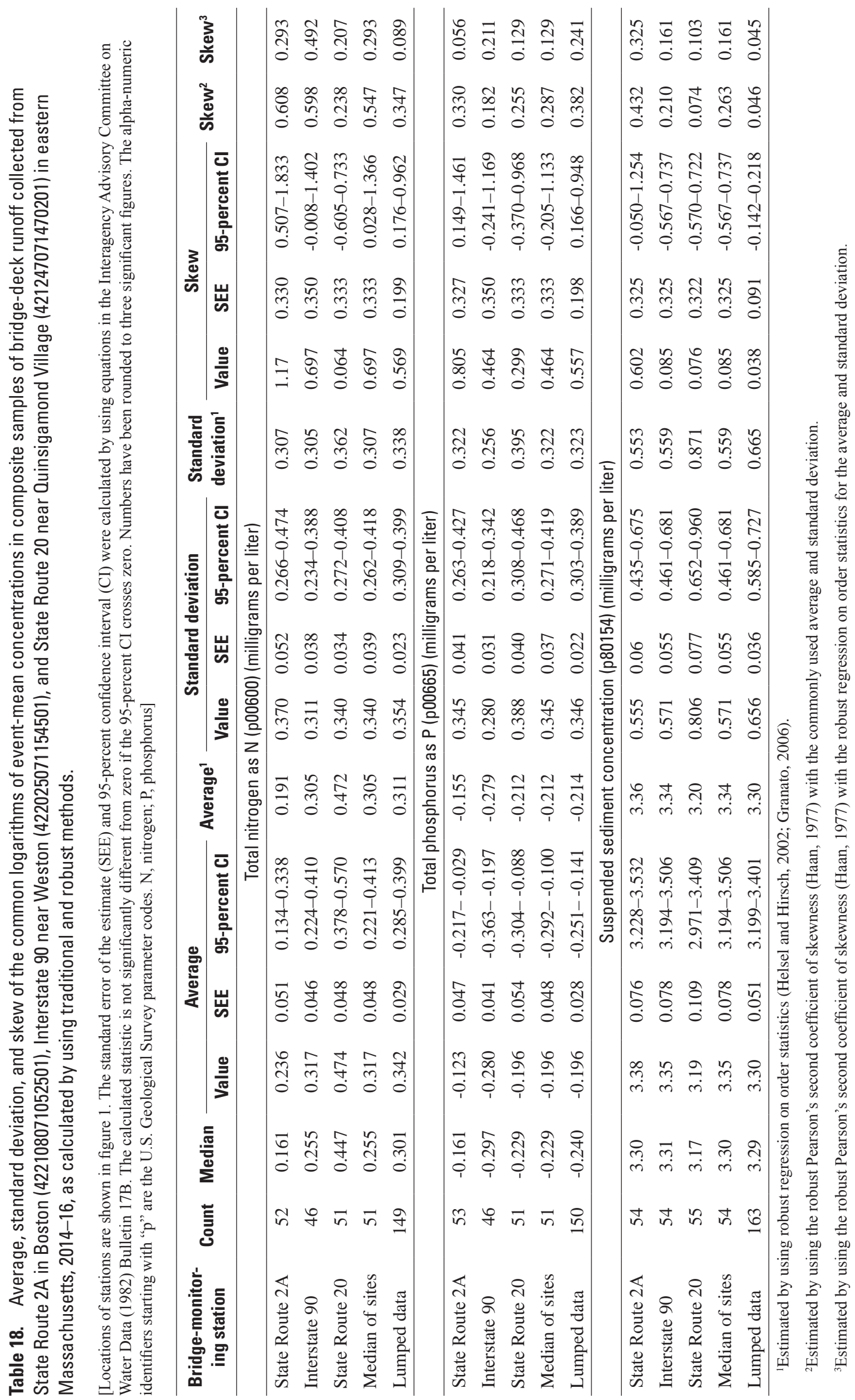




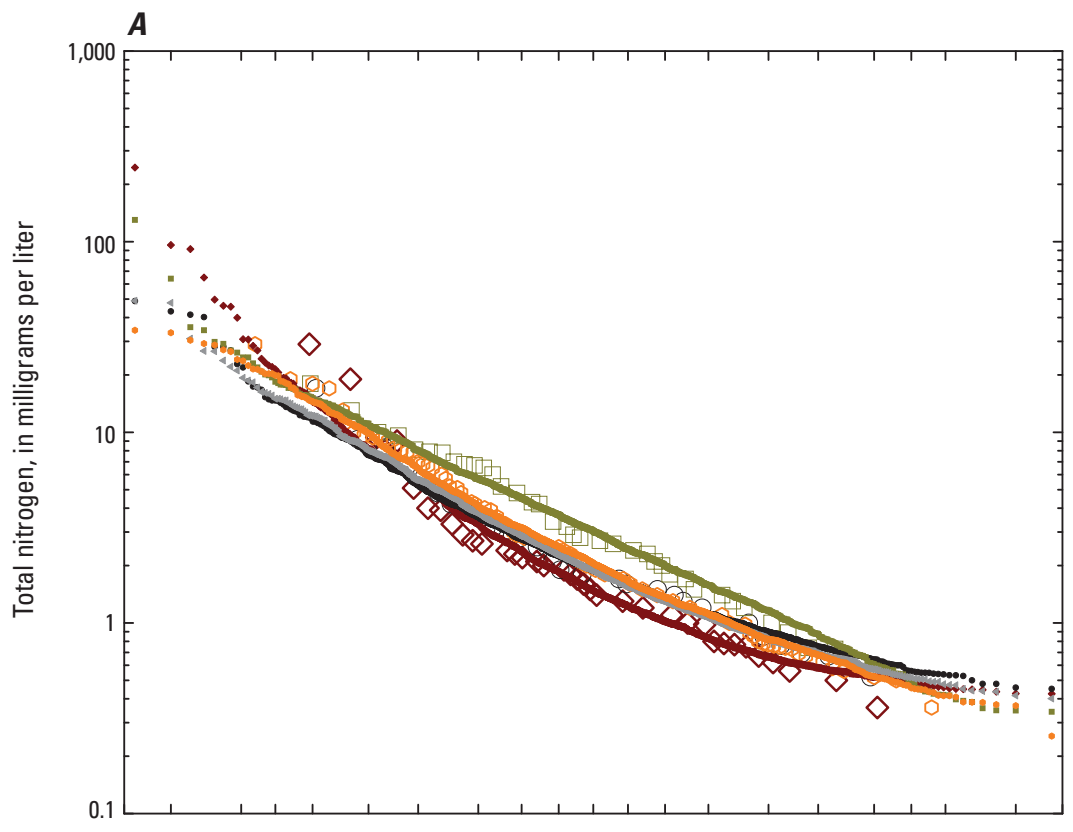

\section{EXPLANATION}

$\diamond \quad$ State Route 2A (422108071052501) data

Interstate 90 (422025071154501) data

$\square \quad$ State Route 20 (421247071470201) data

- Lumped data

- Simulation of State Route 2A data

- Simulation of Interstate 90 data

- Simulation of State Route 20 data

Simulation of runoff quality with the median

- Simulation of lumped data

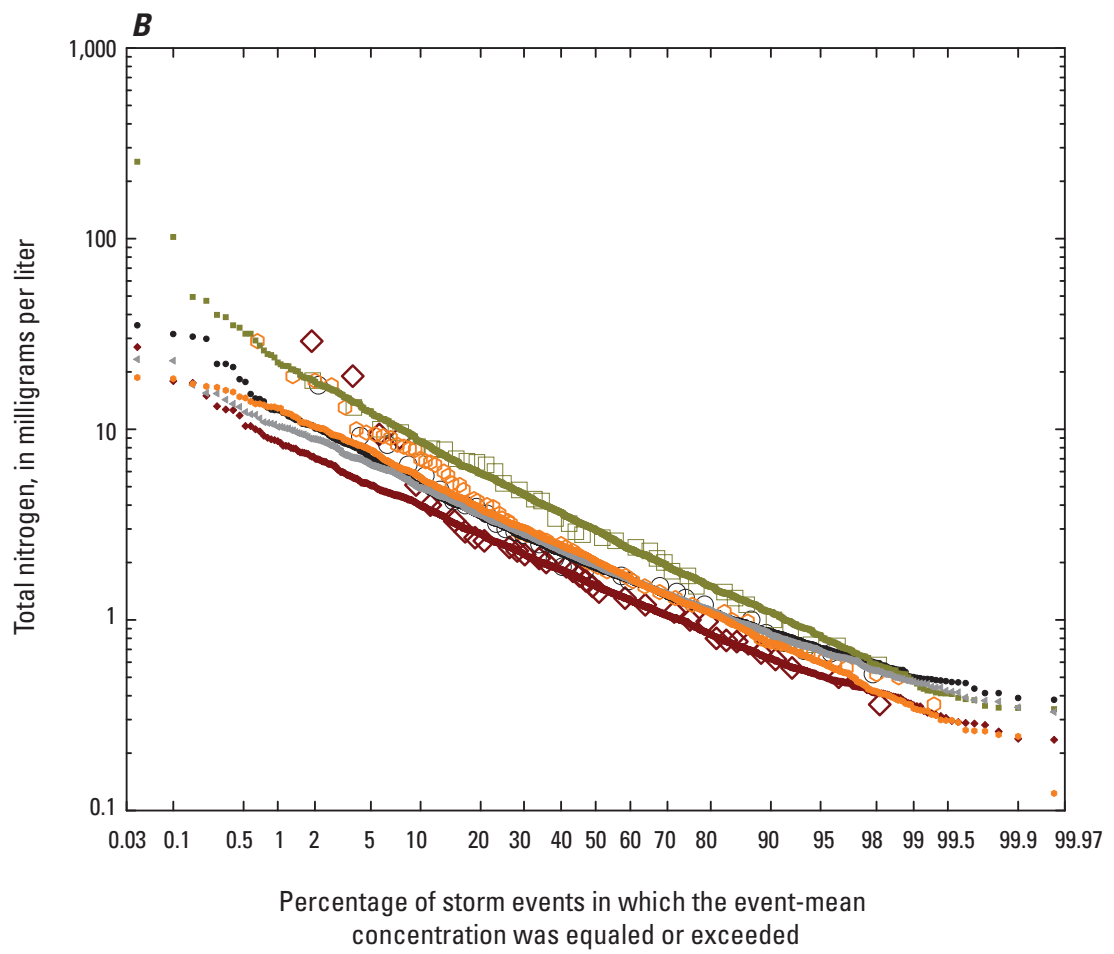

Figure 26. Measured total nitrogen concentrations and concentrations simulated by using $A$, traditional statistics and $B$, statistics calculated by using robust alternative methods. The selected statistics are shown in table 18. 
17). These values were, however, well within TKN concentrations measured in urban runoff. In theory TN concentrations should be greater than or equal to TKN concentrations; the higher TKN values reflect the fact that there are many more TKN than TN values in the highway and urban-runoff databases (table 17). The high urban-runoff concentrations may represent the effects of fertilizer application in urban areas that were not typical of conditions within the highway right-ofway. The simulations performed using the lumped data and simulated statistics shown in table 18 indicated that the two largest measured values (19 and $29 \mathrm{mg} / \mathrm{L}$ ) from the current study may be outliers with actual exceedance probabilities that were smaller than would be assumed by the sample size. In comparison, the robust skew statistic for data from the monitoring station on State Route 20 was higher than the skew calculated by using traditional methods, which resulted in a high outlier for the robust alternative simulation for the bridge on State Route 20 (fig. 26B). In this case, the maximum simulated value for bridge-deck runoff from State Route 20 was $253 \mathrm{mg} / \mathrm{L}$. With the exception of the two outliers (130 and $245 \mathrm{mg} / \mathrm{L}$ ) in the State Route 20 monitoring station dataset, the robust alternatives produced simulated populations that were representative of the data and that were more consistent with highway-runoff maxima from other studies in the HRDB than the simulations done with the classic statistics. Unlike urban areas, which may be fertilized, bridge decks may have a limited source of nitrogen controlling the upper bounds of possible values. However, as data from urban runoff, human wastewater, agricultural wastewater, precipitation, and receiving waters indicated, the simulated values were well within concentrations expected from dissolved and suspended matter in flowing water (table 17).

The effects of selected statistics (table 18) on simulated TP concentrations are shown in figure 27. TP skew values were small and, with the exception of State Route 2A monitoring station dataset and the lumped dataset, were not significantly different from zero. Therefore, unlike TN, neither the data nor the simulation populations were strongly concave up on figure 27 and extreme values were not generated. Maximum values simulated with traditional and robust statistics were well below the maximum for urban runoff (table 17), which probably included runoff from fertilized areas. Maximum values simulated with traditional statistics, however, were between 10 and $20 \mathrm{mg} / \mathrm{L}$ and so were comparable to typical values for strong human wastewater. Concentrations simulated by using the robust alternative statistics were well within the existing highway maximum in table 17 . The simulations performed using the lumped data and simulated statistics shown in table 18 indicated that the two largest measured values measured at the State Route 2A and State Route 20 monitoring stations may have been outliers with actual exceedance probabilities that were smaller than would be assumed by the sample size. As with TN, comparison with data from urban runoff, human wastewater, agricultural wastewater, and receiving waters indicated the simulated TP values were well within concentrations expected from dissolved and suspended matter in flowing water (table 17).

The effects of selected statistics (table 18) on simulated SS concentrations are shown in figure 28. In this case, the maximum simulated values of SS were for the State Route 20 dataset (more than 1,000,000 mg/L). With the exception of the State Route 2A data, the skews of the SS samples were very small and none of the skew values were significantly different from zero. In this case, the relatively large SD for the State Route 20 dataset (table 18) was the statistic that was driving these extreme values. The SDs for the traditional and robust alternative statistics were large. A few high outliers did not cause these relatively large SDs. The large range and the relatively high percentage of SS concentrations below $300 \mathrm{mg} / \mathrm{L}$ at State Route 20 caused the large SDs calculated by using both methods and therefore the large simulated values. Although concentrations approaching or exceeding 1,000,000 mg/L may seem unrealistic, receiving-water monitoring data indicated that such hyperconcentrated flows did occur in environments with high-energy flows and a large supply of erodible sediments (table 17). Although the bridge deck may become sediment limited in a long or large storm, figures 18 and 20 and tables 5 and 6 indicate that a large amount of sediment may be available for wash off. The available sediment could produce large concentration in a small but intense storm. The statistics from this dataset indicated that the maximum measured value of $140,000 \mathrm{mg} / \mathrm{L}$ had a smaller percent exceedance than would be calculated from the sample size (fig. 28), but statistics indicated that this large value may have an exceedance risk representing a 1-in-10- or a 1-in-20-year event.

Because the traditional and robust alternative statistics produced extreme concentrations in these simulations, additional simulations were made by using L-moment statistics, which are not as influenced by extreme values in the data as other calculation methods (Hosking, 1990; Stedinger and others, 1993). The average, SD, and skew of the common (base 10) logarithms of event-mean concentrations in composite samples of bridge-deck runoff calculated by using L-moment statistics are documented in table 19. The medians of each L-moment statistic and the L-moment statistics for the lumped data are also shown in table 19. The L-moment averages were equal to the averages calculated by using traditional methods (table 18) because they were calculated with the same equations. The L-moment SDs and skew statistics in table 19, however, were substantially lower than the analogous statistical values shown in table 18 because L-moments are linear combinations of probability-weighted moments. Examination of simulation results, however, indicated that the L-moment statistics are not suitable for simulating runoff concentrations with the frequency-factor method (fig. 29). No extreme values were generated, but the simulated values did not represent measured values because the SDs and skews did not result in simulated values that were comparable to measured values.

Analysis of the calculated statistics and simulated values indicated that if the median of statistics from the monitored sites were used, neither the traditional nor the robust 


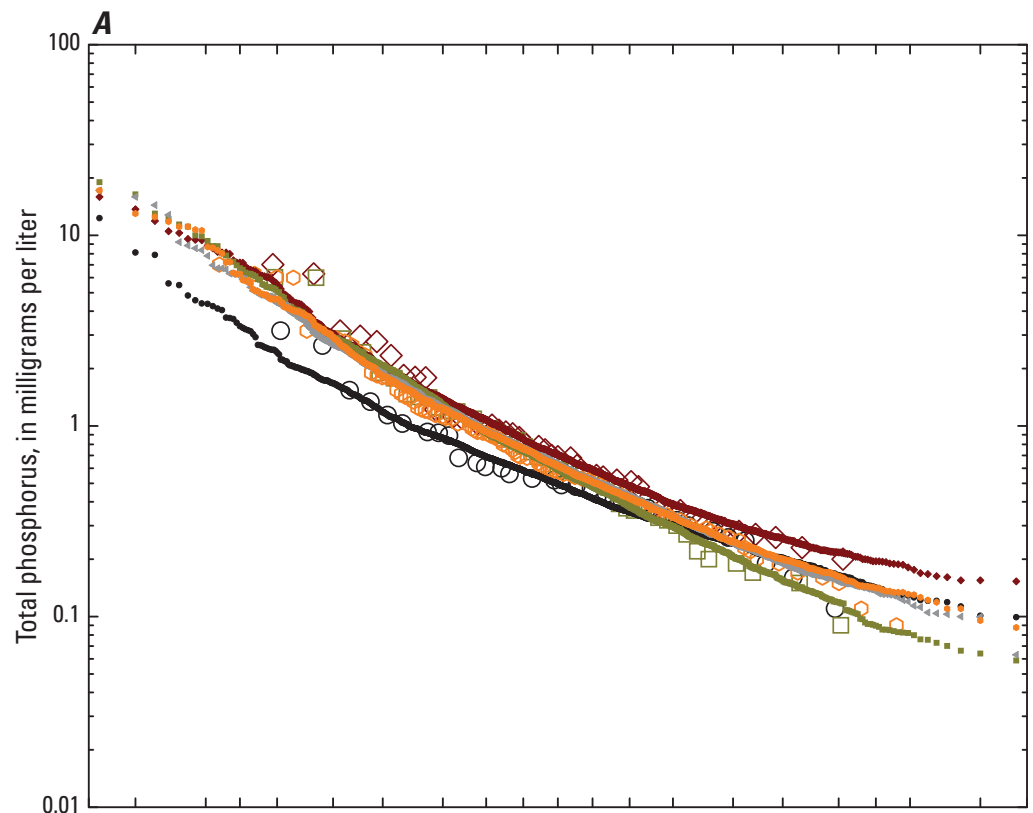

EXPLANATION

$\diamond \quad$ State Route 2A (422108071052501) data

Interstate 90 (422025071154501) data

State Route 20 (421247071470201) data

Lumped data

- Simulation of State Route 2A data

- Simulation of Interstate 90 data

Simulation of State Route 20 data

Simulation of runoff quality with the median of traditional statistics

Simulation of lumped data

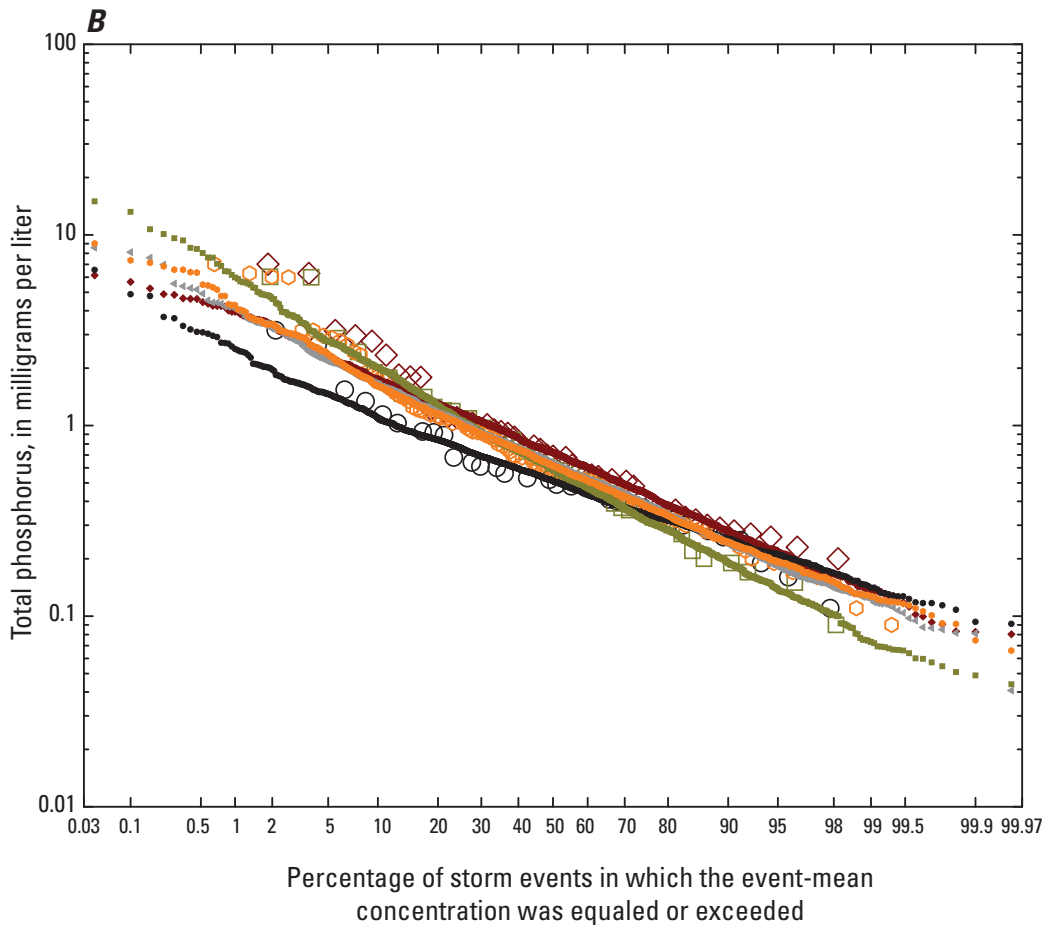

Figure 27. Measured total phosphorus concentrations and concentrations simulated by using $A$, traditional statistics and $B$, statistics calculated by using robust alternative methods. The selected statistics are shown in table 18. 

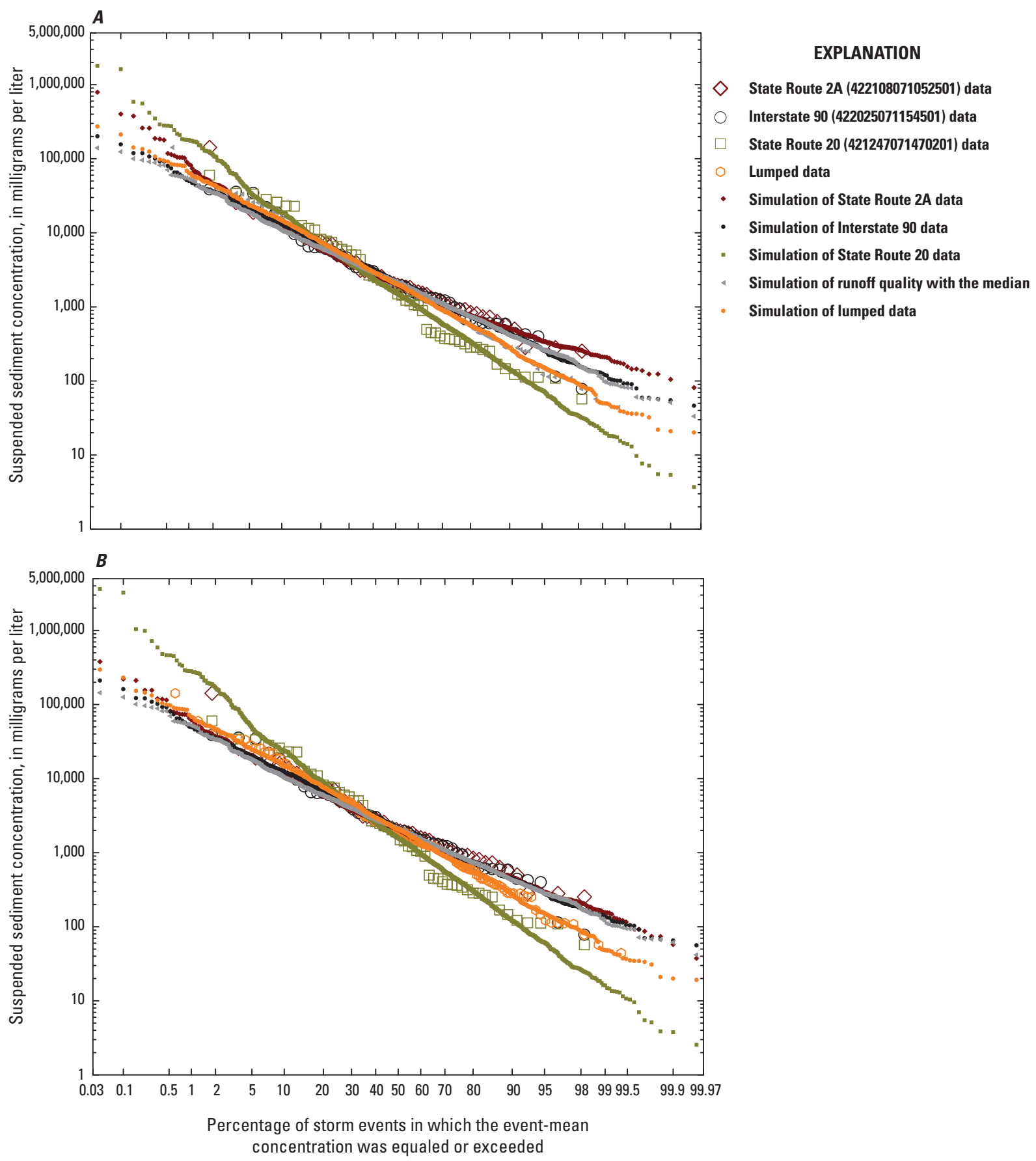

Figure 28. Measured suspended sediment concentrations and concentrations simulated by using $A$, traditional statistics and $B$, statistics calculated by using robust alternative methods. The selected statistics are shown in table 18 . 
Table 19. Average, standard deviation, and skew of the common logarithms of event-mean concentrations in composite samples of bridge-deck runoff collected from State Route $2 A$ in Boston (422108071052501), Interstate 90 near Weston (422025071154501), and State Route 20 near Quinsigamond Village (421247071470201) in eastern Massachusetts, 2014-16, as calculated by using L-moment methods.

[Locations of stations are shown in figure 1. The alpha-numeric identifiers starting with "p" are the U.S. Geological Survey parameter codes. Numbers have been rounded to three significant figures. L-moments are linear combinations of probability-weighted moments used for estimating sample statistics (Hosking, 1990; Stedinger and others, 1993). N, nitrogen; P, phosphorus]

\begin{tabular}{lcccc}
\hline $\begin{array}{c}\text { Bridge- } \\
\text { monitoring site }\end{array}$ & Count & Average & $\begin{array}{c}\text { Standard } \\
\text { deviation }\end{array}$ & Skew \\
\hline \multicolumn{4}{c}{ Total nitrogen as N } & (p00600) \\
\hline State Route 2A & 52 & 0.236 & 0.198 & 0.167 \\
Interstate 90 & 46 & 0.317 & 0.172 & 0.134 \\
State Route 20 & 51 & 0.474 & 0.195 & 0.014 \\
Median of sites & 51 & 0.317 & 0.195 & 0.134 \\
Lumped data & 149 & 0.342 & 0.198 & 0.107 \\
\hline \multicolumn{5}{c}{ Total phosphorus as P (p00665) (milligrams per liter) } \\
\hline State Route 2A & 53 & -0.123 & 0.192 & 0.140 \\
Interstate 90 & 46 & -0.280 & 0.153 & 0.079 \\
State Route 20 & 51 & -0.196 & 0.219 & 0.035 \\
Median of sites & 51 & -0.196 & 0.192 & 0.079 \\
Lumped data & 150 & -0.196 & 0.191 & 0.091 \\
\hline Suspended sediment concentration (p80154) (milligrams per liter) \\
\hline State Route 2A & 54 & 3.38 & 0.311 & 0.097 \\
Interstate 90 & 54 & 3.35 & 0.320 & 0.042 \\
State Route 20 & 55 & 3.19 & 0.466 & 0.022 \\
Median of sites & 54 & 3.35 & 0.32 & 0.042 \\
Lumped data & 163 & 3.30 & 0.372 & 0.009 \\
\hline
\end{tabular}

alternative statistics produced extreme simulated values (table 18). Analysis by robust alternatives provides information about the effect of outliers on sample statistics and the probable exceedance risks of such outliers. In this study, the robust alternative statistics were within the 95 -percent confidence intervals of the traditional statistics. If the medians of site statistics are used to simulate runoff quality for risk analyses or to estimate annual loads, then the traditional statistics will be suitable for such analyses.

\section{Runoff-Quality Risk Analysis}

In Massachusetts, the National Pollutant Discharge Elimination System permits for stormwater runoff currently (2017) specify required management measures rather than numeric discharge limits (Massachusetts Department of
Environmental Protection, 2013). This approach reflects the fact that relatively small isolated BMPs cannot meet discharge standards developed for actively managed municipal wastewater treatment systems; however, stringent numerical dischargequality standards have been proposed in other States (Granato and Jones, 2015). SELDM can be used to assess the risk of exceeding any proposed discharge-concentration standard with and without use of BMPs. In this example, numeric effluent criteria of $8 \mathrm{mg} / \mathrm{L}$ for TN and $1 \mathrm{mg} / \mathrm{L}$ for TP were selected as examples because these are published standards for discharges from wastewater treatment plants (WWTPs) using the best available technology (Massachusetts Department of Environmental Protection, 2013).

It should be noted that bridge-deck flows also are orders of magnitude smaller than WWTP flows. Many of the WWTPs subject to numerical standards commonly discharge more than 1 million gallons per day (Mgal/d). In this example bridgerunoff simulation, the average-annual discharge per acre of bridge deck was 115,497 cubic feet per year, which is equivalent to 0.0024 million gallons per day per acre during an entire year or about 0.037 million gallons per day per acre during the periods of runoff that only occur about 6.5 percent of the year on the basis of the input statistics used for this study. In comparison, about 2.6 acres of the State Route 2A bridge, the largest bridge in this study, is over water.

The risks for exceeding the example TN discharge criteria of $8 \mathrm{mg} / \mathrm{L}$ were substantial for the measured data and simulated long-term concentrations. The percentage of measured storm-event samples that exceeded $8 \mathrm{mg} / \mathrm{L}$ ranged from about 6.7 (Interstate 90 bridge) to 11 percent (State Route 20 bridge) with an average exceedance of about 8.4 percent of events (fig. 30A). Bridge-deck runoff event-mean concentrations simulated by using the median of the robust statistics exceeded the criteria in about 5 percent of events. The differences in exceedances for the data in comparison to the values simulated by using the robust median statistics may indicate that the simulated values were conservative or that the extreme values occurred in the sampled events. Event-mean concentrations in BMP discharges simulated by using the generic (median) BMP statistics (table 10) exceeded the criteria in about 1.6 percent of events. Therefore, neither the simulated runoff nor the simulated BMP discharge quality would meet a water-quality criterion of $8 \mathrm{mg} / \mathrm{L}$ if the commonly used recurrence interval of one event in 3 years is applied because the exceedance risk for one event in 3 years was about 0.58 percent in these simulations.

The risks for exceeding the example TP discharge criteria of $1 \mathrm{mg} / \mathrm{L}$ were even more substantial for the measured data and simulated long-term concentrations than for the TN values. The percentage of measured storm-event samples that exceeded $1 \mathrm{mg} / \mathrm{L}$ ranged from about 14 (Interstate 90 bridge) to 30 percent (State Route 20 bridge) with an average exceedance of about 25 percent of events (fig. 30B). Bridge-deck runoff event-mean concentrations simulated by using the median of traditional statistics exceeded the 1-mg/L criterion in about 28 percent of events. Event-mean concentrations 

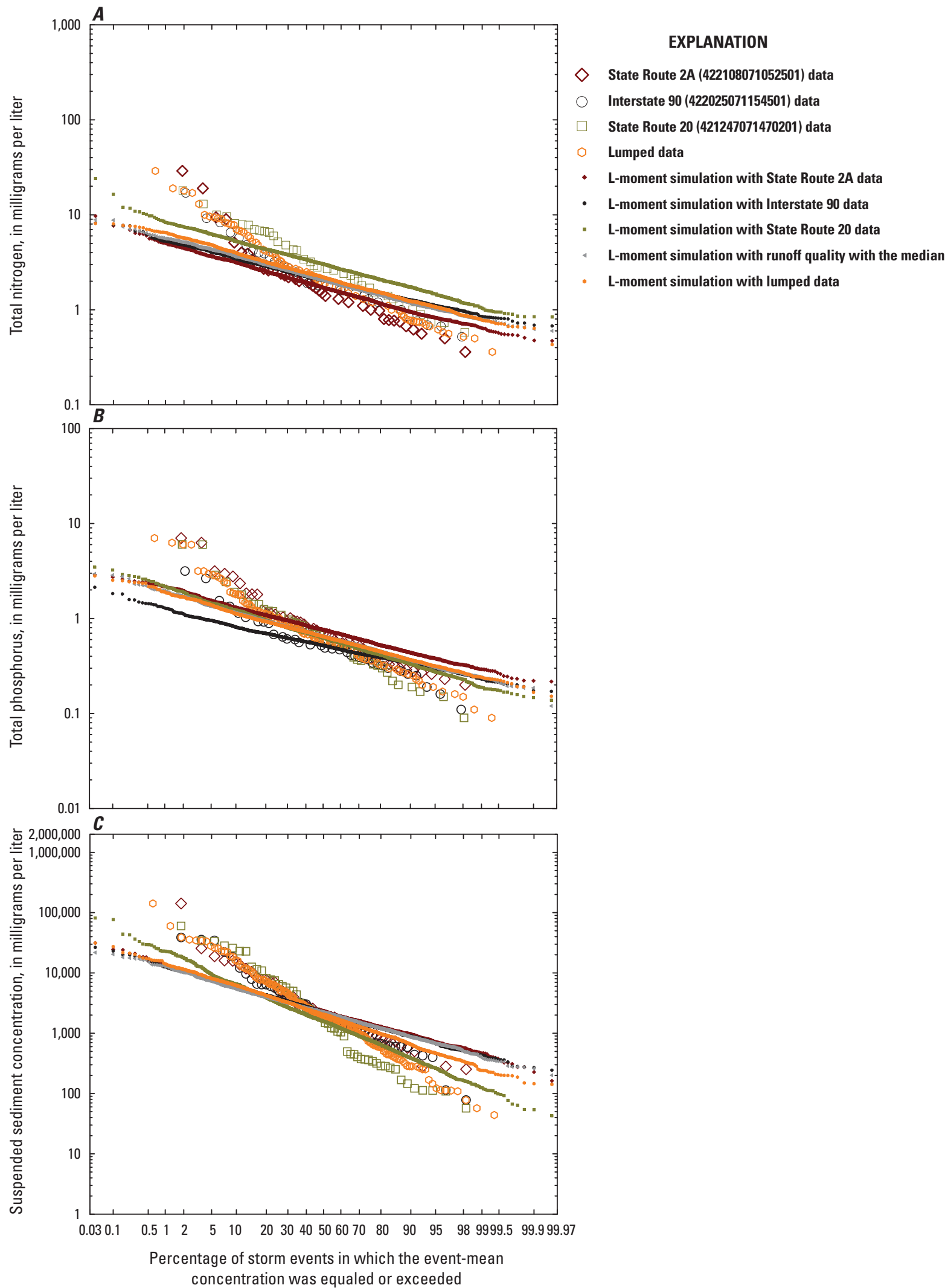

Figure 29. Concentrations simulated by using L-moments and measured $A$, total nitrogen; $B$, total phosphorus; and C, suspended sediment concentrations. The selected statistics are shown in table 19. 


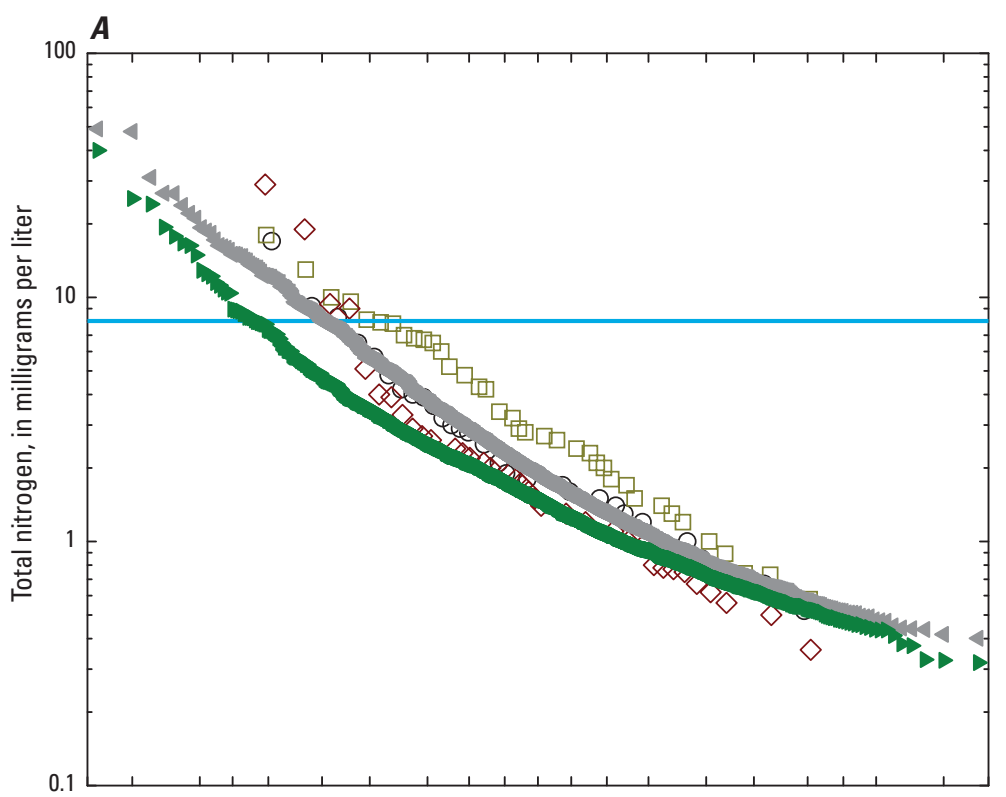

\section{EXPLANATION}

- Example Massachusetts total nitrogen wastewater discharge effluent limit (8 milligrams per liter)

- Example Massachusetts total phosphorus wastewater discharge effluent limit (1 milligram per liter)

O Interstate 90 (422025071154501) data

$\square$ State Route 20 (421247071470201) data

$\diamond$ State Route 2A (422108071052501) data

Highway runoff simulated by using the median of traditional statistics

- Simulated stormwater best-management practice discharge

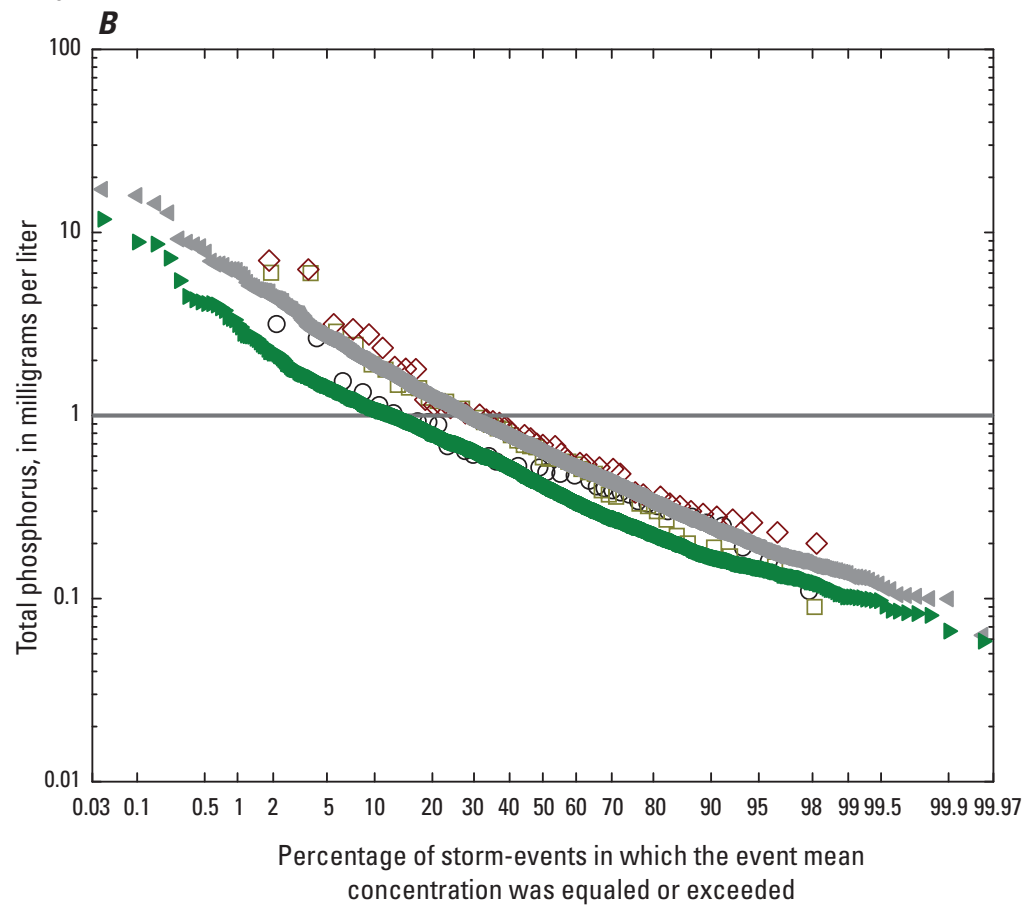

Figure 30. Probability plots of $A$, total nitrogen and $B$, total phosphorus, including measured concentrations, concentrations simulated with the median of robust statistics (table 18), and concentrations simulated by modifying the simulated highway runoff by using the generic best-management practice statistics (table 10).

in BMP discharges simulated by using the generic (median) BMP statistics (table 10) exceeded the 1-mg/L criterion in about 13 percent of events. These exceedances, therefore, did not meet the exceedance risk for one event in 3 years (about 0.58 percent).

In these simulations, the BMP reduced the percentage of concentration exceedances of both TN and TP by more than one-half. Better reductions in the concentration exceedances may be achieved if a specific BMP, designed for nutrient reduction, is used instead of the median of category medians as used in this example. However, this simulation indicates that the numeric WWTP standards for these nutrients may be unattainable, with or without a BMP, unless greater criterion concentrations or a larger exceedance risk is acceptable.

\section{Runoff-Quality Annual Yield Analyses}

Eleven simulations of 29-30 years were performed with the same hydrologic and concentration statistics and different 
random seeds to estimate yields of TN, TP, and SS. In these simulations, SELDM calculated an annual yield in pound per acre per year of pavement for each annual-load accounting year. Yields were simulated for runoff from 1 acre of pavement by using precipitation statistics for ecoregion 59 (the Northeastern Coastal Zone) and standard highway-runoff coefficient statistics (Granato, 2013). The medians of traditional statistics from the three sites (table 18) were used to model long-term constituent yields. Doing multiple simulations with the same hydrologic statistics accounts for stochastic variability in the combinations of concentrations, flows, and loads that could occur during a long period (Granato, 2013; Granato and Jones, 2014, 2017).
The populations of annual yields of TN, TP, and SS from the 11 simulations and the average and median of the values for each plotting position are shown in figure 31 . To construct this graph, plotting-position results for the 30 -year simulations were adjusted by using linear interpolation with the normal variate of each plotting position percentile to calculate yields that were equivalent to the 29-year simulation results. The results of individual simulations show a tight cluster around the median and mean except for the highest and lowest yields (fig. 31). The values of large concentration outliers do not matter for discharge exceedance analysis once they are already over the criterion concentration, but an extreme concentration outlier may have a substantial effect on the maximum annual
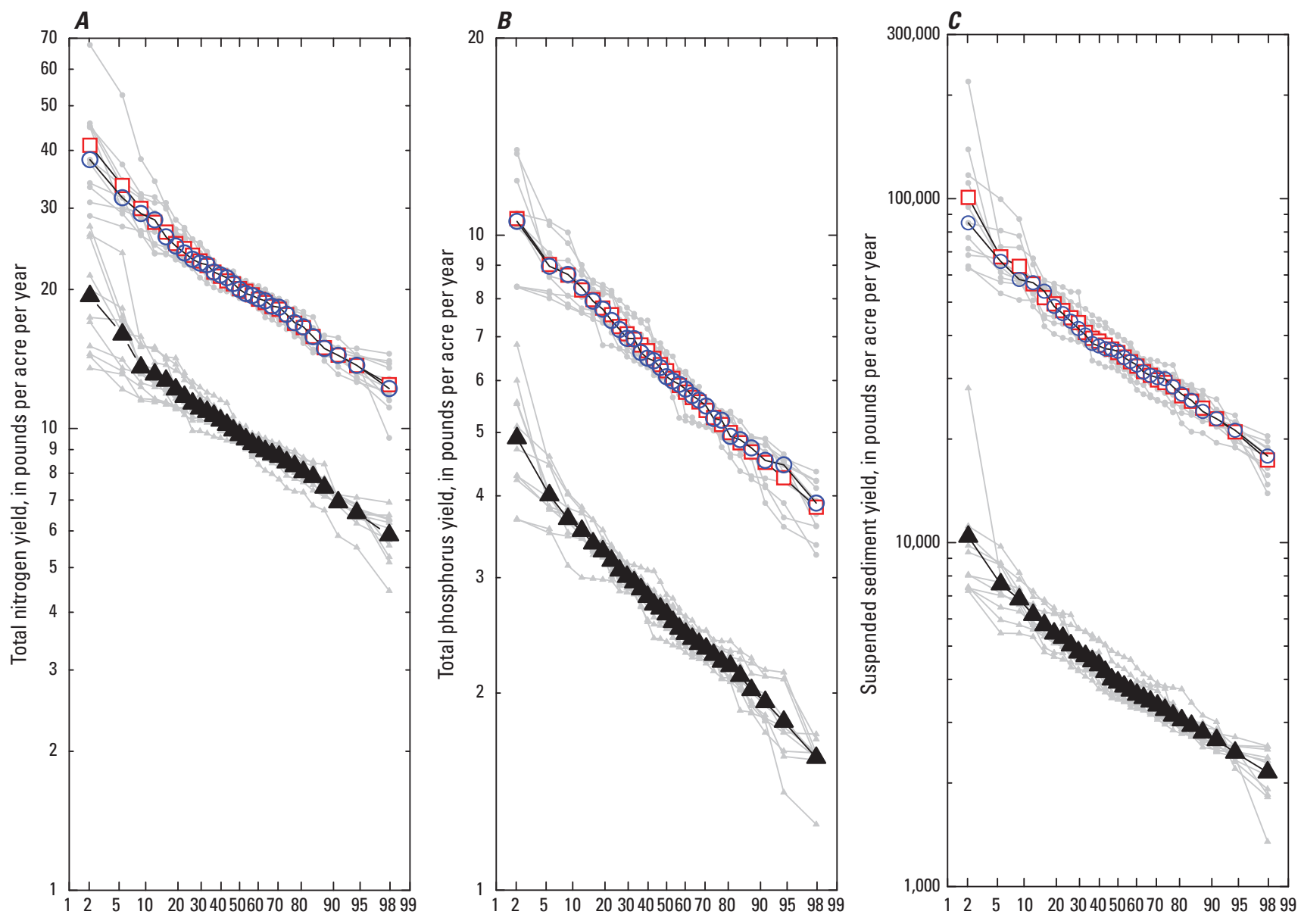

Percentage of years in which the annual yield was equaled or exceeded

\section{EXPLANATION}

- Individual simulations
$-\square-$ Average
- Median
$-\Delta$ - Average best-management practice discharge simulation

Figure 31. Yields of $A$, total nitrogen; $B$, total phosphorus; and $C$, suspended sediment in pounds per acre per year for each simulated year by percentile. The graph shows the individual, average, and median yields from 11 individual simulations. 
yield. An extreme flow event (such as the rainfall volume that may be associated with an intense storm) also may contribute to a high annual yield.

The results of the analyses are shown as long-term average-annual runoff yields for each of the simulations (table 20). The long-term average-annual yield is the sum of the loads, per unit area, for the entire simulation period divided by the number of years in the simulation. The medians of the average-annual yields in the different simulations are presented in table 20 as the best estimator to account for stochastic variability from simulation to simulation. Results of simulations indicated that long-term average yields of TN, TP, and SS may be about 21.4, 6.44, and 40,600 pounds per acre per year, respectively. Granato and Jones (2017) did a similar annual yield analysis for different road classes by using concentration statistics from sites in Massachusetts from version 1.0.0a of the HRDB (Smith and Granato, 2010). They used the average of precipitation statistics from 11 National Weather Service stations in eastern Massachusetts and Rhode Island. The percent differences between the runoff-event precipitation statistics used by Granato and Jones (2017) and the precipitation statistics used in this study were about 0.85 for event volume, 5.2 for event duration, and 1.3 for the number of hours between event midpoints. The comparable yields of TN, TP, and SS in this current bridge-runoff study (table 20) were about 1.3, 3.4, and 16 times the ultra-urban highway yields simulated by Granato and Jones (2017), respectively. This comparison indicates that bridge-deck yields are not representative of yields from the entire road network in Massachusetts; however, bridge-deck yields may be a substantial portion of annual yields from highways in a watershed because the bridge-deck yields were much higher than yields for all the road classes simulated by Granato and Jones (2017). Furthermore, many bridges are over and discharge to receiving waters, whereas State roadways typically discharge to the local land surface.

\section{Runoff Treatment Analyses}

Runoff treatment was analyzed to examine the potential effects of flow reductions and concentration reductions by stormwater BMPs on annual yields from bridge-deck runoff. The SELDM BMP-treatment module has provisions for stochastic modeling of three stormwater treatments: volume reduction, hydrograph extension, and water-quality treatment (Granato, 2013, 2014). Hydrograph extension is an important variable for dilution analyses, but the duration of BMP discharges does not substantially affect the total-annual yields. For this analysis, a generic BMP was simulated by using the median of treatment statistics for flow reductions, concentration reductions, and MICs from seven BMP categories with data from the 2012 International BMP database (Geosyntec

Table 20. Simulated long-term average-annual bridge-deck runoff and stormwater control measure best-management practice discharge yields, in pounds per acre per year for total nitrogen, total phosphorus, and suspended sediment.

[The alpha-numeric identifiers starting with "p" are the U.S. Geological Survey parameter codes. run, stochastic empirical loading and dilution model run number and median of values from the eleven runs; seed, Monte Carlo random seed; years, annual-load accounting years; N, nitrogen; lb/ac/yr, pound per acre per year; runoff, bridge-deck runoff; BMP discharge, stormwater control measure best-management practice discharge; P, phosphorus; NA, not applicable]

\begin{tabular}{|c|c|c|c|c|c|c|c|c|}
\hline \multirow{2}{*}{ Run } & \multirow{2}{*}{ Seed } & \multirow{2}{*}{ Years } & \multicolumn{2}{|c|}{$\begin{array}{c}\text { Total nitrogen as } N \text { (p00600), } \\
\text { in } \mathrm{lb} / \mathrm{ac} / \mathrm{yr}\end{array}$} & \multicolumn{2}{|c|}{$\begin{array}{c}\text { Total phosphorus (p00665) as } \mathrm{P} \\
\text { in } \mathrm{lb} / \mathrm{ac} / \mathrm{yr}\end{array}$} & \multicolumn{2}{|c|}{$\begin{array}{l}\text { Suspended sediment (p80154) } \\
\text { in Ib/ac/yr }\end{array}$} \\
\hline & & & Runoff & BMP discharge & Runoff & BMP discharge & Runoff & BMP discharge \\
\hline 1 & 11,093 & 30 & 21.4 & 10.6 & 6.44 & 2.88 & 36,900 & 3,980 \\
\hline 2 & 856 & 29 & 22.4 & 10.9 & 6.29 & 2.77 & 41,400 & 4,470 \\
\hline 3 & 2,519 & 29 & 21.5 & 10.3 & 6.46 & 2.89 & 38,000 & 4,270 \\
\hline 4 & 3,366 & 29 & 20.4 & 9.72 & 6.30 & 2.70 & 40,700 & 5,100 \\
\hline 5 & 3,418 & 29 & 23.7 & 11.1 & 6.77 & 2.76 & 40,600 & 4,790 \\
\hline 6 & 6,996 & 30 & 21.7 & 10.7 & 6.04 & 2.63 & 41,100 & 4,360 \\
\hline 7 & 10,482 & 30 & 20.5 & 9.47 & 6.60 & 2.80 & 35,400 & 4,120 \\
\hline 8 & 8,418 & 29 & 20.7 & 9.63 & 6.56 & 2.77 & 41,000 & 4,260 \\
\hline 9 & 4,370 & 29 & 20.8 & 9.84 & 6.51 & 2.84 & 34,700 & 3,860 \\
\hline 10 & 5,240 & 29 & 20.3 & 10.0 & 6.23 & 2.56 & 45,400 & 4,890 \\
\hline 11 & 7,022 & 29 & 21.4 & 10.1 & 6.12 & 2.62 & 38,000 & 4,070 \\
\hline Median & NA & NA & 21.4 & 10.1 & 6.44 & 2.77 & 40,600 & 4,270 \\
\hline
\end{tabular}


Consultants and Wright Water Engineers, 2016) (table 10); BMP yields for TN, TP, and SS from bridge-deck runoff are shown in table 20.

The results of the yield analyses of TN, TP, and SS for bridge-deck runoff are shown in figure 31 . The reduction in annual yields at each percentile represents the effects of flow and concentration reduction. Although average-annual yields with and without the BMP treatments are shown, these values represent results of stochastic simulations for each runoff event, not application of average performance statistics for the entire simulation period (Granato, 2013, 2014). Individually, flow reduction and concentration reduction have a substantial effect on the annual yields of TP in these simulations; however, the BMPs can produce excess flows and concentrations in some storms, which can reduce or eliminate the combined effectiveness for those storms. For example, if concentrations are reduced in a given storm but the discharge flow is larger than the runoff inflow, then the total BMP discharge load may be greater than or equal to the runoff load for a particular storm event. Increases in flow can be caused by carryover from previous storms and (or) groundwater discharge to the BMP (especially for wet BMPs). Resuspension of previously deposited constituents can cause increases in discharge concentrations. Results for this runoff-treatment analysis indicated that use of a BMP to treat bridge-deck runoff may reduce TN, TP, and SS discharge yields to about 10, 2.8, and 4,300 pounds per acre per year, respectively. In these simulations, the median BMP with performance statistics shown in table 10 attenuates long-term average-annual bridge-deck runoff yields by about 52 percent for TN, 57 percent for TP, and 89 percent for SS (table 20).

\section{Summary}

The U.S. Geological Survey (USGS) conducted a field study between 2014 through 2016 to document the quality of bridge-deck runoff from three bridges maintained by the Massachusetts Department of Transportation (MassDOT) in eastern Massachusetts. Bridge sites monitored in this study include State Route 2A (Massachusetts Avenue Bridge) in the city of Boston, Interstate 90 in the town of Weston, and State Route 20 near Quinsigamond Village in the city of Worcester. The annual average daily traffic volumes for these bridges ranged from 21,200 to 124,000 vehicles per day. The land use surrounding each bridge was primarily developed land (43 to 78.8 percent) with accompanying high impervious area (25 to 67 percent).

At each bridge, a monitoring system was installed to collect continuous measurements of water level and rainfall (rainfall measurements were not available at the State Route $2 \mathrm{~A}$ bridge location, but estimated from data collected at a nearby USGS streamgage) and to collect composite samples of bridge-deck runoff. Bridge-deck runoff was diverted from a scupper outlet at each bridge to a shelter containing an
$\mathrm{H}$ flume where flow was measured. Composite samples of bridge-deck runoff were collected on a flow-proportional basis by an automatic sampler for more than 50 runoff events at each bridge-deck-monitoring station and analyzed for concentrations of suspended sediment (SS), SS particle size, total phosphorus (TP), dissolved nitrogen (DN), particulate nitrogen (PN), loss on ignition of suspended solids (LOI), and particulate carbon (PC). Samples of runoff were collected year round and during events that were characteristic of the range of antecedent dry periods and event rain totals that existed throughout the study period (August 2014 through August 2016). Samples of bridge-deck sediment also were collected three times during the study period to characterize the distribution of sediment across each bridge deck. A composite sample of sediment from each bridge was analyzed for concentrations of TP and 10 total-recoverable metals in three particle-size ranges.

Quality-assurance data were collected at each monitoring station to ensure the accuracy of the flow and constituent data. Redundant measurements of water level were collected at each monitoring station, runoff coefficients were calculated to help identify sensor error and stormflow alterations, and the theoretical level-flow relation of each flume was tested at each bridge. Field blank and replicate-split samples were collected to identify potential bias in processing methods and contamination resulting from the sampling equipment and the sample-collection, processing, and analysis process. During the study period, 10 field blanks and 33 concurrent replicate-split samples of bridge-deck composite samples were collected and submitted for chemical and sediment analysis. Concentrations of SS in field blanks were slightly greater than the laboratory reporting limit in 7 of 10 field blank samples. Concentrations of LOI, PC, particulate organic carbon (POC), and DN were detected less often in field blanks than concentrations of SS, but in general, contamination bias was low for all constituents. The range of concentrations for each constituent in concurrent replicate-split samples was similar to the range of constituent concentrations measured in composite samples collected during the study. The median relative percent difference (RPD) for concentrations of SS and particle-associated constituents ranged from 10 to 25 percent, except for particulate inorganic carbon (PIC), which was 65 percent, and the median RPD for DN was less than 2 percent. The RPD for replicate-split samples of bridge-deck sediment for TP and total-recoverable metals generally was less than 12 percent in the fine-sediment fraction and ranged from 0 to 64 percent for most metals in the coarser sediment fractions. These differences in the replicatesplit samples represent a measure of the variability associated with sample processing and analytical methods. The RPDs associated with the composite samples of runoff are relatively high but not unusual for water samples containing high concentrations of sand-size particles.

Concentrations of SS, SS particle size, nutrients, LOI, and PC were measured in more than 160 flowweighted composite samples of runoff collected from the three bridge-deck-monitoring stations. Concentrations of SS in composite samples of bridge-deck runoff from the 
three bridge-deck-monitoring stations ranged from 44 to 142,000 milligrams per liter (mg/L); however, median concentrations of SS per site ranged from 1,490 to 2,020 mg/L. Concentrations of LOI and PC in composite samples of runoff ranged from 15 to $1,740 \mathrm{mg} / \mathrm{L}$ and 6.68 to $1,360 \mathrm{mg} / \mathrm{L}$, respectively, and generally represented less than 10 and 3 percent of the median mass of SS, respectively. Concentrations of PC were primarily represented by the particulate organic carbon (POC) fraction. Concentrations of TP and total nitrogen (TN) (sum of DN and PN) in composite samples of runoff ranged from 0.09 to $7.02 \mathrm{mg} / \mathrm{L}$ and 0.36 to $29.0 \mathrm{mg} / \mathrm{L}$, respectively. Median concentrations of TP ranged from 0.505 to $0.690 \mathrm{mg} / \mathrm{L}$ and were highest on the bridge on State Route 2A in Boston. Median DN concentrations ranged from 0.64 to $0.90 \mathrm{mg} / \mathrm{L}$ and generally represented about 40 percent of the TN concentration at each bridge. Median concentrations of DN were similar to annual precipitation-weighted mean concentrations of nitrogen (ammonia plus nitrate) reported in Massachusetts.

Results for one-way analysis of variance and post hoc Tukey pairwise comparison tests performed on the ranktransformed data for each bridge indicated that concentrations of SS, LOI, PC, and TP were not significantly different from bridge to bridge. The mean of the rank-transformed data for TN collected on State Route 20 was significantly higher than the means of the rank-transformed data for the other bridges. Test results for the fractional portion of TN for bridge pairs State Route 2A and Interstate 90, and Interstate 90 and State Route 20 were not statistically different; however, test results for the bridge pair State Route 2A and State Route 20 were significant and indicated that the fractional portions of TN were both significantly higher at the State Route 20 bridge compared to State Route 2A. Median concentrations of TN were about 93 percent lower at State Route 2A in Boston compared to the median concentrations of TN at State Route 20 near Quinsigamond Village.

Samples of sediment were collected from five fixed locations (equally spaced) on three occasions during dry weather on each bridge road surface between April 2015 and September 2016 to assess the distribution of sediment yields on the bridge surface in respect to the scupper inlet location where samples of runoff were collected. Samples of bridge-deck sediment were collected with portable vacuums in the travel lane of the instrument scupper on each bridge, the sediment was dried to a constant weight, and yields were estimated on the basis of the sediment mass and curb distance sampled. Yields of bridge-deck sediment for each of the five sampling locations ranged from 26 to 25,000 pounds per curb-mile (lbs/ curb-mi) and were similar to yields reported elsewhere in Massachusetts and the United States.

Yields of bridge-deck sediment, normalized to the yield measured proximate to the monitoring station at each bridge, indicated that sediment on each bridge surface was not uniform. On State Route 2A, the mean yield of bridgedeck sediment measured proximate to the monitoring station (680 lbs/curb-mi) on the east end of the bridge near Boston was about 55 percent lower than the mean yield of sediment for the entire eastward bridge-deck span, which might be explained by depositional decay of vehicle tracking through the fixed sampling locations as the yield distribution decreased with flow of traffic. Normalized bridge-deck sediment yields for Interstate 90 near Weston indicated that the sediment mass increased from east to west. The mean yield of bridge-deck sediment for Interstate 90 measured proximate to the monitoring station (240 lbs/curb-mi) on the west end of the bridge was similar to the mean yield of sediment for the entire westward bridge-deck span. The distribution of the sediment mass across this bridge was likely related to the contribution of solids from the deterioration of the bridge-deck surface, median barrier, and shoulder area; these solids migrate westward with the bridge-deck slope and flow of traffic. Normalized bridge-deck sediment yields for Route 20 near Quinsigamond Village indicated that the sediment mass decreased from east to west. The mean yield of bridge-deck sediment proximate to the monitoring station on State Route 20 (7,200 lbs/curb-mi) was about 26 percent higher than the mean yield of sediment for the entire westward bridge-deck. The distribution of the sediment mass across this relatively new bridge likely resulted from sediments that washed onto the bridge from the eastern roadway uphill of the bridge. Although these data only represent a semiquantitative assessment of the sediment distribution, visual observations throughout the study period support the findings.

A composite sample of bridge-deck sediment from each bridge was sieved into fine, intermediate, and coarse size fractions (less than 0.0625 millimeter, greater than or equal to 0.0625 to 0.25 millimeter, and greater than or equal to 0.25 millimeter in diameter, respectively), and analyzed for concentrations of TP and 10 total-recoverable metals. These analyses indicated that bridge-deck sediment contained high concentrations of phosphorus and various metals. In particular, the two fine sediment fractions typically had higher concentrations than the coarse sediment fraction. Concentrations of $\mathrm{TP}$ in the fine fraction were about 6 times greater than in the coarse fraction. Total-recoverable concentrations of aluminum (Al), manganese (Mn), and nickel (Ni) were about two times greater in the fine fraction; total-recoverable concentrations for arsenic (As), barium (Ba), cadmium $(\mathrm{Cd})$, chromium $(\mathrm{Cr})$, and zinc $(\mathrm{Zn})$ were about 2 to 17 times greater in the fine sediment fraction; and total-recoverable concentrations of lead $(\mathrm{Pb})$ were about 8 to 65 times greater in the fine sediment fraction compared to the concentration in the coarse sediment fraction. The only total-recoverable metal not detected in the coarse fraction of any of the bridge-deck sediment samples was copper $(\mathrm{Cu})$, but concentrations in the fine fraction were 13 to 47 times more concentrated than concentrations in the intermediate sediment fraction.

The distribution of the sediment in the three size fractions and the relation of TP and total-recoverable metals to each sediment-size fraction indicated that for a given mass of sediment, about 54 percent of the estimated TP is associated with the intermediate and coarse sediment mass. The cumulative proportion of the mass of $\mathrm{As}, \mathrm{Ba}, \mathrm{Cd}, \mathrm{Cu}, \mathrm{Pb}$, and $\mathrm{Zn}$ in 
the intermediate and coarse sediment fraction was less than 56 percent for a given mass of sediment. Only about 5 percent of the sediment-associated $\mathrm{Cu}$ was associated with the intermediate sediment fraction. In contrast, as much as 66 to 84 percent of $\mathrm{Al}, \mathrm{Cr}, \mathrm{Mn}$, and $\mathrm{Ni}$ was associated with the intermediate and coarse fractions of bridge-deck sediment.

Results for Mann-Whitney tests indicated that concentrations of SS in composite samples of bridge-deck runoff for this study were significantly larger ( $p$-values less than 0.001) than in composite samples of highway runoff collected on State Route 2, Interstate 190, Interstate 495, Interstate 95, and Interstate 93 in eastern Massachusetts during a 2005-7 study using similar sampling methods. Highway-runoff samples were collected at the outlet of catch basins, whereby some pretreatment by the catch basin results in a reduction of SS concentrations; therefore, the difference between the two datasets, in part, is likely explained by the lack of any SS reduction by the bridge scuppers. Other factors such as the high bridge walls, concrete barriers in the bridge median, deterioration of bridge components, and bridge wash-on also may have contributed to higher concentrations of SS in samples of bridge-deck runoff. Concentrations of TP and TN in samples of bridge-deck runoff in this study were significantly higher than in samples collected from the selected highway-monitoring stations in eastern Massachusetts during 2005-7. Both of these nutrients were determined to be closely associated with bridge-deck sediment and SS; therefore, the higher concentrations of TP and TN in bridge-deck runoff may be explained by the significantly higher concentrations of SS measured in composite samples of bridge-deck runoff.

Comparisons between bridge-deck sediment quality in this study and highway sediment quality collected in 2005-7 indicated that bridge-deck sediment was less enriched in phosphorus. Concentrations of phosphorus in highway sediment were 3 to 5 times greater in the fine fraction and 6 to 40 times greater in the intermediate and coarse fractions compared to concentrations in the same fractions of bridge-deck sediment. Except for concentrations of $\mathrm{Cr}$ and $\mathrm{Cu}$, concentrations of total-recoverable metals in the fine fraction of bridge-deck sediment were similar (within 50 percent) to the concentration in the same fraction of highway sediment. Concentrations of Cr were 5 to 17 times greater in the intermediate and coarse fraction of highway sediment and $\mathrm{Cu}$ was as much as 49 times greater in the intermediate fraction of highway sediment in comparison to concentrations in the same respective size fractions in bridge sediment samples.

The particle-size distribution and association of each constituent to each sediment-size fraction affects the overall constituent concentration associated with the mass of SS. Bridge-deck sediment as a whole was less enriched chemically compared to highway sediment because it was dominated by the chemically dilute coarse sediment fraction.

Version 1.0.2 of the Stochastic Empirical Loading and Dilution Model (SELDM) was used to simulate concentrations and annual yields of SS, TN, and TP in bridge-deck runoff and in discharges from a hypothetical stormwater treatment best-management practice (BMP) structure. Simulations were performed for a 1-acre portion of a bridge deck by using precipitation statistics for ecoregion 59 (the Northeastern Coastal Zone) and by using the standard SELDM runoff-coefficient statistics. The flow and concentration performance of the BMP was simulated by using the median of statistics from nine BMP categories in the 2012 version of the International BMP database.

High variability in measured concentrations during this study resulted in extreme simulated concentrations when the available data were used to simulate a long-term (29-30year) record; therefore, three methods were used to calculate statistics for stochastic simulations. The first method was to use the average, standard deviation (SD), and skew calculated by using standard equations. The second method was to use the average and SD calculated by using robust regression on order statistics with the Kendall-Theil Robust Line. The robust skew was calculated by using Pearson's second skew with the robust average and SD values. The third method was to use the average, SD, and skew calculated by using the L-moments methods. These methods were used to calculate statistics for each of the three bridges and for a lumped dataset. The medians of these statistics also were calculated. These median statistics were selected for the interpretive simulations so that the simulations could be used to estimate concentrations and yields from other, unmonitored bridges in Massachusetts. Comparisons of the standard and robust statistics indicated that simulation results with either method would be similar, which indicated that the large variability in simulated results was not caused by a few outliers. Comparison to simulations performed using statistics calculated by the L-moments methods indicated that L-moments do not produce extreme concentrations, but they do not produce results that represent the bulk of concentration data.

Runoff-quality risk was analyzed to show how SELDM can be used to evaluate runoff-quality management alternatives. These simulations were done with concentration-criteria discharge standards commonly used for large, advanced wastewater treatment plants. Effluent criteria of $8 \mathrm{mg} / \mathrm{L}$ for TN and $1 \mathrm{mg} / \mathrm{L}$ for TP were selected as hypothetical criteria but not as suggested targets for small stormwater discharges. The risk analysis indicated that TN in bridge-deck runoff may exceed the selected TN criterion in about 5 percent of events. This simulated risk was similar to the exceedance risk estimated from measured data at the bridge sites. In comparison, simulated BMP discharge concentrations exceeded the selected TN criteria in about 1.6 percent of events. The risk analysis indicated that TP in bridge-deck runoff may exceed the selected TP criterion in about 28 percent of events, which was similar to the exceedance risk estimated from measured data at the bridge sites. In comparison, simulated BMP discharge concentrations exceeded the selected TN criteria in about 13 percent of events.

Eleven simulations of 29-30 years were performed with the same hydrologic and concentration statistics and different random seeds to estimate yields of TN, TP, and SS. Results of 
simulations indicated that long-term average yields of TN, TP, and SS may be about 21.4, 6.44, and 40,600 pounds per acre per year, respectively. The long-term average-annual yield is the sum of the loads, per unit area, for the entire simulation period divided by the number of years in the simulation. The TN, TP, and SS yields were about 1.3, 3.4, and 16 times the simulated ultra-urban highway yields in Massachusetts. This comparison indicated that bridge-deck yields were not representative of yields from the entire road network in Massachusetts; however, bridge-deck yields may be a substantial portion of annual loads from highways in a watershed. Furthermore, many bridges are over and discharge to receiving waters, whereas a high proportion of State roadway miles discharge to the local land surface.

Runoff treatment was analyzed to examine the potential effects of flow reductions and concentration reductions by stormwater BMPs on annual yields from bridge-deck runoff. For this analysis, a generic BMP was simulated by using the median of treatment statistics for flow reductions, concentration reductions, and minimum irreducible concentration from seven BMP categories with data from the 2012 International BMP database. This analysis indicated that use of a BMP to treat bridge-deck runoff may reduce TN, TP, and SS discharge yields to about 10, 2.8, and 4,300 pounds per acre per year, respectively. These changes represent long-term average reductions of about 52 percent for TN, 57 percent for TP, and 89 percent for SS. These results are based on the stochastic performance of a generic BMP, and better results may be possible with a better-performing BMP design.

\section{References Cited}

Bannerman, R., Baun, K., Bohn, M., Hughes, P.E., and Graczyk, D.A., 1983, Evaluation of urban nonpoint sources pollution management in Milwaukee County, WisconsinVolume I, Urban stormwater characteristics, constituent sources, and management by street sweeping: Chicago, U.S. Environmental Protection Agency [variously paginated]. [Available from National Technical Information Service, Springfield, VA 22161 (https://www.ntis.gov), item PB 84-114164.]

Barnwell, T.O., Jr., and Krenkel, P.A., 1982, Use of water quality models in management decision making: Water Science and Technology, v. 14, no. 9-11, p. 1095-1107.

Bent, G.C., Gray, J.R., Smith, K.P., and Glysson, G.D., 2001, A synopsis of technical issues for monitoring sediment in highway and urban runoff: U.S. Geological Survey OpenFile Report 00-497, 51 p.

Breault, R.F., and Granato, G.E., 2000, A synopsis of technical issues for monitoring trace elements in highway and urban runoff: U.S. Geological Survey Open-File Report 00-422, $67 \mathrm{p}$.
Breault, R.F., Smith, K.P., and Sorenson, J.R., 2005, Residential street-dirt accumulation rates and chemical composition, and removal efficiencies by mechanical- and vacuum-type sweepers, New Bedford, Massachusetts, 2003-04: U.S. Geological Survey Scientific Investigations Report 20055184, 27 p.

Brown, C., 2013, Available nutrients and value for manure from various livestock types: Ontario Ministry of Agriculture and Food, Factsheet AGDEX 538, 8 p.

Brown, R.C., and Dykstra, J., 1995, Systematic errors in the use of loss-on-ignition to measure unburned carbon in fly ash: Fuel, v. 74, no. 4, p. 570-574.

Burton, G.A., Jr., and Pitt, R., 2002, Stormwater effects handbook-A tool box for watershed managers, scientists, and engineers: Boca Raton, Fla., CRC Press, 911 p.

California Department of Transportation, 2009, BMP pilot study guidance manual: California Department of Transportation, Division of Environmental Analysis, Stormwater Program, CTSW-RT-06-171.02.1, 368 p.

Capel, P.D., and Larson, S.J., 1996, Evaluation of selected information on splitting devices for water samples: U.S. Geological Survey Water-Resources Investigation Report 95-4141, 103 p.

Capel, P.D., Nacionales, F., and Larson, S.J., 1995, Precision of a splitting device for water samples: U.S. Geological Survey Open-File Report 95-293, 6 p.

Chow, V.T., Maidment, D.R., and Mays, L.W., 1988, Applied hydrology: New York, McGraw-Hill, Inc., 572 p.

Church, P.E., Granato, G.E., and Owens, D.W., 1999, Basic requirements for collecting, documenting, and reporting precipitation and stormwater-flow measurements: U.S. Geological Survey Open-File Report 99-255, 30 p.

Clesceri, L.S., Greenberg, A.E., and Eaton, A.D., eds., 1998, Standard methods for the examination of water and wastewater (20th ed.): Washington, D.C., American Public Health Association, American Water Works Association, and Water Environment Federation, p. 3-37-3-43.

Davenport, T.E., 1990, Urban targeting and BMP selection project, in Jennings, M.E., ed., Symposium proceedings on urban hydrology, Denver, Colo., November 4-8, 1990: American Water Resource Association, p. 273-281.

Di Toro, D.M., 1984, Probability model of stream quality due to runoff: Journal of Environmental Engineering, v. 110, no. 3, p. 607-628. 
Driscoll, E.D., Shelley, P.E., and Strecker, E.W., 1990, Pollutant loadings and impacts from highway stormwater runoff, v. III-Analytical investigation and research report: Federal Highway Administration Report FHWA-RD-88-008, $160 \mathrm{p}$.

Edwards, T.K., and Glysson, G.D., 1999, Field methods for measurement of fluvial sediment: U.S. Geological Survey Techniques of Water-Resources Investigations, book 3, chap. C2, 89 p.

Fishman, M.J., and Friedman, L.C., eds., 1989, Methods for determination of inorganic substances in water and fluvial sediments: U.S. Geological Survey Techniques of WaterResources Investigations, book 5, chap. A1, 545 p. [Also available at https://pubs.er.usgs.gov/publication/twri05A1.]

Geosyntec Consultants and Wright Water Engineers, 2016, International stormwater BMP database (ver. 2016-11-17): International Stormwater BMP Database, accessed May 1, 2017, at http://www.bmpdatabase.org.

Granato, G.E., 2006, Kendall-Theil Robust Line (KTRLineversion 1.0)-A visual basic program for calculating and graphing robust nonparametric estimates of linear-regression coefficients between two continuous variables: U.S. Geological Survey Techniques and Methods, book 4, chap. A7, 31 p. [Also available at https://pubs.usgs.gov/tm/2006/ tm4a7/.]

Granato, G.E., 2010, Methods for development of planninglevel estimates of stormflow at unmonitored sites in the conterminous United States: Washington, D.C., U.S. Department of Transportation, Federal Highway Administration, FHWA-HEP-09-005, $90 \mathrm{p}$.

Granato, G.E., 2013, Stochastic empirical loading and dilution model (SELDM) version 1.0.0: U.S. Geological Survey Techniques and Methods, book 4, chap. C3, 112 p., CD-ROM.

Granato, G.E., 2014, Statistics for stochastic modeling of volume reduction, hydrograph extension, and water-quality treatment by structural stormwater runoff best management practices (BMPs): U.S. Geological Survey Scientific Investigations Report 2014-5037, 37 p., [Also available at https://doi.org/10.3133/sir20145037.]

Granato, G.E., 2016, Stochastic empirical loading and dilution model (SELDM) project web site: U.S. Geological Survey website, accessed October 24, 2016, at http://dx.doi.org/10.5066/F7BG2M33.

Granato, G.E., 2017, Highway Runoff DataBase (HRDB version 1.0.0b). U.S. Geological Survey software support page: U.S. Geological Survey web page, accessed November 11, 2017, at https://doi.org/10.5066/F74Q7T5X.
Granato, G.E., Carlson, C.S., and Sniderman, B.S., 2009, Methods for development of planning-level stream-waterquality estimates at unmonitored sites in the conterminous United States: Washington, D.C., U.S. Department of Transportation, Federal Highway Administration, FHWAHEP-09-003, 53 p.

Granato, G.E., and Cazenas, P.A., 2009, Highway-runoff database (HRDB Version 1.0) - A data warehouse and preprocessor for the stochastic empirical loading and dilution model: Washington, D.C., U.S. Department of Transportation, Federal Highway Administration FHWA-HEP-09-004, $57 \mathrm{p}$.

Granato, G.E., and Jones, S.C., 2015, Estimating the risks for adverse effects of total phosphorus in receiving streams with the Stochastic Empirical Loading and Dilution Model (SELDM) in 2015 International Conference on Ecology and Transportation (ICOET 2015), Raleigh, North Carolina, September 20-24, 2015, Proceedings: Raleigh, N.C., Center for Transportation and the Environment, $18 \mathrm{p}$.

Granato, G.E., and Jones, S.C., 2016, Modeling stormflow, total hardness, suspended sediment, and total copper to assess risks for water-quality exceedances with the Stochastic Empirical Loading and Dilution Model (SELDM), in StormCon, Indianapolis, Ind., August 22-25, 2016, Proceedings: Santa Barbara, Calif., Forester Media Inc., 14 p.

Granato, G.E., and Jones, S.C., 2017, Estimating total maximum daily loads with the stochastic empirical loading and dilution model: Transportation Research Record, Journal of the Transportation Research Board, no. 2638, p. 104-112. [Also available at https://doi.org/10.3141/2638-12.]

Gross, Mark, 2005, University curriculum development for decentralized wastewater management-Wastewater characterization: Fayetteville, Ark., University of Arkansas, accessed August 14, 2017, at http://onsite.tennessee.edu/ WW\%20Characterization\%20Text.pdf.

Gupta, M.K., Agnew, R.W., and Kobriger, N.P., 1981, Constituents of highway runoff, v. I, State-of-the-art report: Federal Highway Administration Report no. FHWA/RD-81/042, $111 \mathrm{p}$.

Guy, H.P., 1969, Laboratory theory and methods for sediment analysis: U.S. Geological Survey Techniques of WaterResources Investigations, book 5, chap. C1, 58 p.

Haan, C.T., 1977, Statistical methods in hydrology: Ames, Iowa, Iowa State University Press, 378 p.

Helsel, D.R., 2004, Nondetects and data analysis—Statistics for censored environmental data: Hoboken, N.J., John Wiley \& Sons Publishing Inc., 268 p. 
Helsel, D.R., and Hirsch, R.M., 2002, Statistical methods in water resources-Hydrologic analysis and interpretation: U.S. Geological Survey Techniques of Water-Resources Investigations, book 4, chap. A3, 510 p. [Also available at https://pubs.er.usgs.gov/publication/twri04A3.]

Homer, C.G., Dewitz, J.A., Yang, L., Jin, S., Danielson, P., Xian, G., Coulston, J., Herold, N.D., Wickham, J.D., and Megown, K., 2015, Completion of the 2011 National Land Cover Database for the conterminous United StatesRepresenting a decade of land cover change information: Photogrammetric Engineering and Remote Sensing, v. 81, no. 5, p. 345-354, accessed October 16, 2015, at http://www.asprs.org/a/publications/pers/2015journals/ PERS_May_2015/HTML/files/assets/basic-html/index. html\#345/z\#noFlash.

Hooda, P.S., Edwards, A.C., Anderson, H.A., and Miller, A., 2000, A review of water quality concerns in livestock farming areas: Science of the Total Environment, v. 250, no. 1-3, p. 143-167.

Hosking, J.R.M., 1990, L-moments-Analysis and estimation of distributions using linear combinations of order statistics: Journal of the Royal Statistical Society, Series B, v. 52, p. 105-124.

Interagency Advisory Committee on Water Data, 1982, Guidelines for determining flood flow frequency: Reston, Va., U.S. Geological Survey, Bulletin 17B of the Hydrology Subcommittee, Office of Water Data Coordination, 183 p.

Kayhanian, M., Singh, A., Suverkropp, C., and Borroum, S., 2003, Impact of annual average daily traffic on highway runoff pollutant concentrations: Journal of Environmental Engineering, v. 129, no. 11, p. 975-990.

Kilpatrick, F.A., and Schneider, V.R., 1983, Use of flumes in measuring discharge: U.S. Geological Survey Techniques of Water-Resources Investigations, book 3, chap. A14, 46 p.

Law, N.L., DiBlasi, K., and Upal, G., 2008, Deriving reliable pollutant removal rates for municipal street sweeping and stormdrain cleanout programs in the Chesapeake Bay Basin: Center for Watershed Protection, 73 p.

Malina, J.F., Barrett, M.E., Jackson, A., and Kramer, T., 2005, Characterization of stormwater runoff from a bridge deck and approach highway, effects on receiving water quality: Center for Transportation Research, University of Texas at Austin, Federal Highway Administration Publication (FHWA/TX-06/0-4543-1), 88 p.

Marsalek, J.H., 1991, Pollutant loads in urban stormwaterReview of methods for planning-level estimates: Water Resources Bulletin, v. 27, no. 2, p. 283-291.
Massachusetts Department of Environmental Protection, 2013, Massachusetts nutrient management report 2013: Massachusetts Executive Office of Energy and Environmental Affairs, accessed May 14, 2017, at http:/www.mass.gov/ eea/agencies/massdep/water/watersheds/massachusettsnutrient-management-report-2013.html.

Massachusetts Department of Transportation, 2017a, Transportation data management system_-Traffic volume counts: Massachusetts Department of Transportation database, accessed March 10, 2017, at http://mhd.ms2soft.com/tcds/ tsearch.asp?loc $=$ Mhd\&mod $=$.

Massachusetts Department of Transportation, 2017b, PROJECT_NO=600905: Massachusetts Department of Transportation database, accessed April 21, 2017 , at https://hwy.massdot.state.ma.us/ProjectInfo/Main. asp?ACTION=ViewProject\&PROJECT_NO=600905.

Massachusetts Office of Geographic Information [MassGIS], 2007, Impervious surface February 2007: MassGIS data, accessed October 16, 2015, at http://www.mass.gov/anf/ research-and-tech/it-serv-and-support/application-serv/ office-of-geographic-information-massgis/datalayers/ impervioussurface.html.

Minitab, Inc., 2010, Minitab 17 Statistical Software [computer software]: State College, Pa., Minitab, Inc. [Also available at http://www.minitab.com.]

National Atmospheric Deposition Program, 2017a, Annual data for site MA22 (Boston University) [data for water years 2015-16]: National Atmospheric Deposition Program website, accessed April 24, 2016 , at http://nadp.sws.uiuc.edu/data/sites/sitedetails. aspx?id=MA22\&net=NTN.

National Atmospheric Deposition Program, 2017b, Annual data for site MA08 (Quabbin Reservoir) [data for water years 2015-16]: National Atmospheric Deposition Program website, accessed April 24, 2016, at http://nadp.sws.uiuc.edu/nadpdata/annualReq. asp? site $=$ MA08.

National Institute of Standards and Technology, 2012, NIST/ SEMATECH e-Handbook of statistical methods: National Institute of Standards and Technology handbook, accessed May 1, 2017, at http://www.itl.nist.gov/div898/handbook/.

North Carolina Department of Transportation, 2017, North Carolina bridge information: North Carolina Department of Transportation web page, accessed May 1, 2017, at http:/www.ncdot.gov/projects/ncbridges/.

Novotny, Vladimir, 2004, Simplified databased total maximum daily loads, or the world is log-normal: Journal of Environmental Engineering, v. 130, no. 6, p. 674-683. 
Patton, C.J., and Kryskalla, J.R., 2003, Methods of analysis by the U.S. Geological Survey National Water Quality Laboratory_Evaluation of alkaline persulfate digestion as an alternative to Kjeldahl digestion for determination of total and dissolved nitrogen and phosphorus in water: U.S. Geological Survey Water-Resources Investigations Report 03-4174, 33 p. [Also available at https://pubs.er.usgs.gov/ publication/wri034174.]

Peavy, H.S., Rowe, D.R., and Tchobanoglous, George, 1985, Environmental engineering: New York, McGraw-Hill Publishing Company, 640 p.

Pitt, R.E., 1979, Demonstration of nonpoint pollution abatement through improved street cleaning practices: Washington, D.C., U.S. Environmental Protection Agency, EPA600/2-79/161, 269 p.

Pitt, Robert, Maestre, Alex, and Morquecho, Renee, 2015, National stormwater quality database (NSQD, version 4.02): National Stormwater BMP Database, accessed May 5, 2017, at http://www.bmpdatabase.org/nsqd.html.

Risley, J.C., and Granato, G.E., 2014, Assessing potential effects of highway runoff on receiving-water quality at selected sites in Oregon with the Stochastic Empirical Loading and Dilution Model (SELDM): U.S. Geological Survey Scientific Investigations Report 2014-5099, 74 p.

Rus, D.L., Patton, C.J., Mueller, D.K., and Crawford, C.G., 2012, Assessing total nitrogen in surface-water samplesPrecision and bias of analytical and computational methods: U.S. Geological Survey Scientific Investigations Report 2012-5281, 38 p. [Also available at https://pubs.usgs.gov/ sir/2012/5281/sir12_5281.pdf.]

Sartor and Boyd, 1972, Water pollution aspects of street surface contaminants: Washington, D.C., U.S. Environmental Protection Agency, EPA-R2-72-081, 186 p. [Also available at http://unix.eng.ua.edu/ rpitt/Publications/StormwaterTreatability/Water_Pollution_Aspects_Of_Street_Surface_ Contaminants.pdf.]

Seattle Public Utilities and Herrera Environmental Consultants, 2009, Seattle street sweeping pilot study-Monitoring report: Herrera Environmental Consultants, 266 p.

Selbig, W.R., and Bannerman, R.T., 2007, Evaluation of street sweeping as a stormwater-quality-management tool in three residential basins in Madison, Wisconsin: U.S. Geological Survey Scientific Investigations Report 2007-5156, 103 p.

Selbig, W.R., Bannerman, Roger, and Bowman, George, 2007, Improving the accuracy of sediment-associated constituent concentrations in whole stormwater samples by wet-sieving: Journal of Environmental Quality, v. 36, no. 1, 7 p.
Shoemaker, Leslie, Lahlou, Mohammed, Doll, Amy, and Cazenas, Patricia, 2000, Stormwater best management practices in an ultra-urban setting-Selection and monitoring: Federal Highway Administration, Office of Natural Environment, FHWA-EP-00-002, 287 p.

Shreve, E.A., and Downs, A.C., 2005, Quality-assurance plan for the analysis of fluvial sediment by the U.S. Geological Survey Kentucky Water Science Center Sediment Laboratory: U.S. Geological Survey Open-File Report 2005-1230, $28 \mathrm{p}$.

Smith, K.P., 2002, Effectiveness of three best management practices for highway-runoff quality along the Southeast Expressway, Boston, Massachusetts: U.S. Geological Survey Water-Resources Investigations Report 02-4059, 62 p.

Smith, K.P., 2005, Hydrologic, water-quality, bed-sediment, soil-chemistry, and statistical summaries of data for the Cambridge, Massachusetts, drinking-water source area, water year 2004: U.S. Geological Survey Open-File Report 2005-1383, 110 p.

Smith, K.P., and Granato, G.E., 2010, Quality of stormwater runoff discharged from Massachusetts highways, 2005-07: U.S. Geological Survey Scientific Investigations Report 2009-5269, 198 p.

Sorenson, J.R., 2013, Potential reductions of street solids and phosphorus in urban watersheds from street cleaning, Cambridge, Massachusetts, 2009-11: U.S. Geological Survey Scientific Investigations Report 2012-5292, 66 p. plus appendix 1 on a CD-ROM in pocket. [Also available at https://pubs.usgs.gov/sir/2012/5292/.]

Stedinger, J.R., Vogel, R.M., and Foufoula-Georgiou, Efi, 1993, Frequency analysis of extreme events, chap. 18 of Maidment, D.R., ed., Handbook of hydrology: New York, McGraw-Hill, Inc., p. 18.1-18.66.

Taylor, Scott, Barrett, Michael, Leisenring, Marc, Sahu, Sheila, Pankani, Daniel, Poresky, Aaron, Questad, Adam, Strecker, Eric, Weinstein, Neil, and Venner, Marie, 2014, Long-term performance and life-cycle costs of stormwater best management practices: National Cooperative Highway Research Program Report 792, 148 p.

U.S. Environmental Protection Agency, 1996, Method 3050B-Acid digestion of sediments, sludges, and soils (revision 2): U.S. Environmental Protection Agency Method 3050B, 12 p., accessed April 17, 2005, at https://www.epa.gov/sites/production/files/2015-06/documents/epa-3050b.pdf. 
U.S. Environmental Protection Agency, 2000, Method 6010B-Inductively coupled plasma-atomic emission spectrometry: U.S. Environmental Protection Agency Method 6010B, 25 p., accessed April 17, 2005, at https://www.epa.gov/sites/production/files/ documents/6010b.pdf.

U.S. Geological Survey, 2016, USGS water data for the Nation: U.S. Geological Survey National Water Information System database, accessed June 10, 2016, at http://dx.doi.org/10.5066/F7P55KJN.

U.S. Geological Survey, variously dated, National field manual for the collection of water-quality data: U.S. Geological Survey Techniques of Water-Resources Investigations, book 9, chaps. A1-A9, accessed April 5, 2013, at http://water.usgs.gov/owq/FieldManual/.

Veres, D.S., 2002, A comparative study between loss on ignition and total carbon analysis on minerogenic sediments: Studia Universitatis Bave-Bolyai, Geologia, XLVII, 1, p. 171-182.
Wagner, C.R., Fitzgerald, S.A., Sherrell, R.D., Harned, D.A., Staub, E.L., Pointer, B.H., and Wehmeyer, L.L., 2011, Characterization of stormwater runoff from bridges in North Carolina and the effects of bridge deck runoff on receiving streams: U.S. Geological Survey Scientific Investigations Report 2011-5180, 95 p. plus 8 appendix tables.

Waschbusch, R.J., 1999, Evaluation of the effectiveness of urban stormwater treatment unit in Madison, Wisconsin, 1996-97: U.S. Geological Survey Water-Resources Investigations Report 99-4195, 49 p.

Zimmerman, C.F., Keefe, C.W., and Bashe, J., 1997, Method 440.0 - Determination of carbon and nitrogen in sediments and particulates of estuarine/coastal waters using elemental analysis: Washington, D.C., U.S. Environmental Protection Agency, EPA/600/R-15/009, 10 p., accessed June 10, 2016, at https://cfpub.epa.gov/si/si_public_record_report. cfm?dirEntryId=309418. 


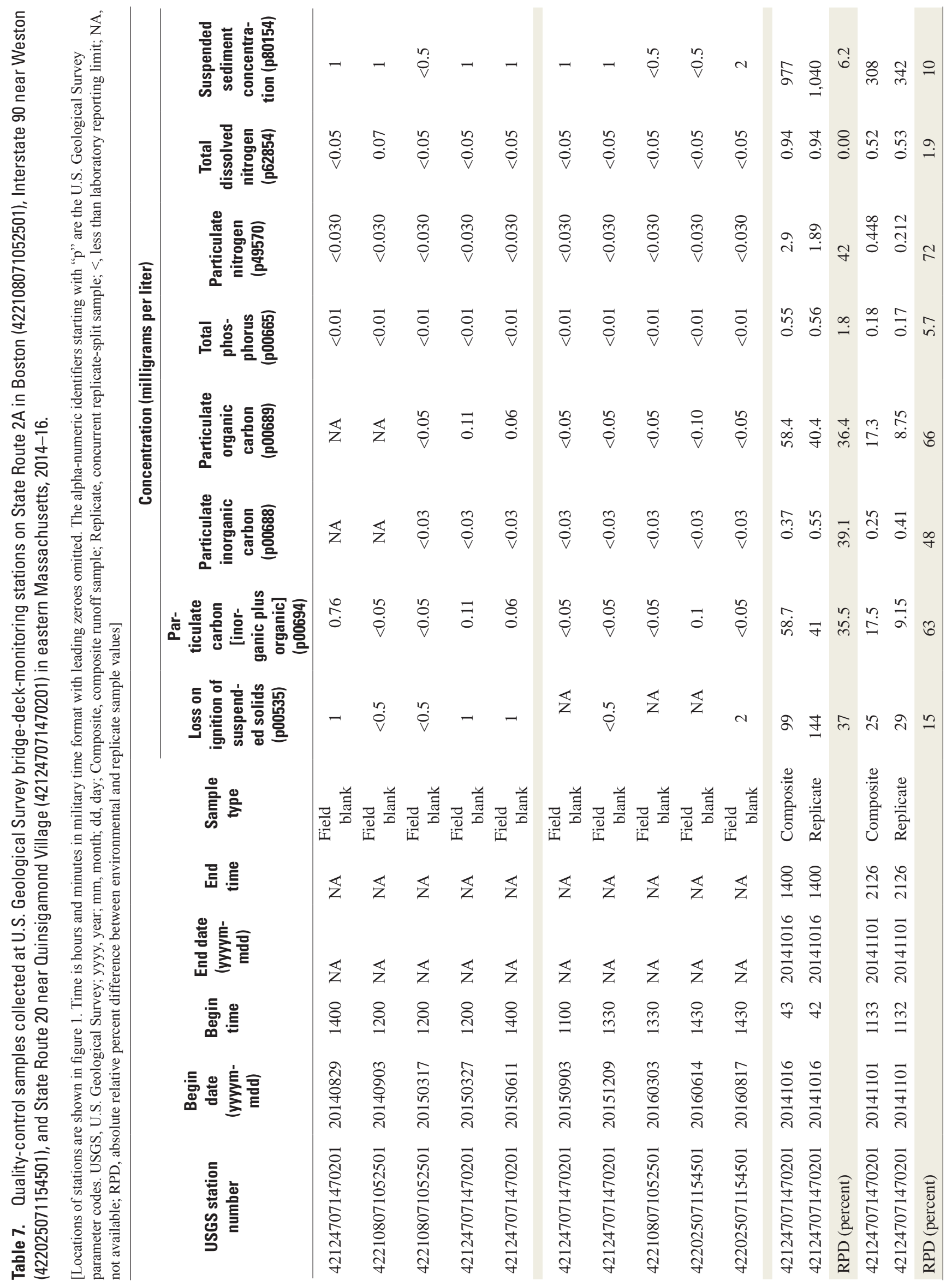




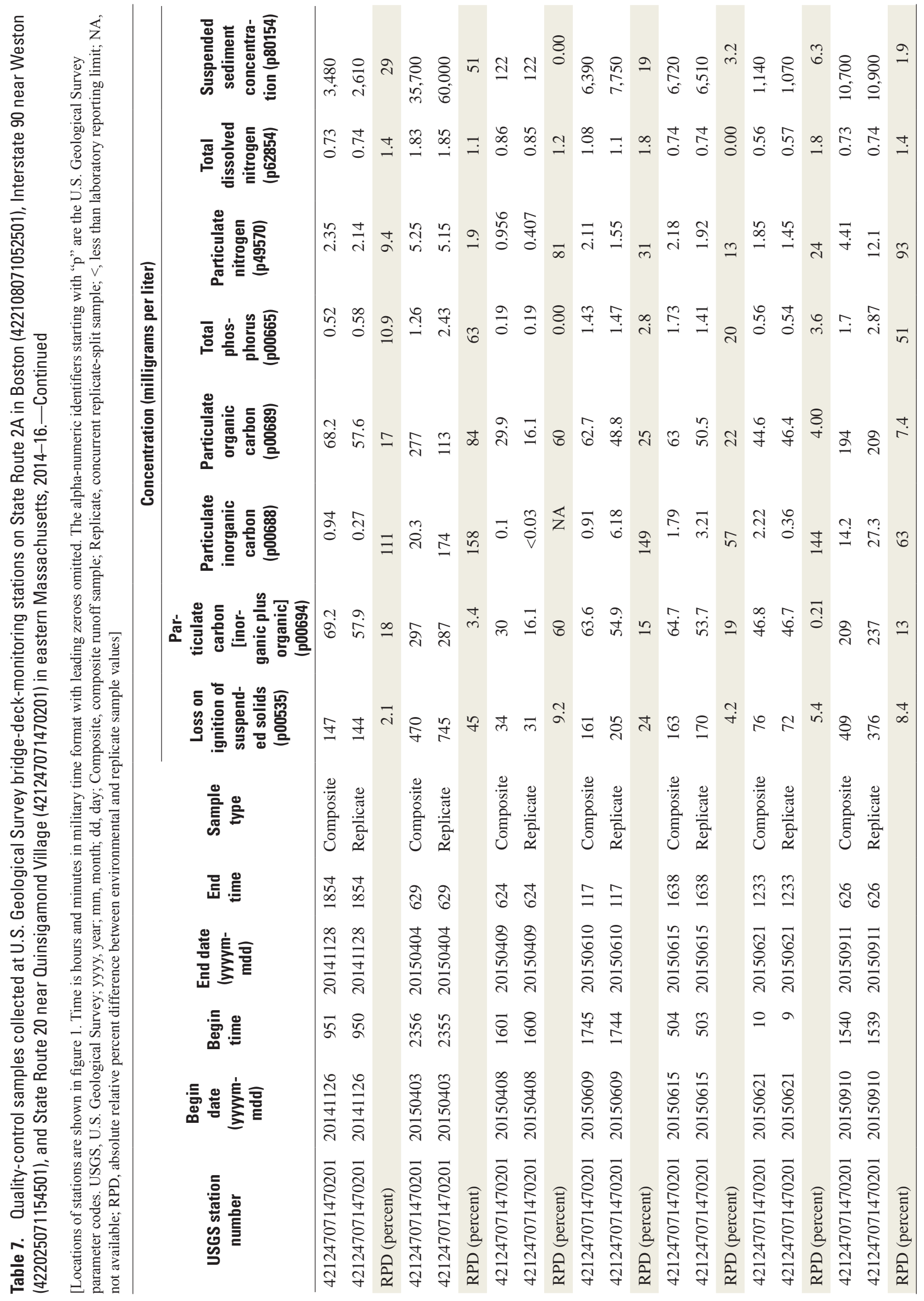




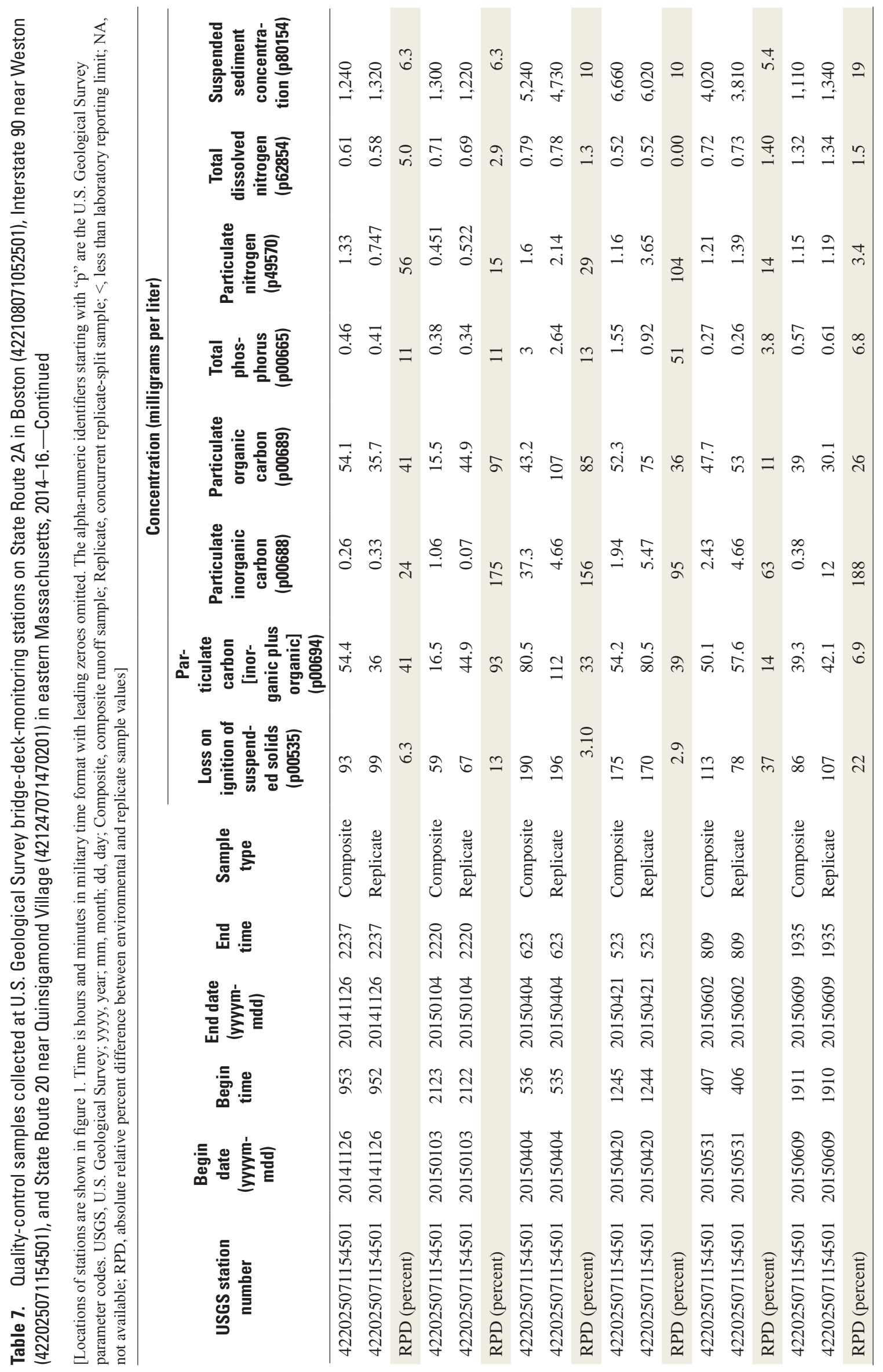




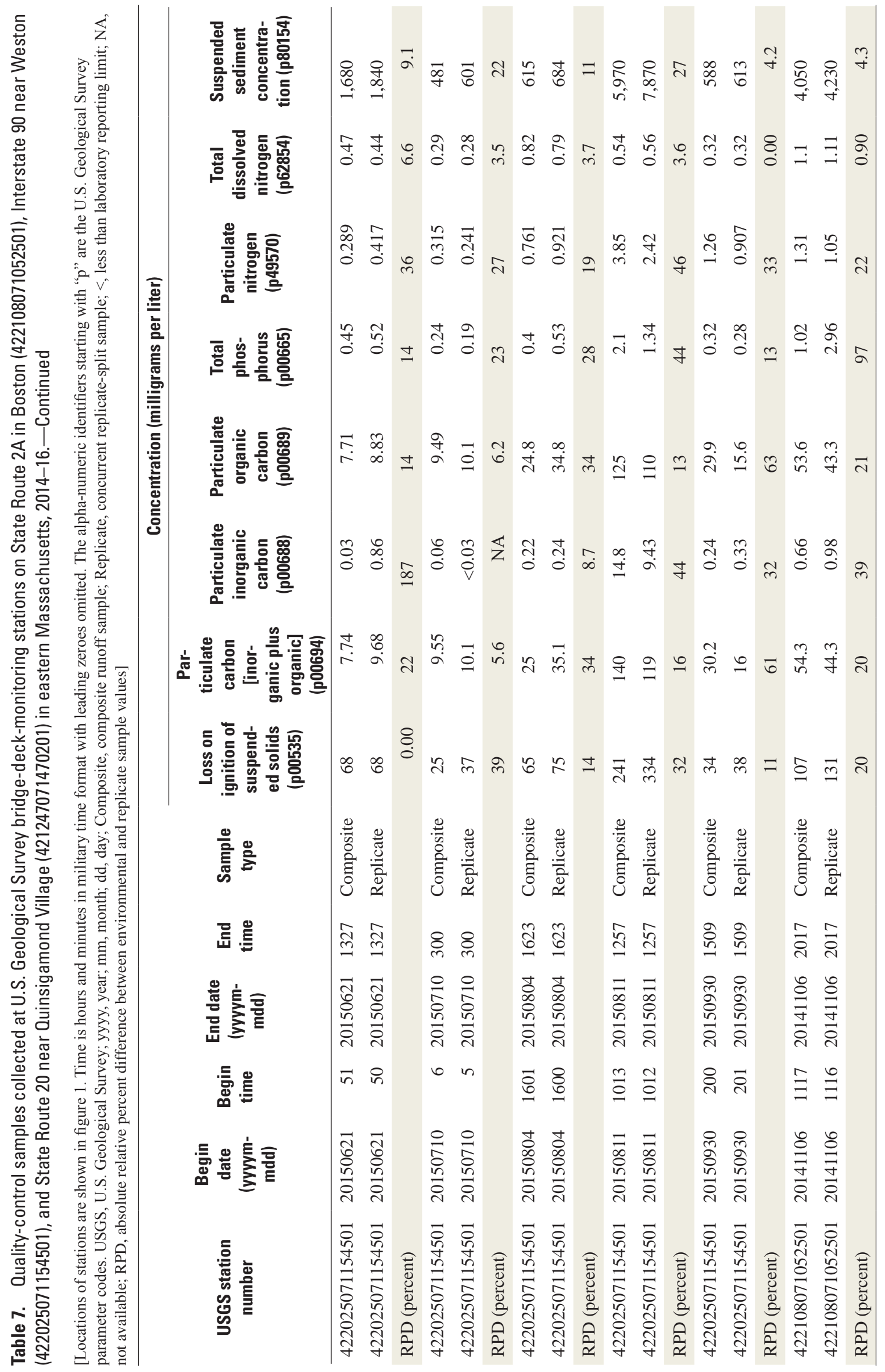




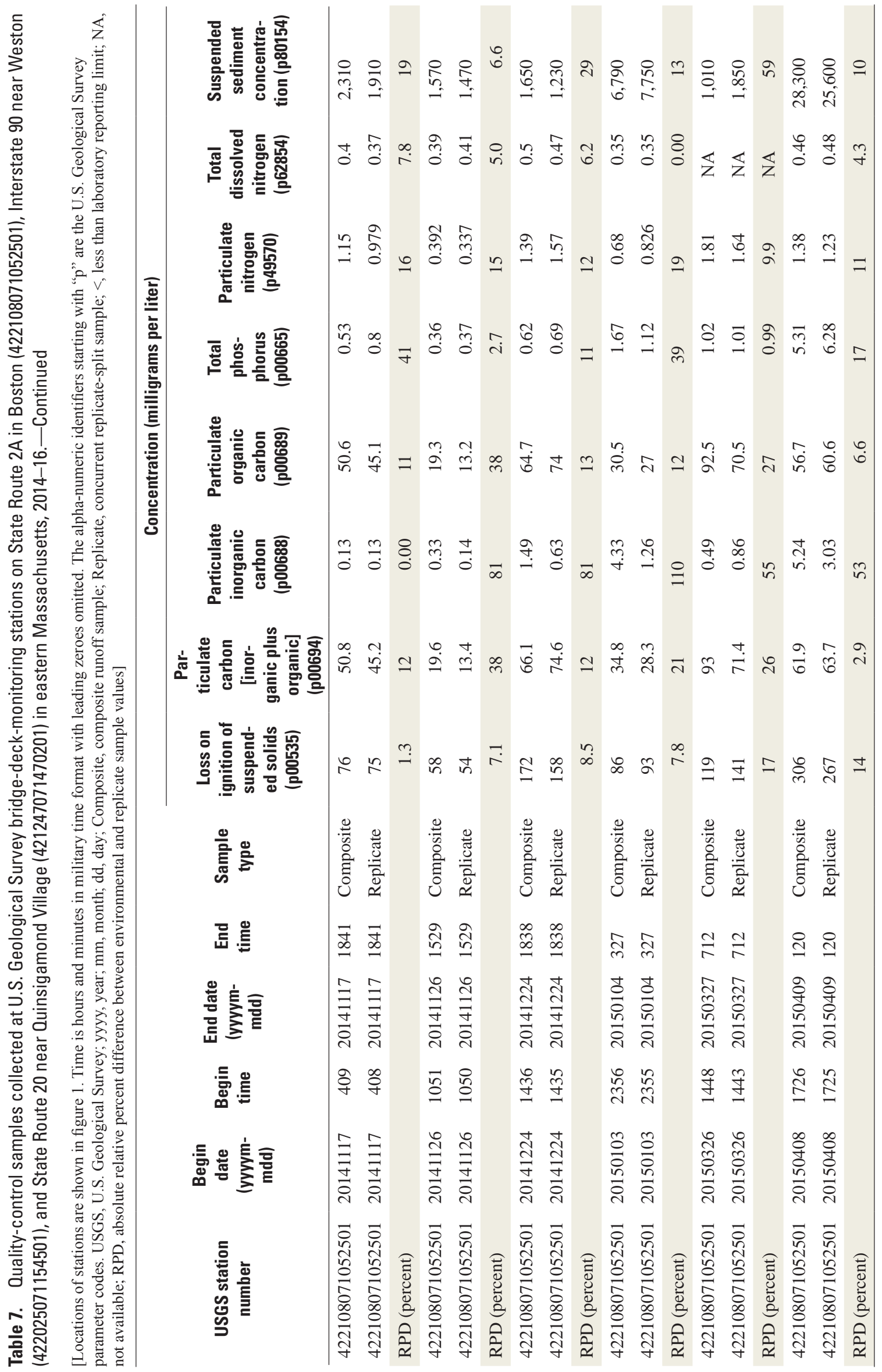




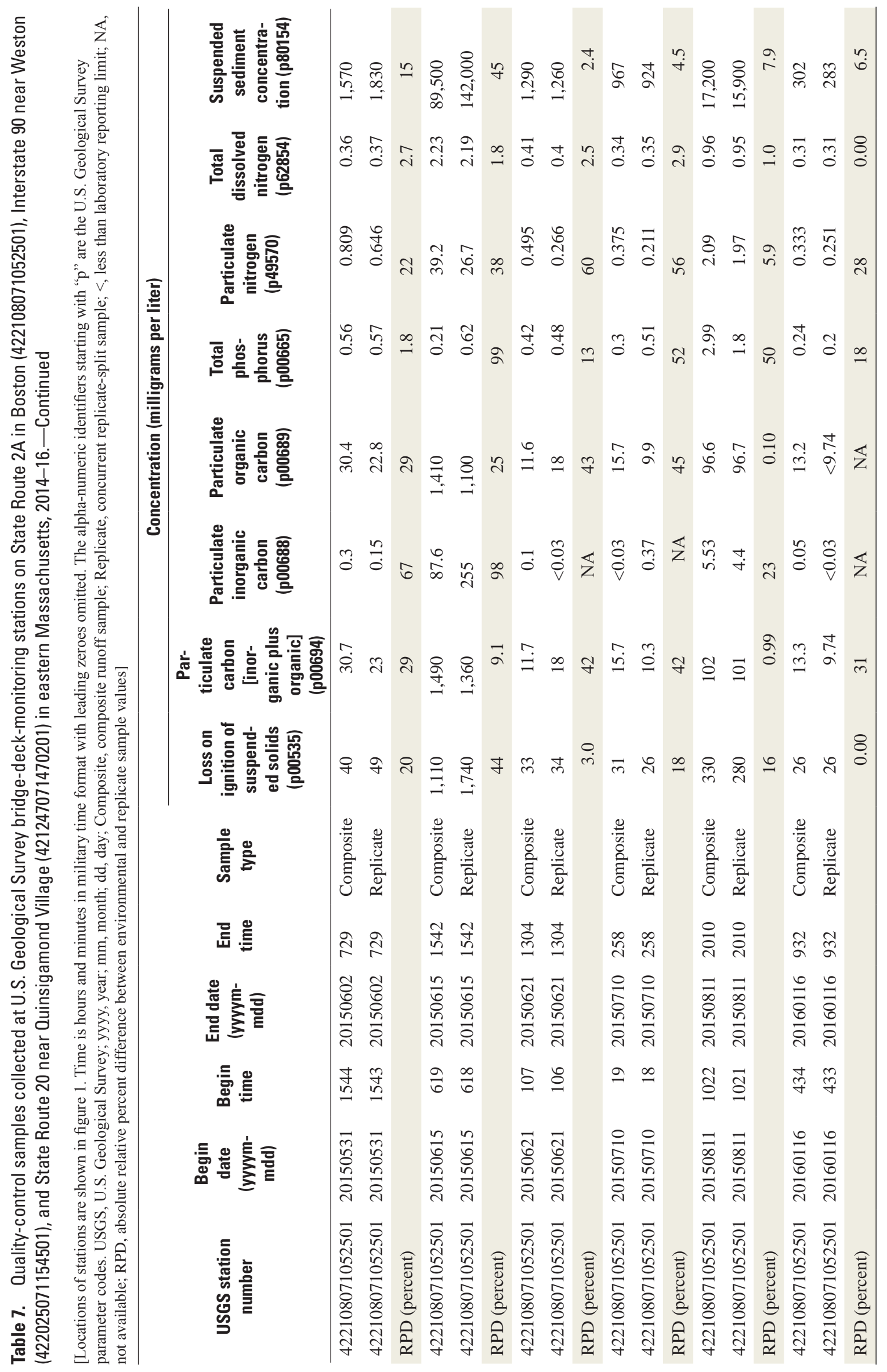



Director, New England Water Science Center U.S. Geological Survey

10 Bearfoot Road

Northborough, MA 01532

dc_nweng@usgs.gov

or visit our website at

https://newengland.water.usgs.gov

Publishing support provided by the Pembroke and Rolla Publishing Service Centers 
